\title{
Engineers of the Arnhem Land plateau: Evidence for the origins and transformation of sheltered spaces at Nawarla Gabarnmang
}

\author{
Jean-Jacques Delannoy, Bruno David, Jean-Michel Geneste, \\ Margaret Katherine, Benjamin Sadier and Robert Gunn
}

\section{Introduction}

Nawarla Gabarnmang is a large archaeological rockshelter on the Arnhem Land plateau (Figure 10.1). It was rediscovered in June 2006 when Ray Whear and helicopter pilot Chris Morgan sighted an unusually large overhang during a routine aerial survey. They landed the helicopter and found themselves in a stunning gallery with many hundreds of rock paintings (David et al. 2011). The site lies on Buyhmi clan lands in Jawoyn Country. The Jawoyn words 'nawarla gabarnmang' mean 'place of hole in the rock', a descriptive label given to it by the late Bardayal 'Lofty' Nadjamerrek in 2006-2007, and that is now generally used as the site's proper name both by members of the Jawoyn community and by others. That name refers to the rockshelter itself, but also to the area immediately around it that spans a few tens of metres. This includes a continuous array of shallow overhangs and rock faces often imbued with rock art, various landscape features including a southern 'courtyard' delimited by a long, pillared rock face to its south, and other archaeological manifestations (Figure 10.2). For the sake of clarity, in this chapter we refer only to the main rockshelter as Nawarla Gabarnmang, and other nearby features through descriptive terms befitting the specific discussion at hand.

Human occupation at Nawarla Gabarnmang began more than 47,200-51,700 cal BP (median age $=49,350 \mathrm{cal} \mathrm{BP}$ ), as determined by Bayesian statistics of radiocarbon dates from excavation Square F, with optically stimulated luminescence ages in adjacent Squares $\mathrm{I}+\mathrm{L}+\mathrm{M}$ indicating a slightly earlier antiquity (David et al. completed manuscript). Occupation continued into the ethnographic period of the late 1800s and early 1900s (see Chapters 9 and 12). The richness of the buried archaeological deposits dating from the earliest to the latest occupational levels, in particular the stone artefacts, makes Nawarla Gabarnmang a useful reference for understanding artefact characteristics in the central part of the Arnhem Land plateau (e.g. David et al. 2011, 2013; Geneste et al. 2010, 2012). Equally significant is Nawarla Gabarnmang's rock art; with 1391 paintings and stencils on the ceiling alone (i.e. excluding the extensively decorated walls of its numerous pillars), it is one of the most decorated rock art sites in all of Arnhem Land (Gunn 2016; see also Chapter 12) (Figure 10.3). The oldest art yet revealed from the site consists of a small piece of an originally larger decorated rock that retains part of a black charcoal painting or drawing excavated from Square E and dating to c. 26,739-27,657 cal BP (David et al. 2013, 2014:20). 


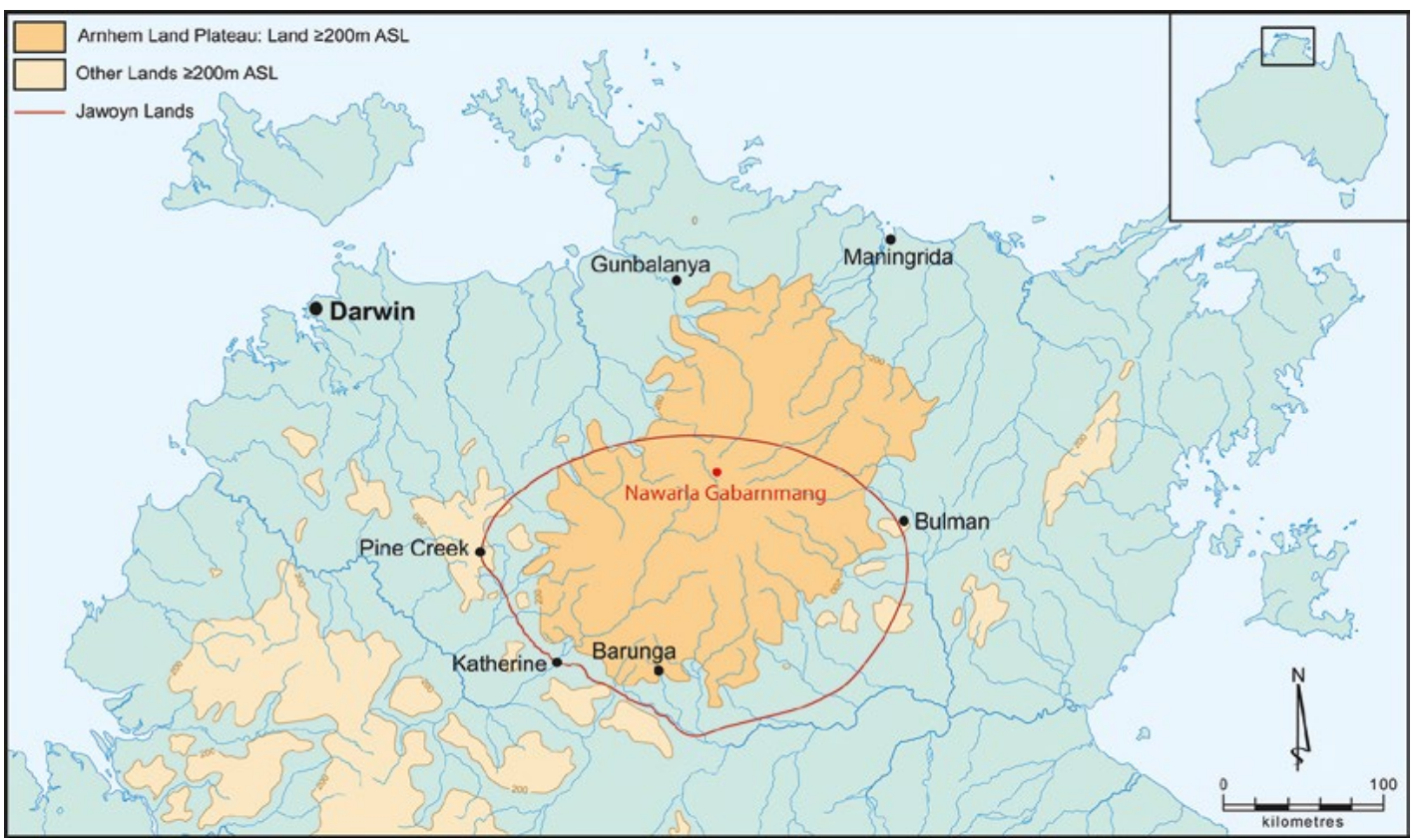

Figure 10.1 Location of Nawarla Gabarnmang on the Arnhem Land plateau.

Source: Illustration by Kara Rasmanis.

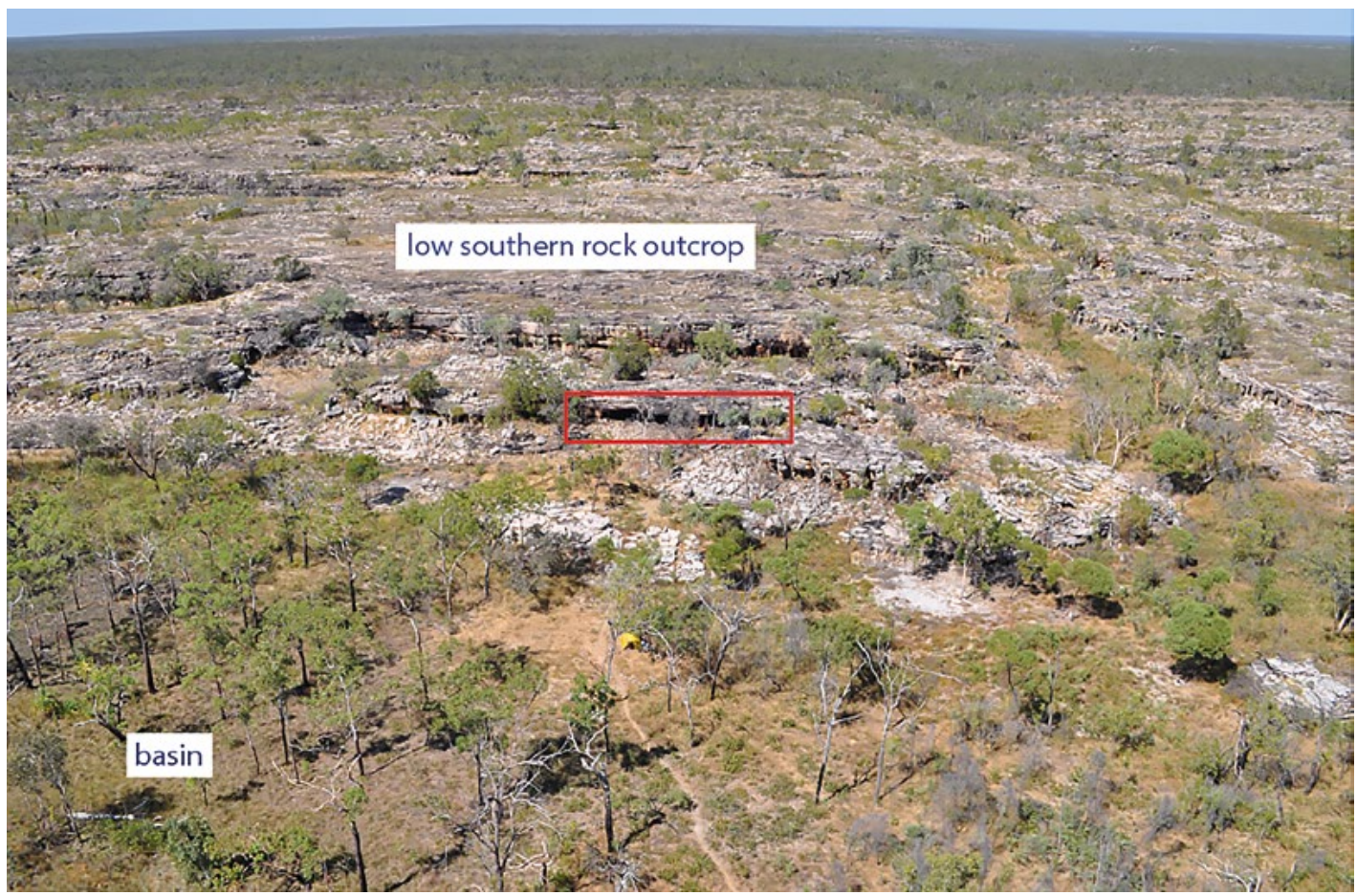

Figure 10.2 Aerial photograph of Nawarla Gabarnmang and surrounding features, looking south.

The red rectangle identifies the site's northern entrance.

Source: Photograph by Bruno David. 


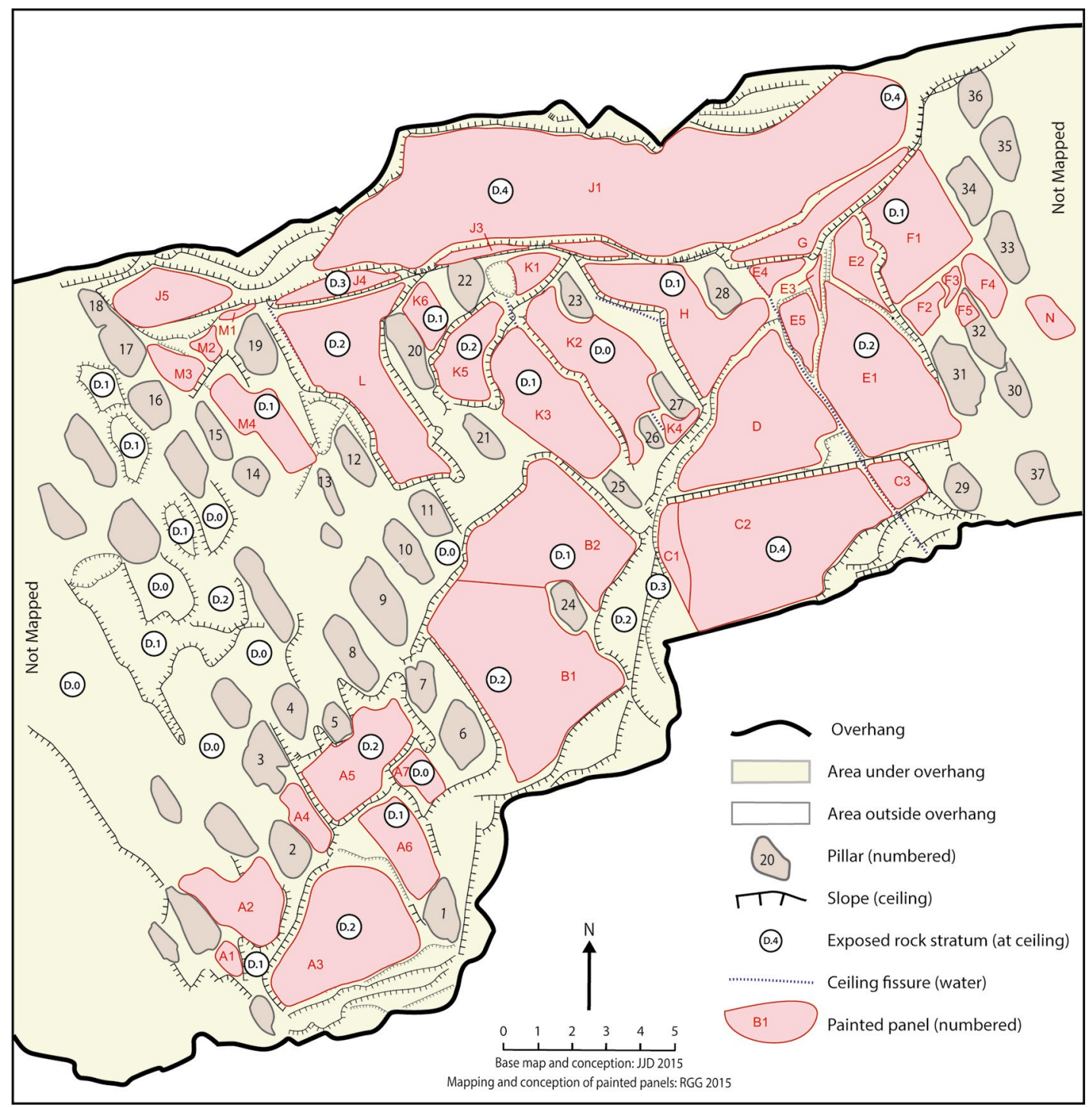

Figure 10.3 Location of rock art panels, with all features mapped on the ceiling.

Source: Illustration by Jean-Jacques Delannoy, Robert Gunn and Kara Rasmanis.

The study of the rock art, including hundreds of superimpositions, has enabled investigations of both the sequence of artistic conventions and the periodicity of occupation relating to some artistic phases (Gunn 2016; see also Chapters 11 and 12). Under the ground, the excellent preservation of buried layers, including the sharp boundaries and shallow sediment interfaces between many stratigraphic units (Figure 10.4) and the presence of buried horizontal rock slabs that have sealed some horizons (Figure 10.5), has resulted in a high degree of chronostratigraphic integrity for much of the deposit. This good preservation and high chronostratigraphic resolution is closely connected with the site's peculiar architecture; an expansive rockshelter measuring $32 \mathrm{~m}$ long $\times 23 \mathrm{~m}$ wide $\times 1.8-2.0 \mathrm{~m}$ high (these measurements correct and update previously published measurements), held aloft by 50 rock pillars supporting a large protective roof over a flat floor, at a high point on the Arnhem Land plateau (Figure 10.6). The long and wide, well-sheltered ceiling is made up of flat and horizontal, but staggered, sections, offering its art and accumulated sediments below good protection from the elements. No scree slope leads into the site, nor does vegetation grow on its surface, and so there is a total absence of sediment mixing caused by colluvial processes or surface water flow into the site. This absence of surface vegetation coupled with the presence of an extensive roof overhead has also protected the art and surface deposits from the effects of bushfires. 


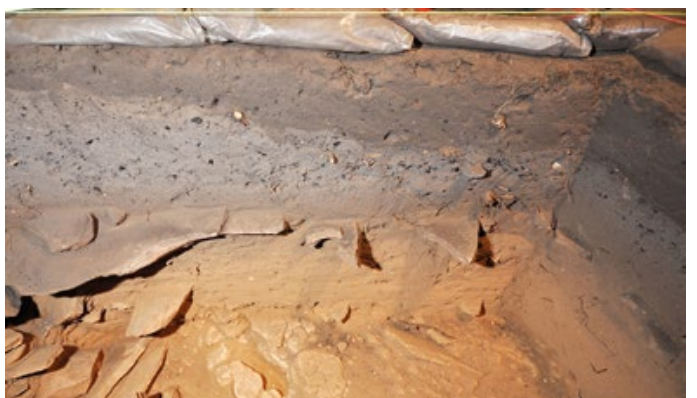

Figure 10.4 South wall of Squares $F+++L+M$, showing sharp and thin interfaces between stratigraphic units in the excavations in progress.

The ground surface is very close to the top of the photograph; the depth of the dig as shown here ranges between c. 53-60 cm.

Source: Photograph by Jean-Michel Geneste.

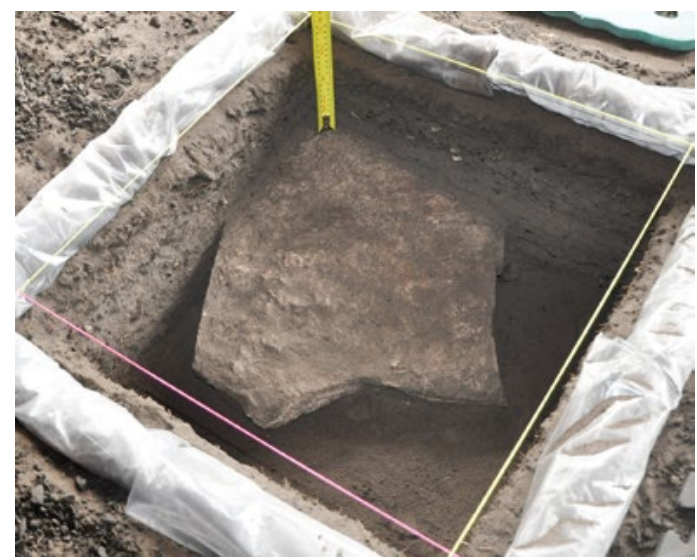

Figure 10.5 Flat rock slab originating from the ceiling, lying horizontally in Square $\mathrm{E}$.

Source: Photograph by Bryce Barker.

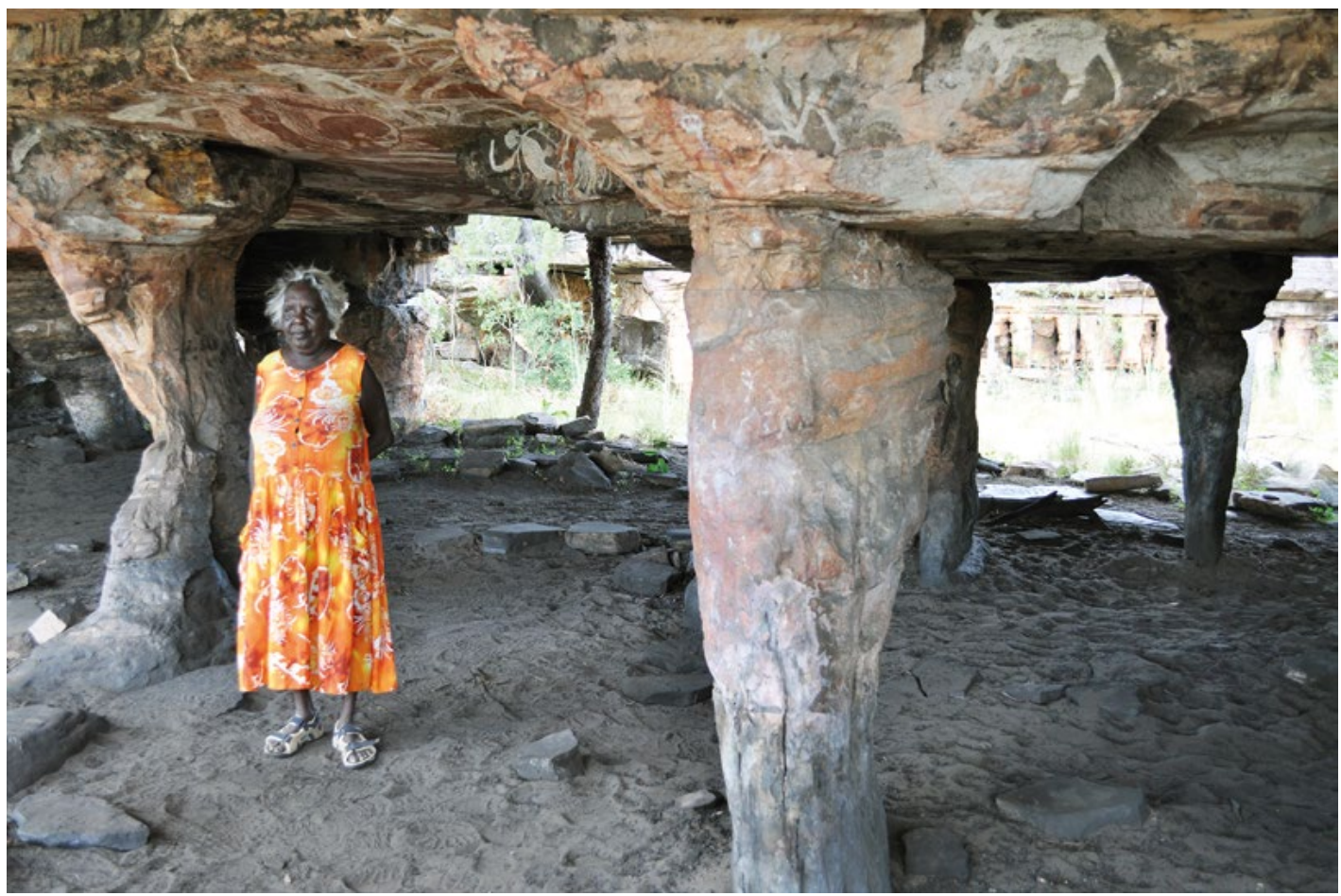

Figure 10.6 The sheltered pillarscape, with senior Jawoyn Elder and Traditional Owner Margaret Katherine.

Source: Photograph by Bruno David.

The unusual configuration of the pillared rockshelter requires interpretation, for it is by understanding the history of the site's architecture that we can come to understand the age of the decorated rock surfaces, the distribution across the site of buried occupational deposits of varied ages, and various kinds of landscape engagements. The site has an entirely different morphology to the more common rockshelters found under the edges of low and localised clifflines (such as Dalakngalarr; see Chapter 13) or under isolated rock stacks (such as JSARN-124 site 3; see Chapter 15). While Nawarla Gabarnmang was subject to the same kinds of geological processes as these other kinds of sites, unlike the others it has resulted in an impressive rock 
formation. A question of particular importance is thus how the rockshelter formed. There are a few rocks on its floor, and those that are present do not match the geological characteristics of the nearby ceiling or pillars. Indeed, one of the first things that senior Aboriginal Elders Bardayal 'Lofty' Nadjamerrek, Peter Bolgay and Jimmy Kalariya told Ray Whear in 2006-2008 (Ray Whear, pers. comm. 2010) when they first entered the site shortly after its rediscovery in 2006 was that the isolated blocks of rocks that can today be seen occasionally lying flat on the ground in the sheltered area was that they are 'pillows' placed there by the old people; this is where people slept. These rocks cannot, therefore, be explained as natural roof-fall or pillar collapse, as typically expected of rockshelter sites. Nawarla Gabarnmang is, in this aspect also, very different to other rockshelters in Arnhem Land, where evidence of roof-fall can readily be seen in the collapsed rock debris found beneath or adjacent to remnant overhangs.

Defining the nature and antiquity of Nawarla Gabarnmang's extant and past morphology is critical to understanding the site's occupational history, because the archaeological deposits and the rock art are both inscribed in the site's very particular physical configuration, a site morphology that has changed through the course of a long history of human presence. This chapter thus examines how people have interacted with the material fabric of the site, including what the site looked like when people first arrived, and how it has changed since those first arrivals. We also ask how the sub-surface archaeological evidence relates to the art currently visible on the rock, and to changes in the site's structure as evident from both detached blocks of rock and the present configuration of the bedrock base, pillars, ceiling and roof.

\section{Environmental context}

Nawarla Gabarnmang is situated at the heart of the Arnhem Land plateau, in an elevated region from which radiate the headwaters of the Katherine River to the south, South Alligator River and Jim Jim Creek to the west and northwest, East Alligator River to the north, and Mann River and McCaw Creek to the east (Figure 10.7). It is located $400 \mathrm{~m}$ above sea level (ASL), along the northern edge of an elevated rock outcrop that forms a low plateau. That rock outcrop is surrounded on the Arnhem Land plateau by a vast basin (380 m ASL). Numerous archaeological sites are found along the edges of the basin where exposed rock is found on either side. The basin effectively acts as a landscape-scale east to west corridor between the headwaters of the Katherine and Mann rivers and, a bit further afield, the Wilton and Roper rivers and their expansive watersheds (see Figure 9.17).

This geographical setting had great potential to have been used by Aboriginal people as a thoroughfare across the top of the plateau and to connect traversable basins between the headwaters of major river systems. The late senior Aboriginal Elders Bardayal 'Lofty' Nadjamerrek, Peter Billis and Jimmy Kalariya (pers. comm. to Ray Whear 2006-2008) had noticed this when they had commented that in this flat, grassy landscape 'everything looks the same' (Ray Whear, pers. comm. 2015). This was a place where 'you wouldn't walk alone' to avoid getting lost, 'even for us old people'. And they further stated that the featureless grassy basins of this high country were a renowned trademark of Buyhmi clan lands; it was when you began to approach Nawarla Gabarnmang that this featureless landscape started to become more rocky and to have clearer relief. 


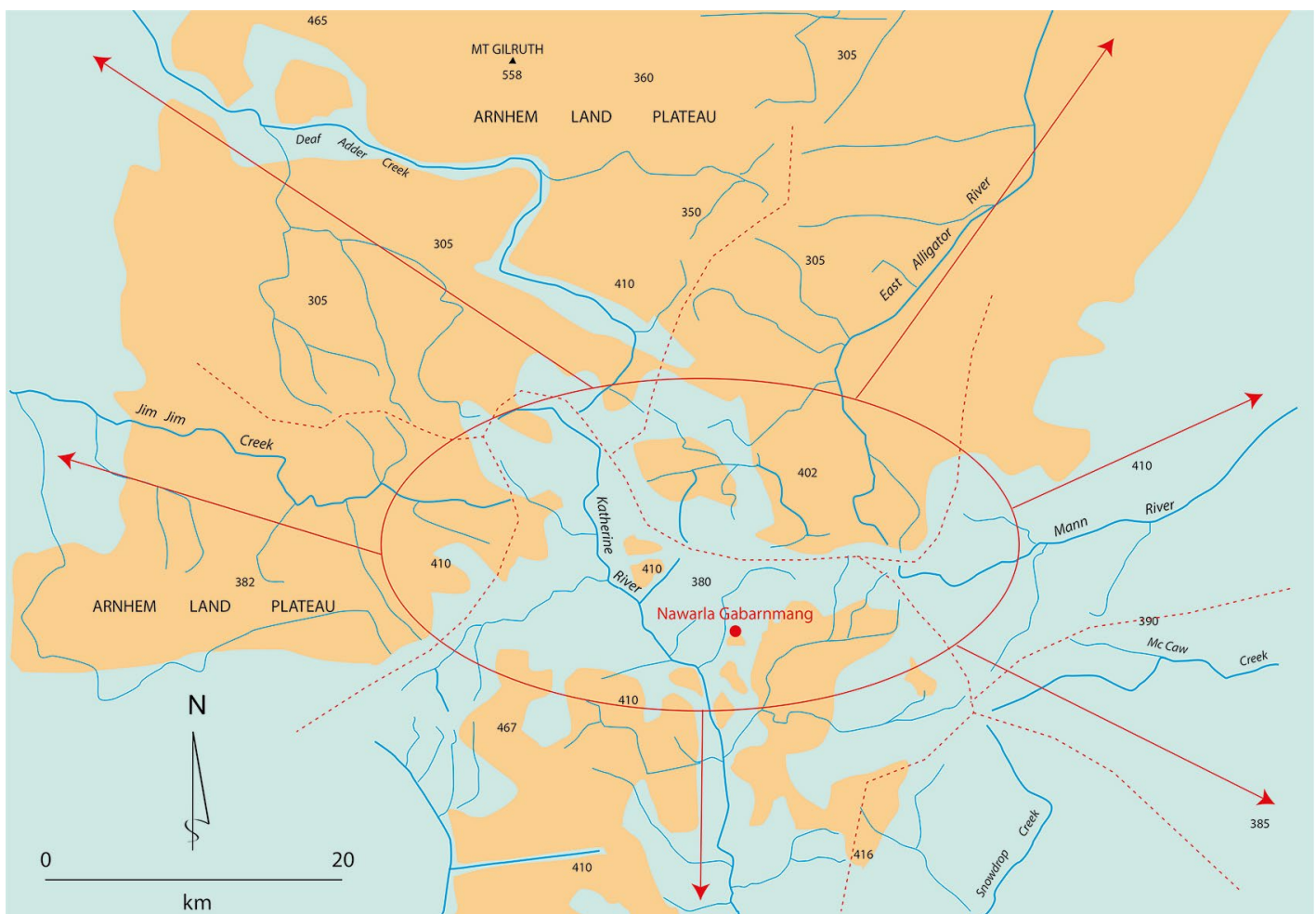

Figure 10.7 Location of Nawarla Gabarnmang, showing expanses of outcropping rock (orange) and the headwaters of river systems amidst the high basins of the central Arnhem Land plateau. Source: Illustration by Jean-Jacques Delannoy.

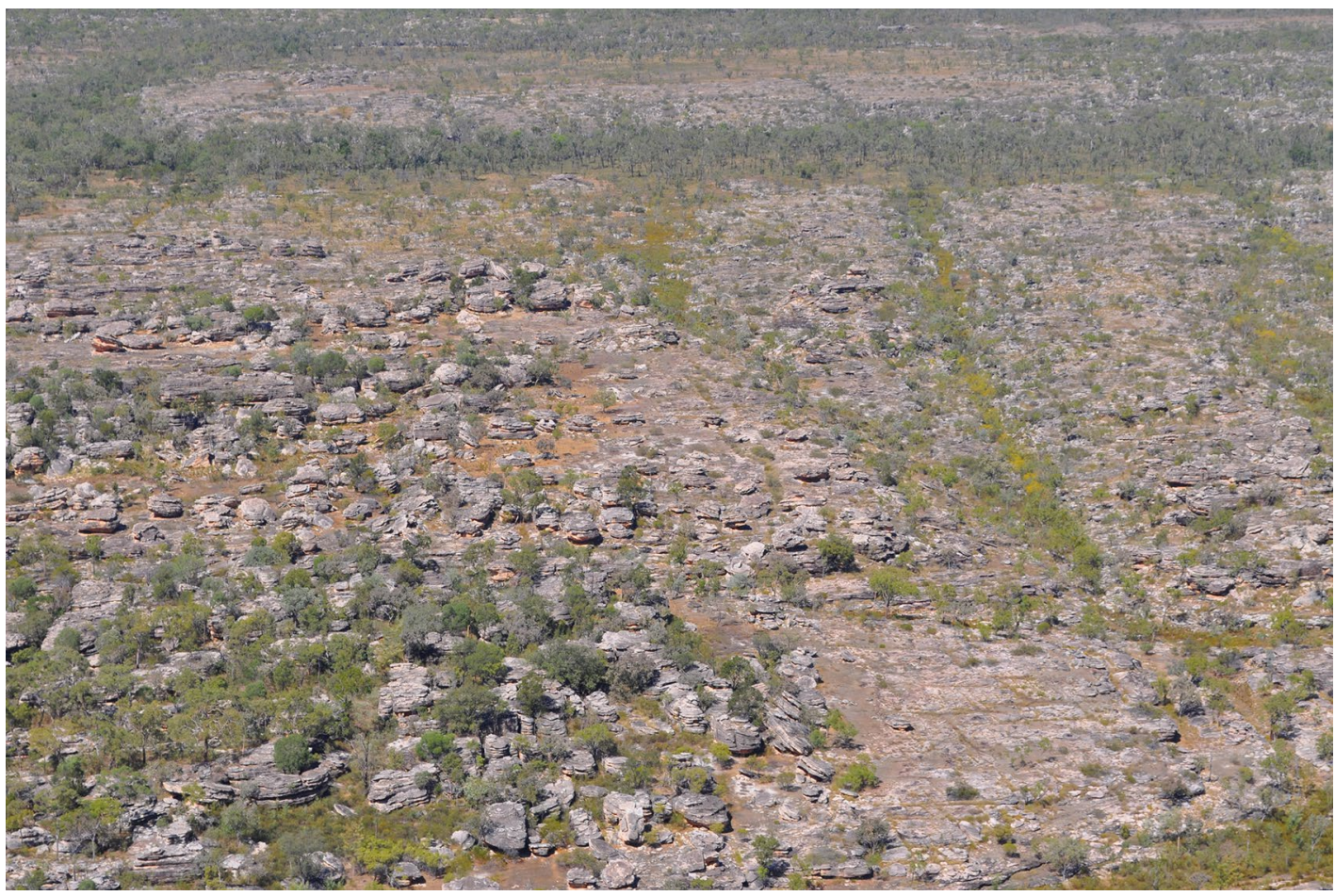

Figure 10.8 Rockshelter landscape of the western Arnhem Land plateau, Jawoyn Country. Source: Photograph by Bruno David. 
Even though the relief of the landscape from the basin to the elevated land on either side is only a few tens of metres high, these two landscape types have very different characteristics: while the basin consists largely of soft sediments and extensive grass cover, the surrounding elevated areas mostly consist of exposed outcropping rock largely devoid of vegetation (Figure 10.2). The elevated rock is dissected by a network of narrow fissures oriented in a triple-checkerboard pattern: east to west, south-southeast to north-northwest and north-northeast to south-southwest. The density of fissures is testimony to the bedrock's hardness and therefore resistance to tectonic deformation; rather than fold, as is more common among softer rocks, tectonic activity caused the hard quartzites of the Arnhem Land plateau to fracture under pressure. Across the landscape, the dissected low quartzitic plateaux have resulted in rich complexes of rockshelters, large numbers of which are decorated with rock art (Figure 10.8).

In the area of Nawarla Gabarnmang, the bedrock consists of Marlgowa Formation sandstones and quartzites (Kombolgie subgroup, Katherine River group, MacArthur geologic basin, Proterozoic; see Carson et al. 1999). These rocks were formed from ancient sands deposited some 1700 million years ago. The quartzites are essentially composed of quartz grains originating from littoral sands well rolled by repeated water action. These originally loose sands were then converted into rock through strong compaction caused by subterranean metamorphic processes. Traces of the original deposition of these sands have survived this metamorphic transition from sand to sandstone to quartzite, in the form of well-differentiated superimposed rock strata variably exhibiting ripple marks and evidence of cross-bedding. These individual rock strata can each be distinguished geologically, enabling us to determine how individual site morphologies changed over both geological and archaeological time frames (for specific examples, see Chapters 11 and 13-15). Here, the quartzitic bedrock lies deep underground over Gilruth Volcanic Member basalts rich in iron oxides (Ferenczi and Sweet 2004). These volcanic rocks outcrop c. $10 \mathrm{~km}$ to the north of Nawarla Gabarnmang. Less than $1 \mathrm{~km}$ to the south of the site, dolerite is found in association with one of Arnhem Land's major transverse fault lines.

Given that local waterways have low gradients and the local bedrock consists of hard quartzites highly resistant to erosion, the Nawarla Gabarnmang relief has been more shaped by the particular properties of the local bedrock geology than by river action. This is especially evident in the hydrography, where across the landscape minor and usually seasonal, low-energy waterways suddenly change their course along $90^{\circ}$ angles that directly map on to the network of bedrock fractures. The same situation applies to the rectilinear edges of the low basins drained by the upper reaches of the Katherine River. These low basins have characteristically flat beds containing alluvial sandy silts. Numerous swampy areas within these low basins are testimony to the presence of impermeable quartzitic bedrock at shallow depths. The thickness of these alluvial sediments in the basin that abuts the northern edge of Nawarla Gabarnmang is less than $1 \mathrm{~m}$. This shallow depth can be explained by the following causes:

1. The low quantity of available sediment, a result of the hard quartzite's strong resistance to erosion.

2. The low capacity of sediments to be transported by water, given the low gradient of waterways.

3. The evacuation of alluvial deposits from the plateau by wind action. The aeolian sands analysed from a number of archaeological excavations undertaken within $10 \mathrm{~km}$ of Nawarla Gabarnmang indicate that such aeolian activity is considerable on the Arnhem Land plateau (e.g. see Chapters 14 and 15). Jones and his colleagues (see individual chapters in Jones 1985) had elsewhere found that archaeological sites at the foot of the Arnhem Land plateau have accumulated vast quantities of sediment originating from the plateau, especially after the 
onset of human occupation (now dated around 65,000 years ago) when it is presumed firing practices cleared broad areas of surface grass cover thereby accelerating the mobilisation of sands by wind action.

While the structure of the landscape around Nawarla Gabarnmang is entirely consistent with the above, the archaeological site itself presents evidence of an entirely different agency for its present morphology.

\section{Nawarla Gabarnmang: How the shelter formed}

Nawarla Gabarnmang directly fronts this shallow basin (Figure 10.9). It is set in a small, largely isolated section of the rock plateau separated from the rest of the outcrop by a corridor of lowlying land that corresponds with a fracture-line oriented north-northwest to south-southeast. From this corridor, an elongated 'courtyard' of low-lying area aligns east-west and delimits the southern margin of the rockshelter (Figure 10.10). That elongated courtyard is delimited by a mass of large rocks at both its extremities, rendering it a semi-enclosed depression. Nawarla Gabarmnang both separates and connects the large basin to the north with this small semienclosed low-lying courtyard to the south. The outcropping rock of which Nawarla Gabarnmang is a part acts as a separation between the two low-lying areas, while the hollow of the shelter under the roof acts to connect them. Nevertheless, the bedrock at the base of the rockshelter is always noticeably more elevated than the low-lying areas on either side.
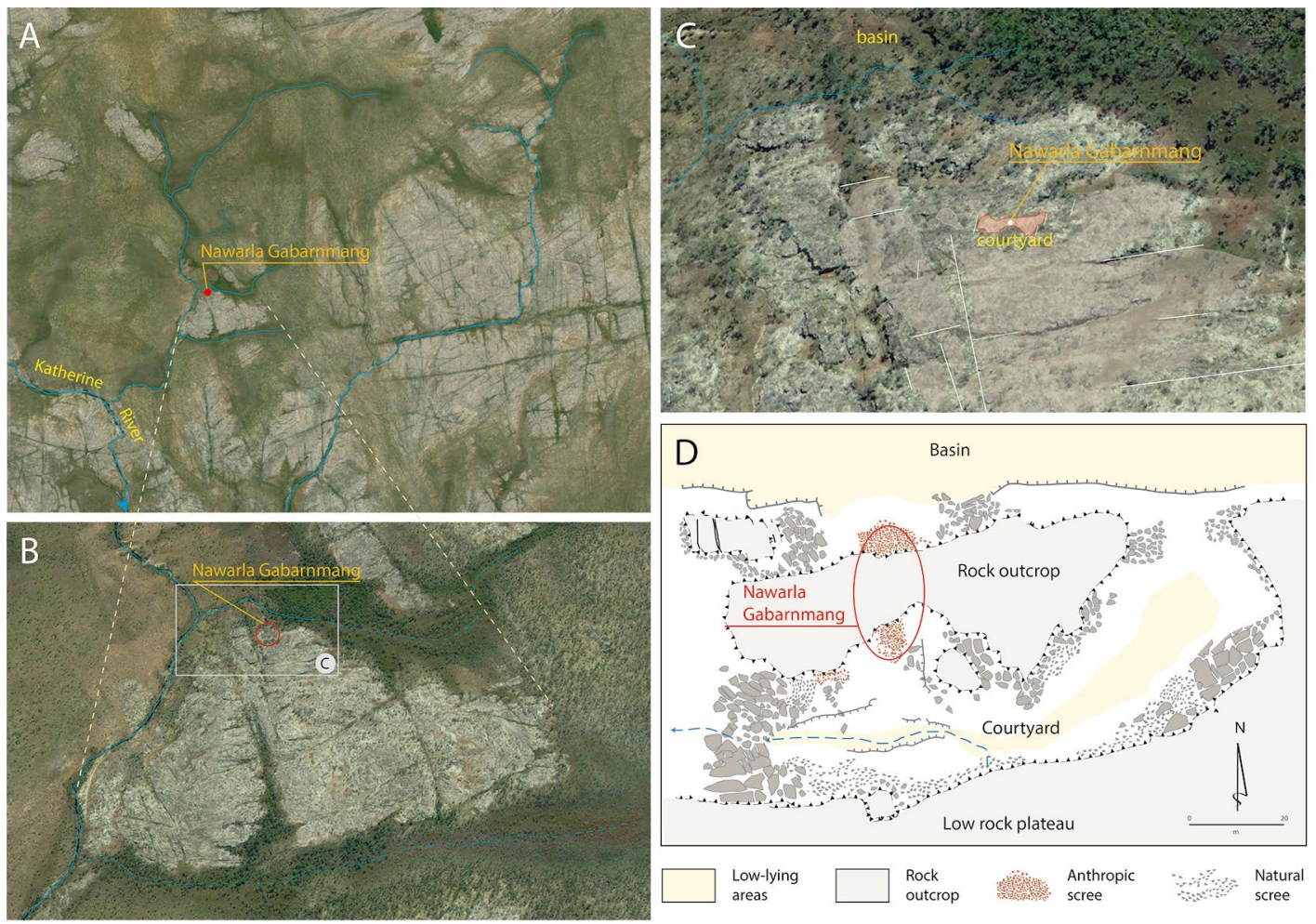

Figure 10.9 Environmental context.

A: Location of Nawarla Gabarnmang along the northern edge of a rock outcrop that abuts a basin drained by the headwaters of the Katherine River. B: Detail of A, the rock outcrop with Nawarla Gabarnmang, showing its east-west, NNE-SSW and NNW-SSE fissures. These same fissure lines are also found in the rock at the site itself. C: Detail of B, close-up of the northern edge of the rock outcrop that houses Nawarla Gabarnmang (area highlighted in pink). D: Map of Nawarla Gabarnmang relative to key landscape features mentioned in the text.

Source: Photographs and illustration by Jean-Jacques Delannoy.

\section{terira australis 47}



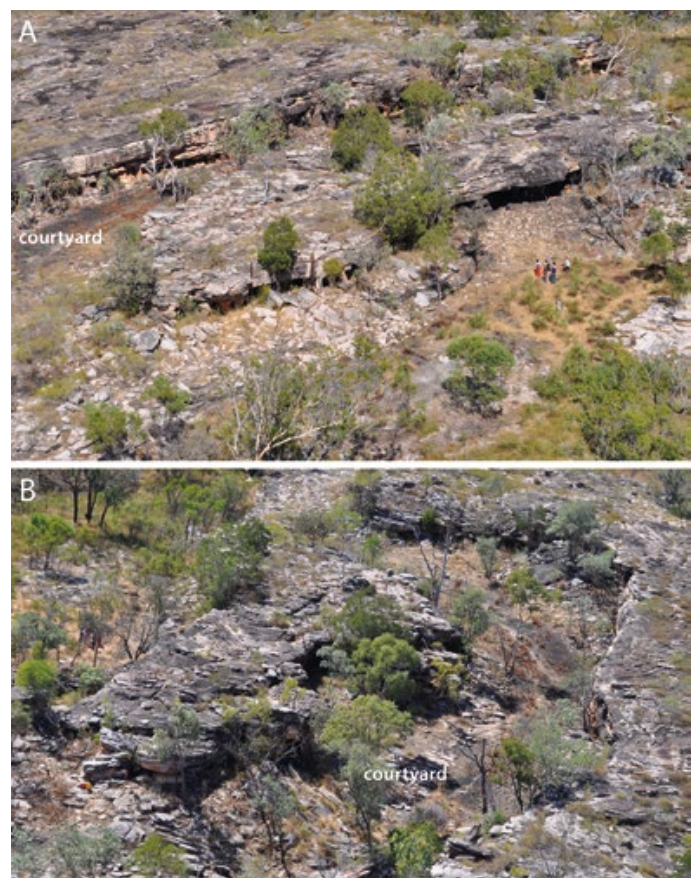

Figure 10.10 The low-lying 'courtyard' between Nawarla Gabarnmang and the edge of the rock outcrop to the south.

A: The courtyard as viewed from just east of the northern entrance. B: The courtyard as viewed from the southwestern side of the site.

Source: Photographs by Bruno David.
The rockshelter at Nawarla Gabarnmang has large ceiling surfaces supported by 50 rock pillars, 36 of which carry rock art (Figure 10.11). Many additional pillars are found beyond this archaeological area, in increasing numbers and densities (and therefore with decreasing space between them), until they merge into continuous rock. Of key interest to us is the open character of the inter-pillar space within the archaeological rockshelter. That open space in the northern, southern, central and central-eastern parts of the site is strongly distinguished from sectors further to the west and east, where the spaces between pillars become much smaller and labyrinth-like. Understanding this patterning of pillars across the site, and of the spaces between pillars, is of major significance to our overall archaeological project, for it is on these pillar walls and ceilings, and in these nowopen spaces, that people undertook various activities (see below).
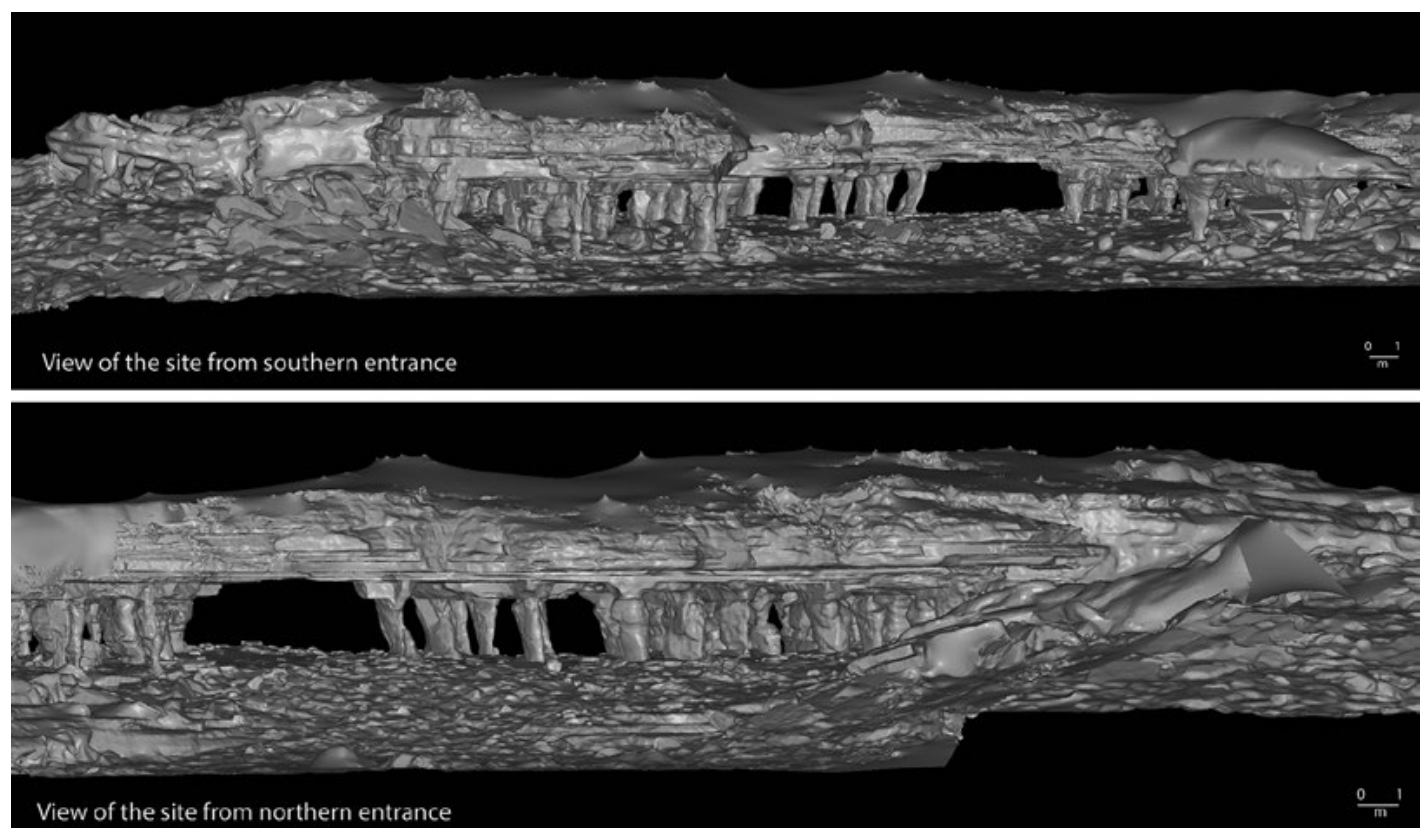

Figure 10.11 Views of Nawarla Gabarnmang from southern (top) and northern (bottom) entrances, as generated from the laser 3-D model.

Both views clearly show the sheltered area formed by a roof held aloft by pillars, along with the wide, open space of the contiguous central and central-eastern area.

Source: Illustration by Jean-Jacques Delannoy. 
Today, Nawarla Gabarnmang's ceiling is shaped like an inverted stairway, each step measuring between 10 and $40 \mathrm{~cm}$ thick (Figure 10.12). The horizontal surfaces between the steps are generally flat. The height above ground of each flat surface is a function of the thickness of the sum of missing rock strata on the ceiling; that is, the height of the stagger from step to step represents the thickness of the missing rock strata from one step to the next.

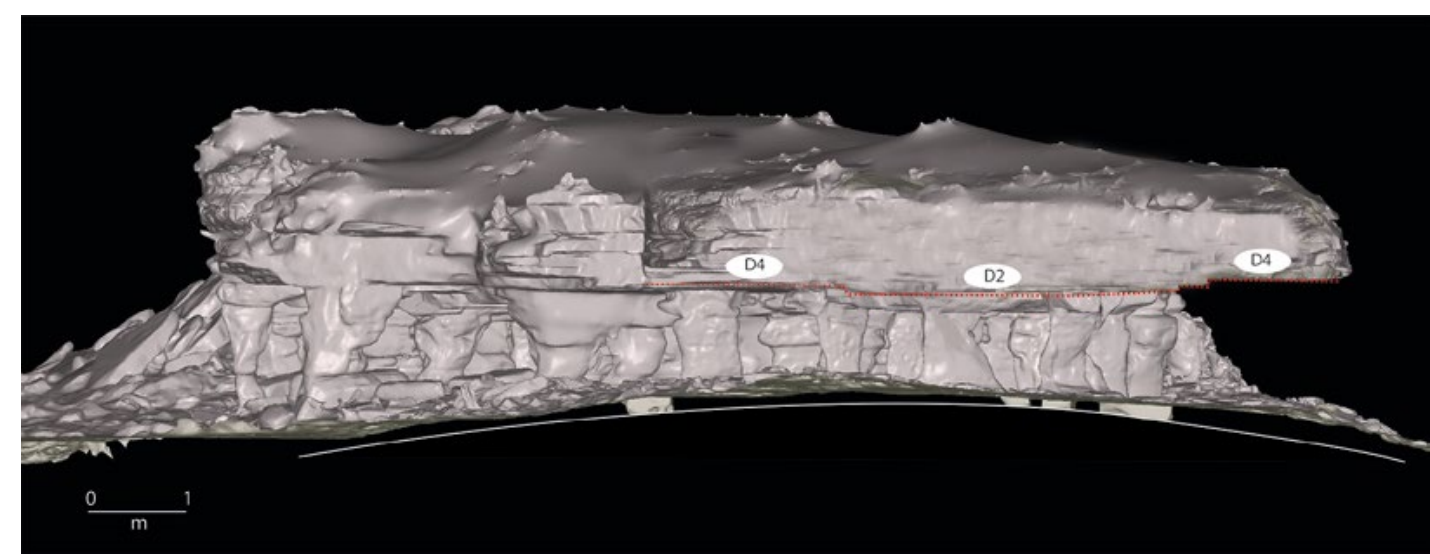

Figure 10.12 South-north transect across the open, central-eastern sector of the site, showing Squares $\mathrm{C}+\mathrm{G}+\mathrm{K}+\mathrm{N}, \mathrm{E}+\mathrm{J}$, and $\mathrm{F}+\mathrm{I}+\mathrm{L}+\mathrm{M}$ to their base.

Here the 'inverted stairway' ceiling profile is apparent, with the most elevated areas along the ceiling's southern and northern ends. The presently exposed rock strata (D2 to D4) are shown. The thin, curved white line at the base of the image shows the shape of the present ground surface; the line is offset downwards to highlight its curvature.

Source: Illustration by Jean-Jacques Delannoy.

From the centre of the site moving northward, the ceiling tends to get higher. We have numbered each rock stratum from a strategic rock layer labelled stratum D0, which originally spanned the entire site and is the first rock stratum above the pillars (Figures 10.13 and 10.14). Seventeen rock strata were unambiguously distinguished by their clear stratification and by the presence of characteristic reference marks (e.g. ripples of varied amplitude and frequency) (Figure 10.14). From strata D4 to D-12, each stratum can be identified by its thickness, presence of crossbedding and petrographic characteristics (e.g. texture and granulometry of constituent quartz grains). A more detailed characterisation of mineralogy has also been undertaken on thin sections of strata for which detached samples could be obtained from the archaeological excavations (Figure 10.15). Seven individual squares or sets of contiguous squares were excavated at the site (see Chapter 11), and each has revealed the presence of blocks or slabs of rock beneath the surface (e.g. Figure 10.5); from these we could investigate source pillars and ceiling strata. The geological characterisation of the sequence of rock strata permitted us to determine where these detached blocks came from. Coupled with detailed maps (see below) that enabled their repositioning to particular sectors of the site, and given that they could be radiocarbon dated through stratigraphic associations, the collapsed blocks enabled us to begin historicising Nawarla Gabarnmang's particular, and peculiar, extant architecture. 


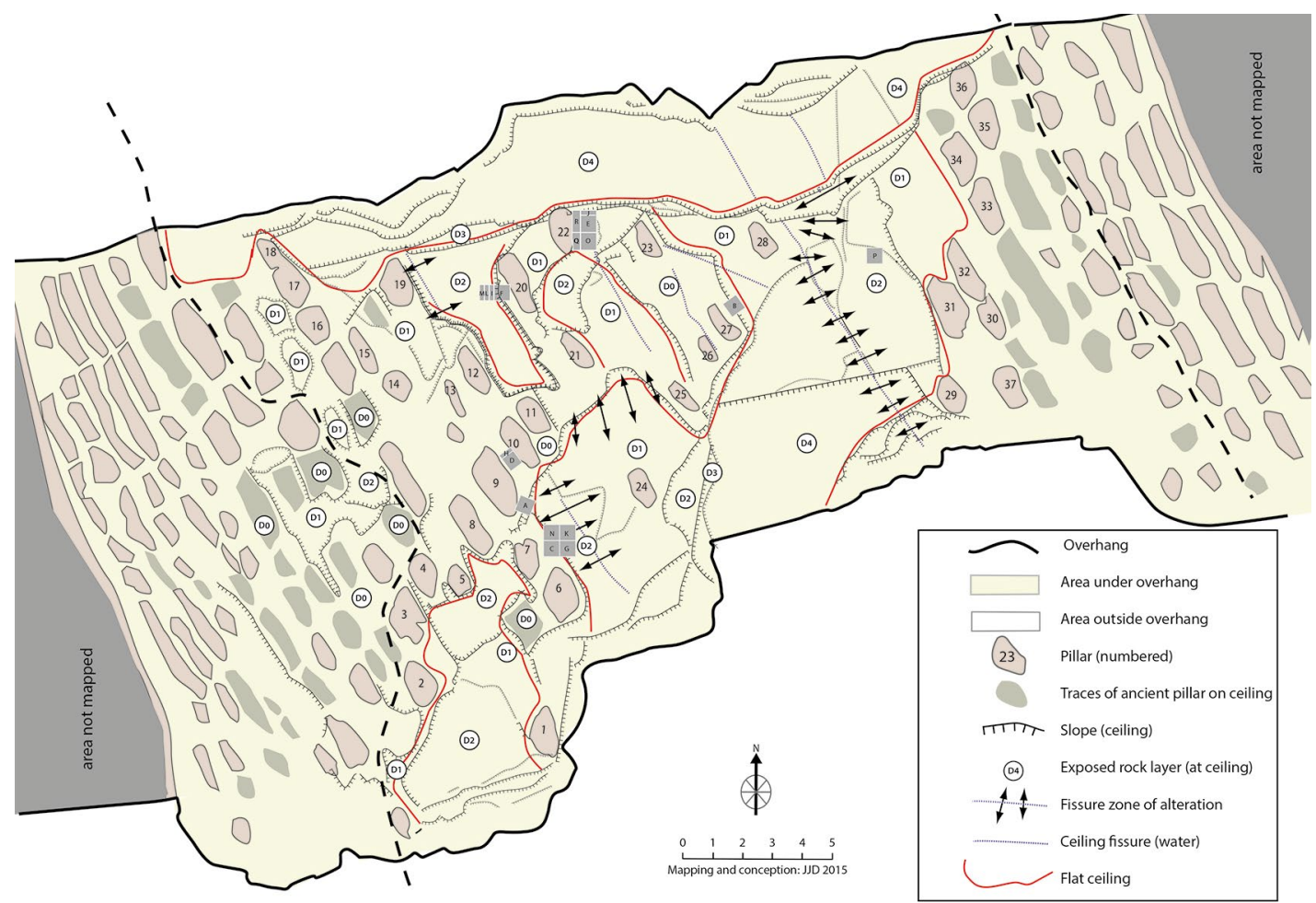

Figure 10.13 Geomorphological map of the ceiling. The zone between the dashed lines delimits the archaeological site studied in this chapter.

The map shows the natural high density of pillars in the western and eastern sectors of the site on one hand, versus the anthropic low density of pillars in the contiguous central and central-eastern sector.

Source: Illustration by Jean-Jacques Delannoy.
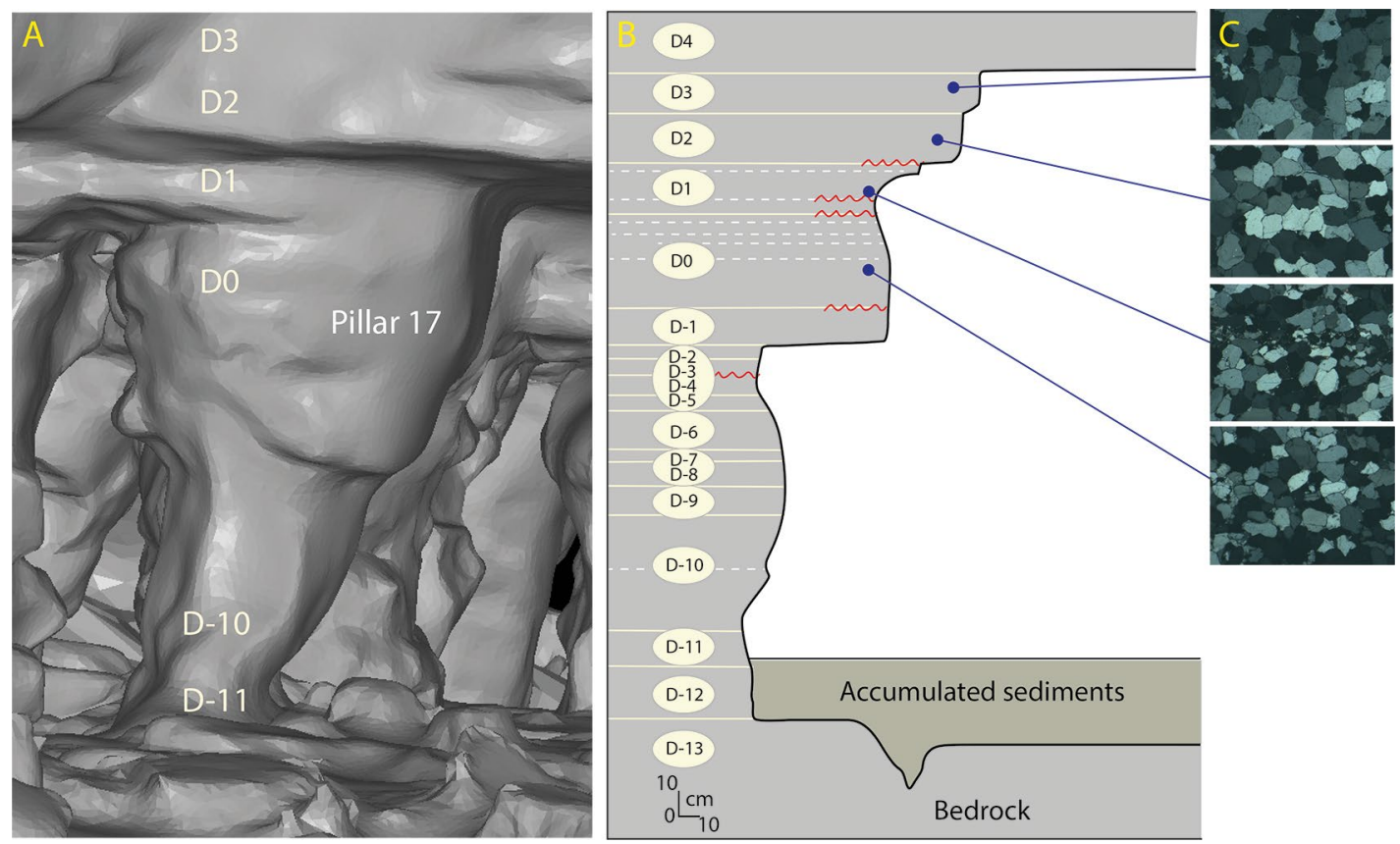

Figure 10.14 Rock strata making up the bedrock on the ground, pillar and ceiling levels.

A: View of Pillar 17 from the 3-D model. B: Sequence of rock strata at Pillar 17. C: Examples of thin sections of ceiling strata DO to D3.

Source: Illustration by Jean-Jacques Delannoy. 
The Archaeology of Rock Art in Western Arnhem Land, Australia

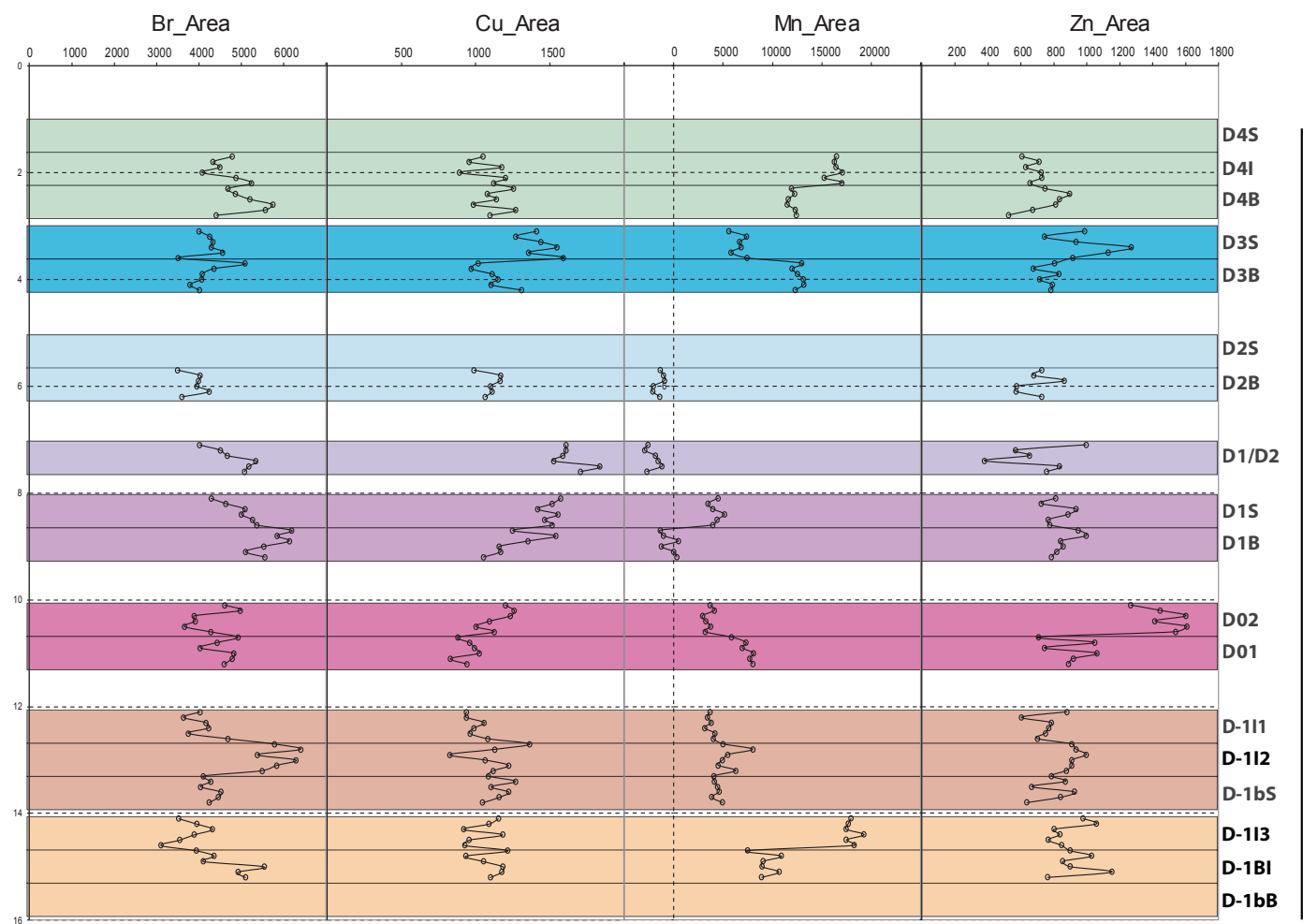

\section{Minor elements}

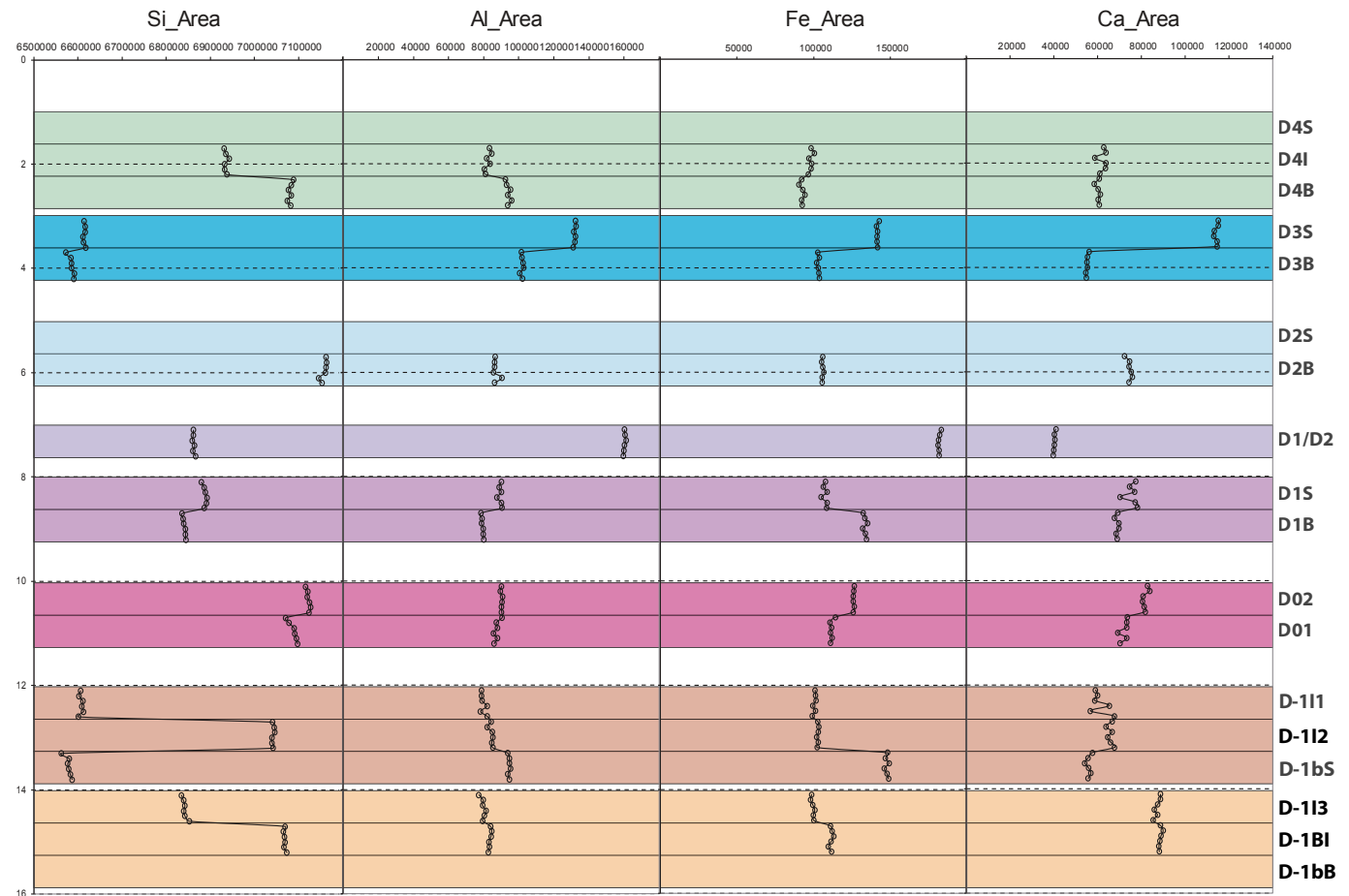

\section{Major elements}

Figure 10.15 Results of XRF core scanner analysis of individual rock strata.

Each rock stratum has a distinctive elemental fingerprint that can be used to identify collapsed blocks at various levels of the archaeological excavations. The Y-axis represents the individual rock strata (D4 to D-1), some of which are divided into subunits (e.g. D4S = upper layer of stratum D4; D4I = intermediary layer of stratum D4; D4B = basal layer of stratum D4).

Source: XRF core scanner analysis A.L Develle; illustration by Jean-Jacques Delannoy. 


\section{Of collapsed ceiling strata and missing rockfalls}

Today, the flatness of each ceiling level can be securely associated with the collapse of successive rock strata. We thus ask:

1. What did the ceiling look like before those ceiling strata collapsed?

2. When did those ceiling strata collapse?

Understanding the history of the ceiling's morphology is significant not just for understanding the history of the site's configuration, but more particularly to enable us to understand the context and age of the extant rock surfaces, and thereby to determine maximum ages for the art on those surfaces.

While the height above ground of the ceiling increases towards its northern and southern sides, the level of the ground surface does the opposite: it is lower along the site's northern and southern margins. This is not what we would expect to find; there should, rather, be piles of rock and correspondingly elevated floor levels under the highest ceiling levels where strata D1 to D3 have fallen and are now missing from the ceiling, such as along the northern and southern ceilings. But instead, the ground surface is largely devoid of rocks, and below the northern ceiling in particular, the ground level dips down towards the site's entrance. There is thus a noncorrespondence between geomorphological processes of ceiling collapse that we can see through the negative scars left by the missing (collapsed) rock strata on the ceiling, and the geometry of the floor level. Where has the missing rock gone?

\section{Scree slopes fronting Nawarla Gabarnmang's northern and southern entrances}

The ground level just outside the northern and southern entrances into Nawarla Gabarnmang consists of rocky screes that slope down from the rockshelter to the low-lying basin on the north and the courtyard on the south. Along these scree slopes, the rocks exhibit a remarkable character; they are of a consistent shape and size, typically $30-40 \mathrm{~cm}$ long $\times 20-40 \mathrm{~cm}$ wide $\times$ $10-20 \mathrm{~cm}$ thick (Figure 10.16). The thickness of these flat, tabular rocks matches the thickness and petrography of the various rock strata that make up the lower levels of the roof within the rockshelter. The northern scree slope in particular contains at least hundreds, and possibly thousands, of such rocks of regular shape and size, and these are limited to the slope that directly fronts the entrance (i.e. they are not spread further eastward or westward along other nearby parts of the northern edge of the rock outcrop, although isolated rocks of similar shape and size are occasionally found within the site; the 'pillows' of Aboriginal testimony). Here, the sediments of the northern scree, including the accumulated rocks, sit directly on a bedrock surface that steps downwards towards the low-lying basin. We note a similar situation to the south of the site, where the bedrock surface at the southern entrance steps downwards into the courtyard.

These two scree deposits emphasise Nawarla Gabarnmang's slightly perched character $3 \mathrm{~m}$ above the low-lying areas on either side (Figure 10.16). It is important to ask about the contents of these scree deposits and how they got there, because there is no evidence of localised overhang collapse that could account for them. These scree deposits are very distinct from the piles of rock that are often found below the edges of overhangs or cliff faces and that generally correspond with the collapse of overhangs (see Chapter 13) or with the detachment of sections of rock wall through mechanical weakening of cliff-lines. We are also curious to find out when these rocks accumulated as scree along the margins of the site, in particular whether, and how, their antiquity corresponds with patterns of human activity. To address these questions, we need further to understand the site's geological history. 

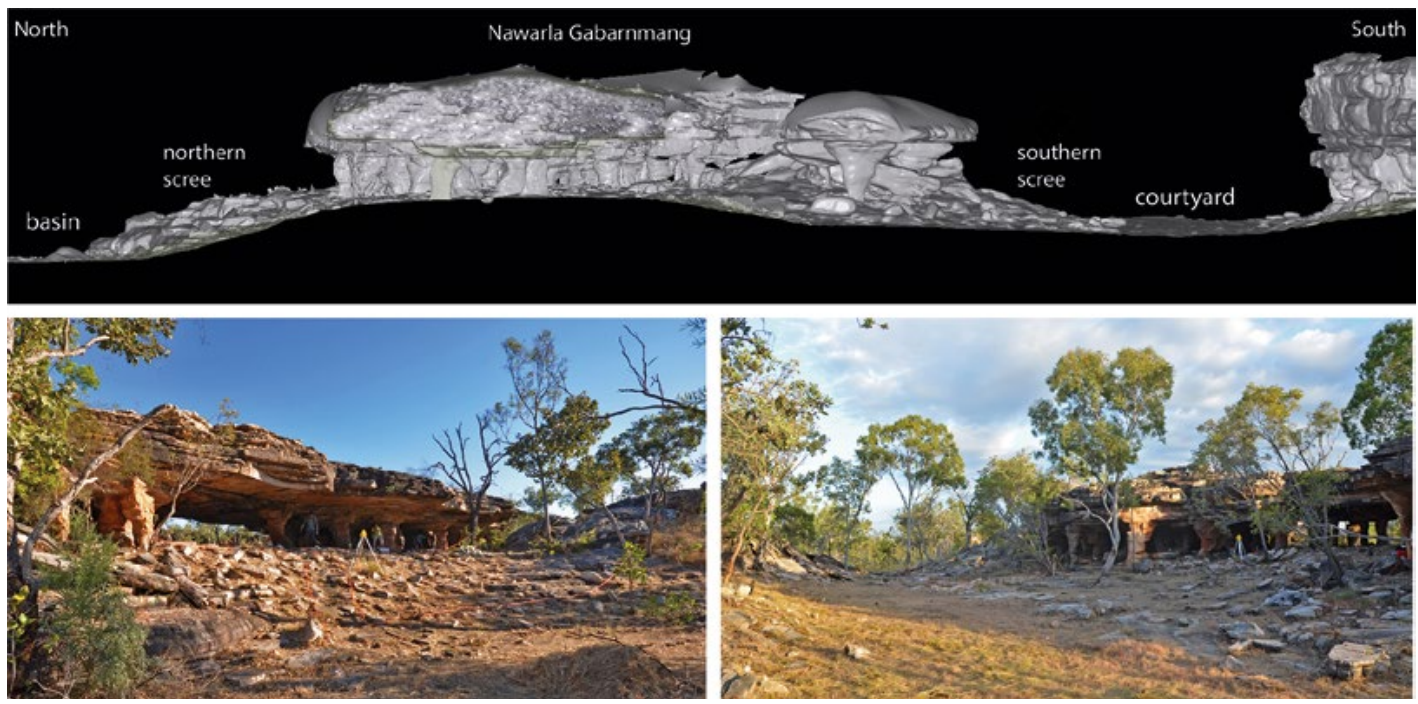

Figure 10.16 Transect across Nawarla Gabarnmang, relative to the basin to the north and the courtyard to the south.

Top: Generated from the laser 3-D model. Bottom left: From the basin looking towards the site's northern entrance. Bottom right: From the courtyard, looking towards the site's southern entrance.

Source: Photographs by Jean-Jacques Delannoy.

\section{The spacing of pillars}

The sheltered area (the height of the voids between pillars) under Nawarla Gabarnmang's ceiling clearly corresponds to a particular geological horizon. Across the landscape, this horizon is characterised by narrow and regularly spaced vertical cavities that map on to parallel fissure lines (see above). Figures 10.17 and 10.18 show the edge of the low rock plateau on the opposite side of the courtyard to the south of Nawarla Gabarnmang. It features the regular spacing of rock pillars and inter-pillar voids along a single geological horizon sandwiched between underlying and overlying quartzite strata that are not thus sculpted. The presence of this pillar landscape along a single stratigraphic horizon signals differential erosion of the rock conditioned by its geology; rock strata that are variably resistant to the formation of voids. Generally speaking, quartzites are not particularly soluble and thus not particularly amenable to the formation of cave-like voids. These voids could only form over very long periods of geological time.

At Nawarla Gabarnmang the voids between pillars are of interest because they represent the sheltered space. Here, the pillars are noticeably more widely spaced than in neighbouring areas where the voids are approximately the same width as the pillars. In order to understand how the spaces between the pillars became so wide at Nawarla Gabarnmang, let us begin by considering the edge of the low rock plateau to the south of the site (Figures 10.18 and 10.19). Here we can clearly see different stages of cavity-formation; from razorblade-thin fissures to nano-cavities to wide voids one can walk through. Five observations are pertinent:

1. Irrespective of their size (fine fissures to voids that are a few metres wide), vertically the voids directly map onto the network of fissures evident across the landscape, and horizontally they map onto joints between rock strata.

2. The geometry of connected spaces between the pillars has resulted in a labyrinthine network of corridors along the three axes of the fracture planes.

3. Between the pillars are found spaces with areas of variable stages of void production: a) fully formed voids up to a few tens of metres long; and b) soft, chemically altered rock that has not yet eroded away. 
4. Irrespective of the length of the voids ('corridors'), their terminals consist of altered, friable rock.

5. Patination has developed on the rock around the voids' circumference (pillars, ceiling and floor).

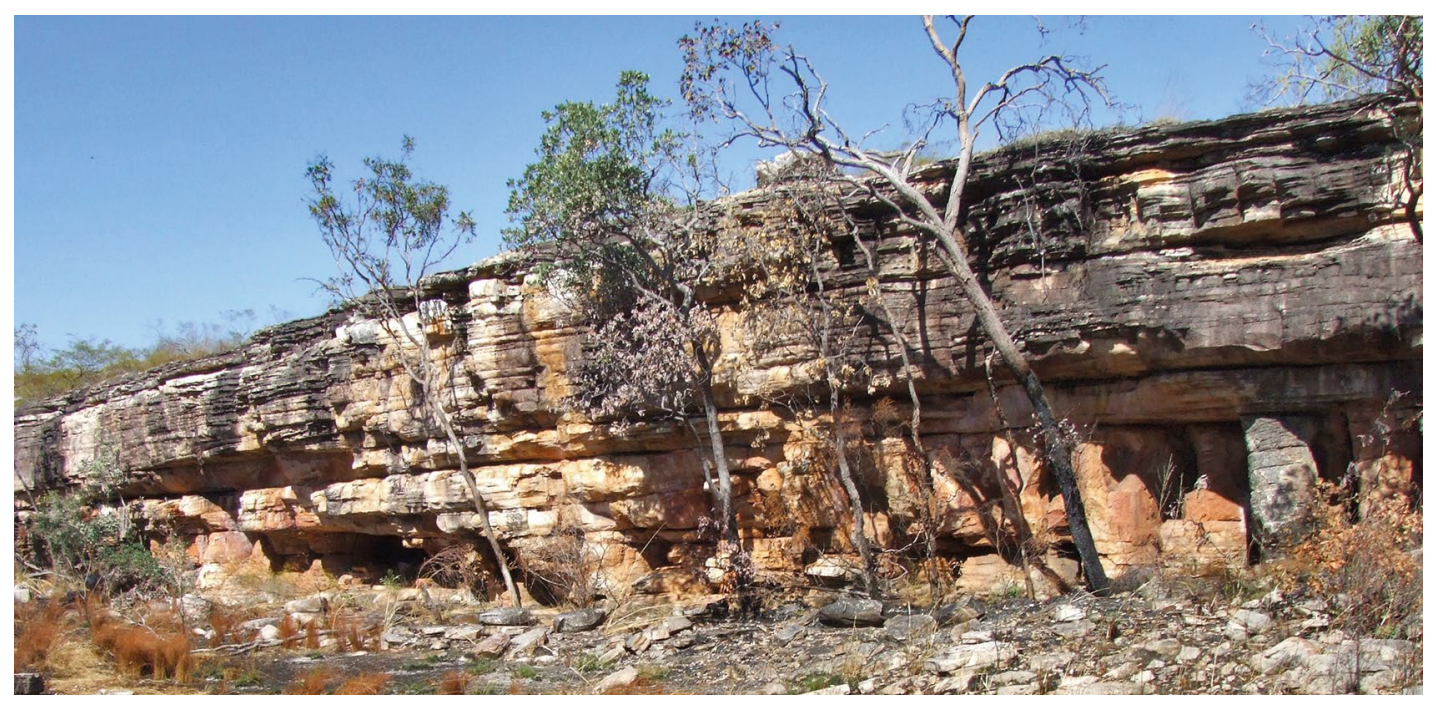

Figure 10.17 Northern edge of the rock outcrop that delimits the southern side of the courtyard, to the south of the site.

Source: Photograph by Jean-Jacques Delannoy.

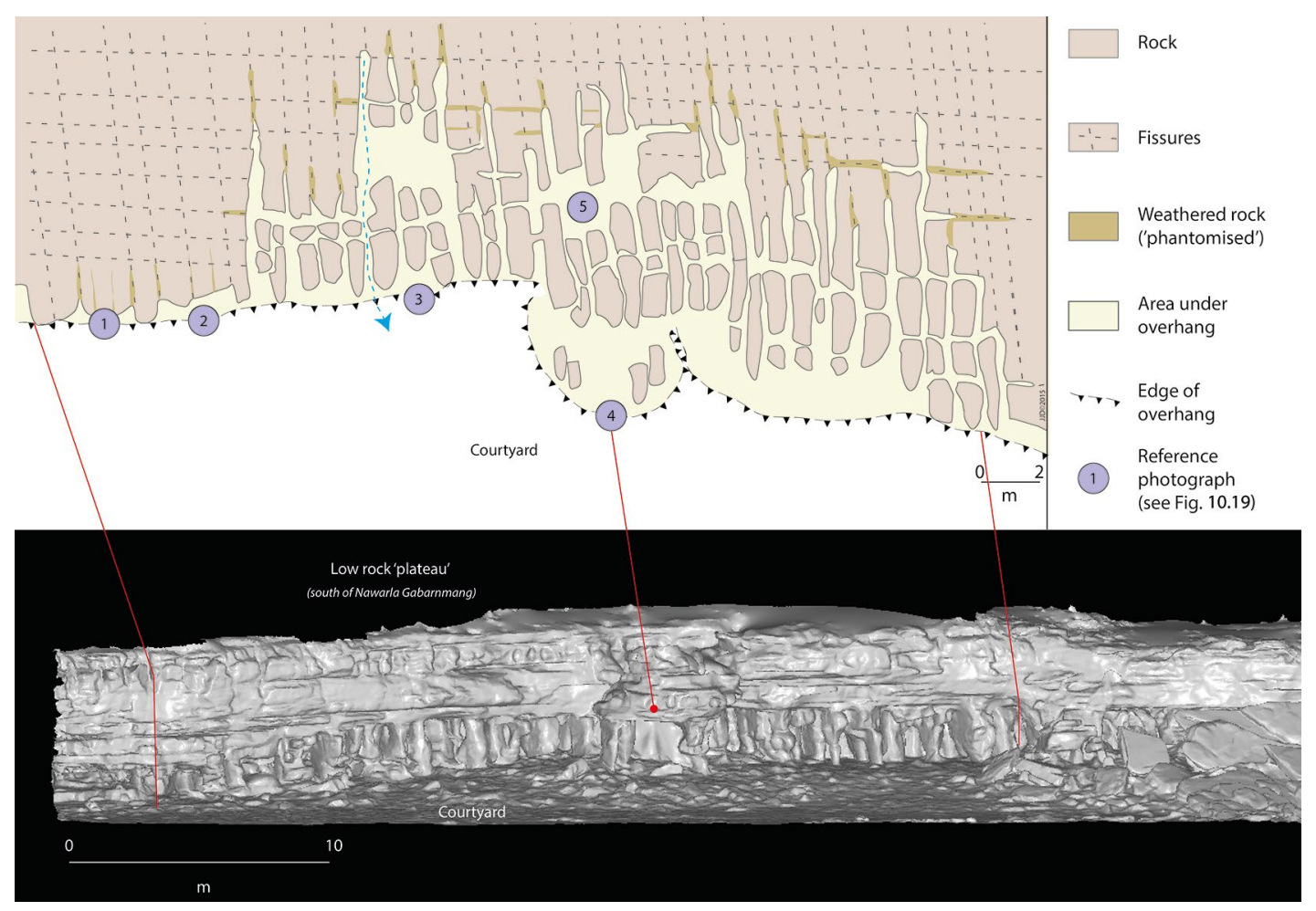

Figure 10.18 Different stages in the natural, geological evolution of the pillarscape along the edge of the rock outcrop that delimits the southern side of the courtyard.

The numbers in the purple circles refer to the rock features shown in Figure 10.19.

Source: Illustration by Jean-Jacques Delannoy. 


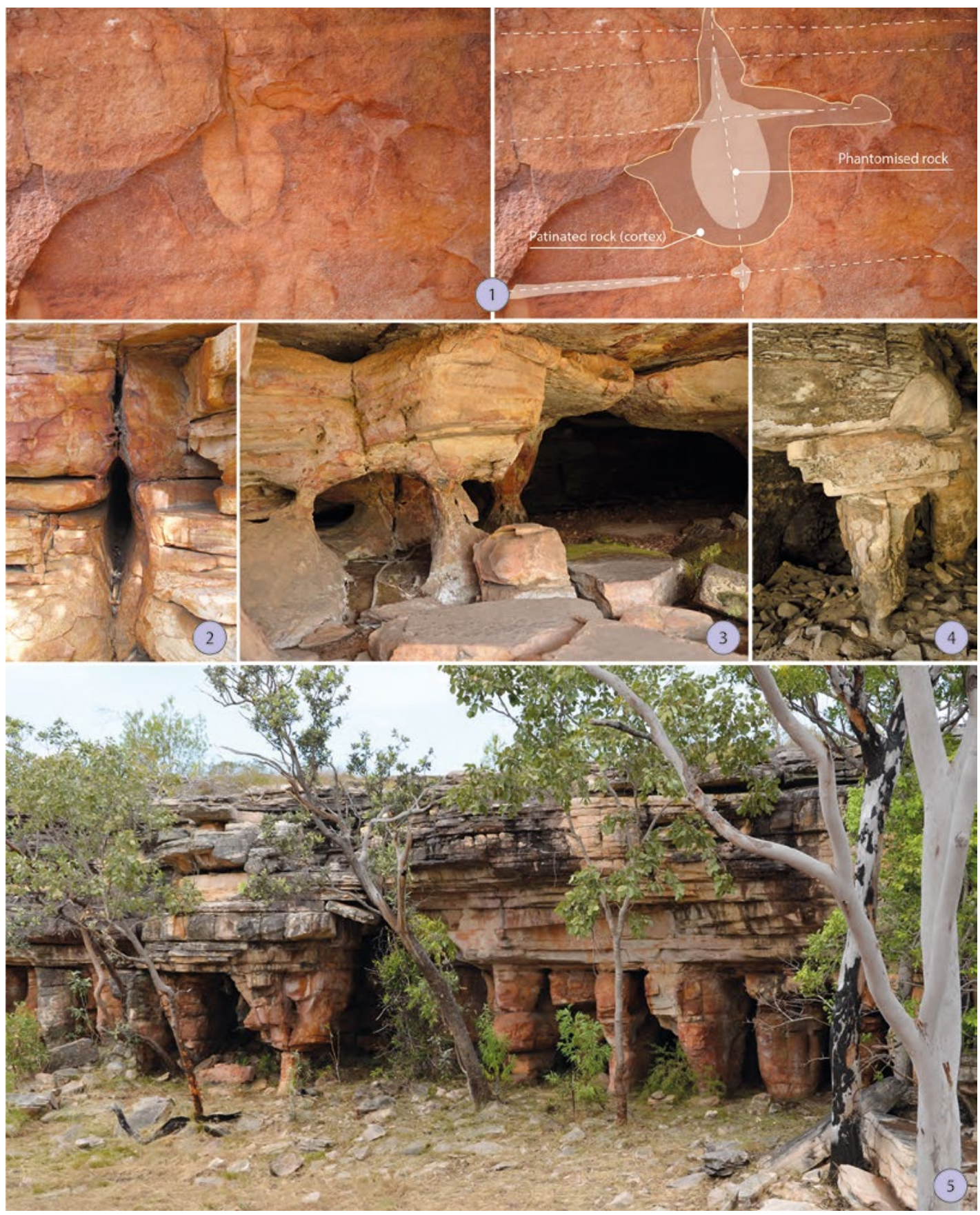

Figure 10.19 Different stages in the natural, geological evolution of the pillarscape along the edge of the rock outcrop that delimits the southern side of the courtyard, from thin fissure lines (1), to the weathering of the matrix surrounding the fissures (phantomisation), to the erosion of weathered products leading to the formation of remnant rock (pillars) separated by voids (2-5).

Source: Photographs by Jean-Jacques Delannoy.

These characteristics indicate a pillar landscape formed through dissolution of the rock along fissures over geologically very long periods of time. This phenomenon of 'ghost rock' formation or 'phantomisation' was first described and theorised by Erhard (1967) to explain altered pockets of rock that can go down to great depths below ground - $100 \mathrm{~m}$ or more - and then by Quinif (2010) to refer to different types of voids that cannot be accounted for by more classical processes of karstification, but found in soluble and apparently non-soluble types of rock (Figure 10.20). 

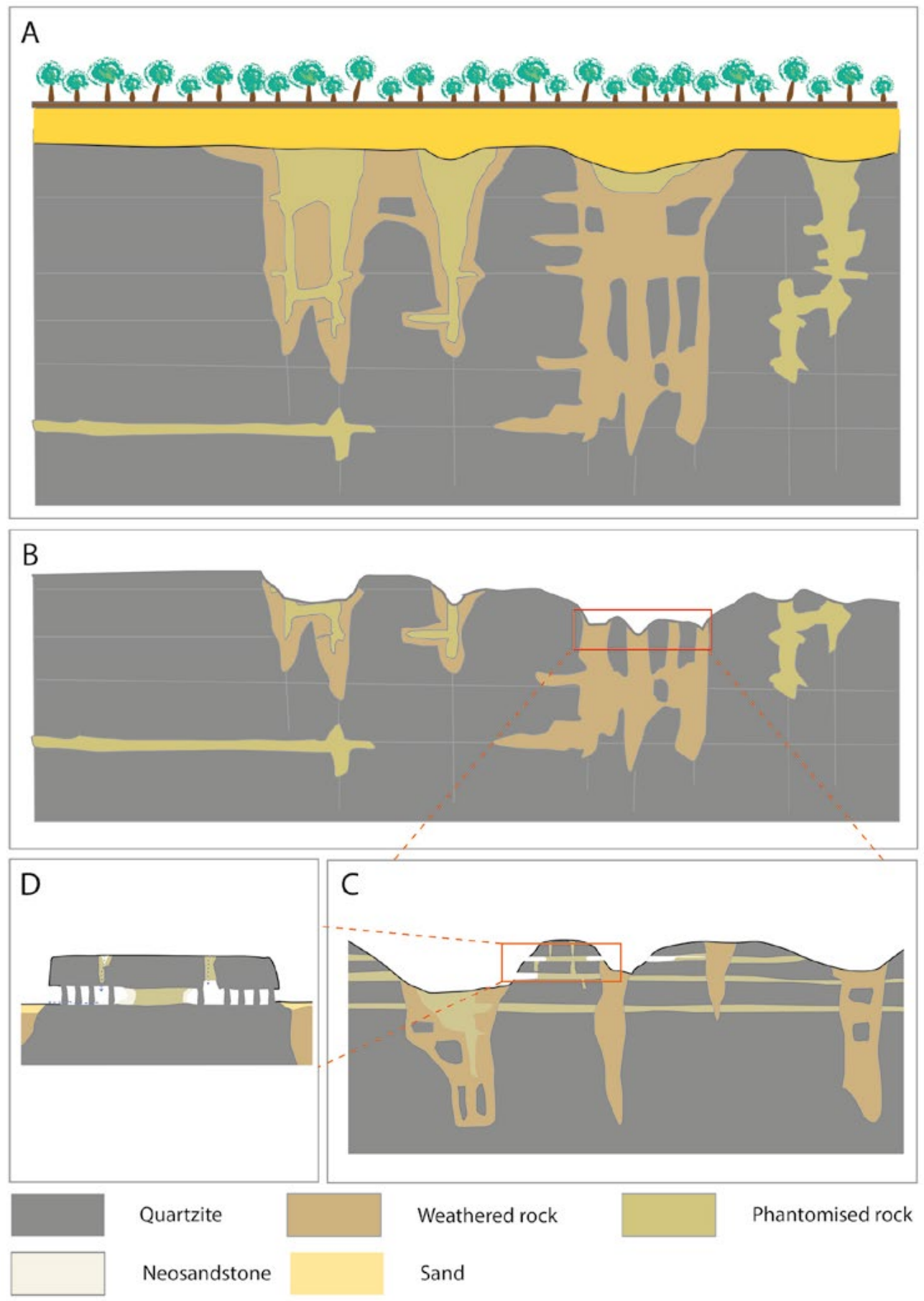

Figure 10.20 Stages in the process of phantomisation and creation of pillarscapes on the Arnhem Land plateau.

A: Over very long geological timescales, subterranean weathering of the quartzite along vertical fissure lines and horizontal joints (c. 120 million years ago). This process takes place below the watertable, where water circulates very slowly. The ensuing weathered rock is thus 'phantomised'. B: As the gradient of waterflows increase, surface levels collapse, causing the erosion of weathered rock. These basin areas are lower, relative to more elevated surrounding rock landscapes where the quartzite is more resistant. C: Close-up of an area between basins. Water passes through phantomised zones, exiting into the basins via phantomised joints. These waterflows help further evacuate weathered (phantomised) rock within the rock outcrop, creating inter-pillar voids. D: Present state in the evolution of Nawarla Gabarnmang. 'Neosandstone' refers to the reversion of quartzite to sandstone during its weathering (after Quinif 2010).

Source: Illustration by Jean-Jacques Delannoy. 
The process of phantomisation (see Armstrong et al. 2013; Martini and Grimes 2012) through slow dissolution of the rock along fissure lines at a time when the rock lay underground beneath the watertable was followed by the evacuation of altered products when the bedrock became raised above ground. This two-stage transformation enables us to understand the presence of voids that form corridors between rock pillars and the labyrinthine structure of the spaces both at Nawarla Gabarnmang and in nearby areas (Figure 10.13). But that process does not easily explain the large open spaces found in the main chamber of Nawarla Gabarnmang today. Here, the morphology of the pillars is similar to that present in the eastern and western sides of the site where the spaces between pillars are much narrower, and along the low rock plateau on the other side of the courtyard to the south. Yet, in the central, central-eastern, northern and southern sectors of Nawarla Gabarnmang, the spatial configuration of the pillarscape is very different to that of other places nearby, in that the density of pillars is noticeably less (Figure 10.13). This lower density of pillars is a key to understanding the processes that have shaped the wide, open spaces within Nawarla Gabarnmang.

At Nawarla Gabarnmang, the flatness of the surfaces on the extant ceiling indicates that it is the result of successive roof collapses (see above). Through those ceiling collapses, the space within the site has expanded upwards through time, but in doing so they have also erased traces of the shape of the earlier inter-pillar voids. These collapses could not have taken place if the ceiling was supported by numerous additional pillars to the ones currently present; they must have occurred in the absence of supporting pillars. So, why were those pillars missing?

To explore this question, we have constructed a three-dimensional (3-D) model of Nawarla Gabarnmang from a high-resolution laser-generated 3-D mapping of the site and surrounds, coupled with detailed geomorphological maps made on-site (see below). The 3-D model of the ceiling (Figures 10.13 and 10.21) clearly shows the strong negative correlation between the density of pillars and the width of the ceiling: the more pillars there are, the narrower the ceiling is. Yet those areas with few pillars have vast ceiling surfaces and wide, open spaces devoid of collapsed rocks at ground level, especially in the northern, southern, central and central-eastern sectors of the site. In these areas, the rock strata that constitute the extant ceiling surfaces are those most elevated in the site's geological series (strata D4-D3-D2) (Figure 10.21). On the other hand, where the density of pillars is greatest in the western part of the site, the ceiling level is lower, less flat and corresponds with rock strata that are less elevated in the geological series (strata D0 and D1). This suggests that the more or less open character of the site involved the disappearance of pillars and subsequent ceiling collapse.

From these initial observations of the site's extant configuration, we can work out the following evolutionary sequence for Nawarla Gabarnmang:

1. Creation of voids through processes of phantomisation.

2. Expansion of these voids by successive ceiling collapse in the face of disappearing pillar supports.

Why pillars disappeared has not yet been determined. To address this, we will need to turn to the evidence buried underground and revealed by the archaeological excavations. 


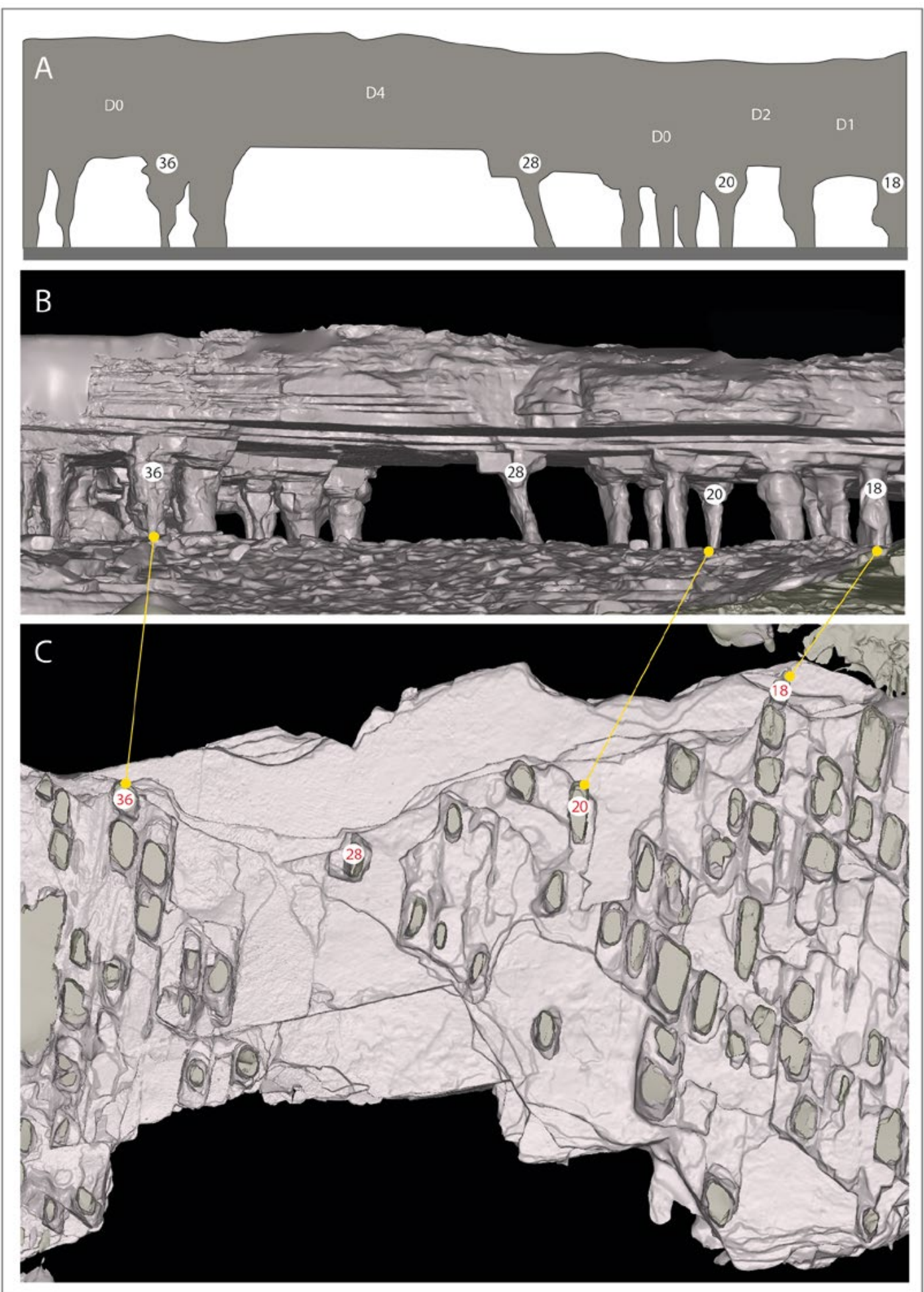

Figure 10.21 Nawarla Gabarnmang.

A: Looking southward from northern entrance. B and C: View of ceiling, showing extant pillars and remnant traces of missing pillars at ceiling level.

Source: Illustration by Jean-Jacques Delannoy. 
So far we have focused on Nawarla Gabarnmang's present configuration and on the geological origins of its pillarscape. The processes of phantomisation that caused the pillarscape in the first place are not now active because they take place below the watertable, and the hard quartzites are extremely resistant to erosion. So we can conclude that when people first arrived at the site around 50,000 years ago, what they encountered was a rockshelter much like the one we now see, but with a more regular set of pillars, less extensive ceiling surfaces; overall it had significantly less open sheltered space. So how did the site's internal space come to open up in more recent times, either preceding human occupation or coetaneous with it? Understanding this latter phase of the site's evolution is critical to understanding the age of the decorated rock surfaces, and therefore the maximum age of the rock art on those surfaces.

The general and more specific questions we now pose are:

- Why is the sheltered space at Nawarla Gabarnmang considerably more open than in nearby pillarscapes?

- Why are there fewer pillars, occurring in lower concentrations, at Nawarla Gabarnmang than in nearby pillarscapes?

- Why is there a lack of fit between the geometry of the ceiling and the shape of the ground level, and a non-correspondence between a large amount of missing ceiling strata along the northern and southern edges of the site yet a paucity of blocks on the ground?

- Why is there a large scree slope with blocks of regular shape and size immediately outside the northern and southern entrances of Nawarla Gabarnmang, and yet no evidence for collapsed overhangs in those areas?

Answering these questions requires knowledge of what lies underground, and geomorphological details obtained with good spatial resolution.

\section{The archaeological excavations}

Needless to say, from an archaeological perspective, Nawarla Gabarnmang is an exceptional site. We first began research at the site at the request of the Jawoyn Association, who asked us to determine whether or not in situ cultural deposits lay buried underground, and, if so, what these could tell us about the past. A number of isolated and juxtaposed squares were excavated across the site, each square usually being $50 \mathrm{~cm}$ wide or smaller to enhance chronostratigraphic and spatial control over excavated sediments; our aim was to eventually undertake a larger excavation in one or more parts of the site, after the broader pattern was understood. Table 10.1 lists the excavated squares, the year they were excavated, their size, where they occur in the site, their maximum depth and the maximum age of human occupation. Eighteen squares have been excavated; three are single (Squares A, B and P), and the rest are contiguous with one or more other squares to form four sets of spatially distinct pits covering especially the northwestern and southwestern sectors of the site (Squares $\mathrm{C}+\mathrm{G}+\mathrm{K}+\mathrm{N}, \mathrm{D}+\mathrm{H}, \mathrm{E}+\mathrm{J}+\mathrm{O}+\mathrm{Q}+\mathrm{R}, \mathrm{F}+\mathrm{I}+\mathrm{L}+\mathrm{M}$ ). The rationale for the location of some of the excavations had much to do with the sequence of results (e.g. dates, assemblages, ability to reveal evidence of the antiquity of the rock art on extant pillars and ceiling surfaces) we obtained from one year to the next; as results appeared, new questions were raised and new excavations undertaken where answers might best be found. Thus, in the first year of research (2010), we excavated Squares A and B. Unexpectedly for such shallow and well-stratified deposits, Square A revealed cultural deposits going down to 45,180 $\pm 910 \mathrm{cal}$ BP, but deeper cultural sediments were evident in a very narrow crack (a phantomised fissure line) in the bedrock at the bottom of the square (see David et al. 2011; Geneste et al. 2010, 2012), indicating that nearby excavations in well-protected areas might reveal evidence of that earlier occupation. Square D was opened the following year to further track the early evidence 
of human occupation revealed in Square A, and Squares $\mathrm{F}+\mathrm{I}+\mathrm{L}+\mathrm{M}$ were in part a continuation of this same tracking of old deposits across increasingly well-protected sectors of the site. Other squares were positioned to sample what appeared for contextual reasons to be deep soft deposits, intriguing sectors of the site, areas that would have been inaccessible or difficult of access to medium-sized or large animals and areas with high potential to shed light on the age of nearby rock art. These excavations were in all cases undertaken in very shallow arbitrary excavation units (very often measuring a few millimetres, the better to investigate questions of taphonomy and chronostratigraphy) following the stratigraphy.

Table 10.1 Details of the excavated squares, Nawarla Gabarnmang.

\begin{tabular}{|l|l|l|l|l|l|}
\hline $\begin{array}{l}\text { Excavation } \\
\text { squares }\end{array}$ & $\begin{array}{l}\text { Year(s) } \\
\text { excavated }\end{array}$ & $\begin{array}{l}\text { Size of pit } \\
(\mathrm{cm})\end{array}$ & $\begin{array}{l}\text { Location in site } \\
\text { (sector) }\end{array}$ & $\begin{array}{l}\text { Nature of material on } \\
\text { which deepest cultural } \\
\text { deposits lie }\end{array}$ & $\begin{array}{l}\text { Median age of occupation at base } \\
\text { (cal BP, all on charcoal dated by } \\
\text { AMS radiocarbon) }\end{array}$ \\
\hline A & 2010 & $50 \times 50$ & SW & bedrock & 45,180 \\
\hline$B$ & 2010 & $50 \times 50$ & Central & bedrock & 5046 \\
\hline $\mathrm{C}+\mathrm{G}+\mathrm{K}+\mathrm{N}$ & $2011-2012$ & $100 \times 100$ & SW & bedrock & 21,922 \\
\hline $\mathrm{D}+\mathrm{H}$ & 2011 & $60 \times 50$ & WSW & bedrock & 46,576 \\
\hline $\mathrm{E}+\mathrm{J}+\mathrm{O}+\mathrm{Q}+\mathrm{R}$ & $2011-2012$ & $130 \times 90$ & NW & bedrock & 46,278 \\
\hline $\mathrm{F}+\mathrm{I}+\mathrm{L}+\mathrm{M}$ & $2011-2012$ & $100 \times 50$ & WNW & sands and rocks & 49,350 (non-basal) \\
\hline $\mathrm{P}$ & 2012 & $50 \times 50$ & Central-eastern & rock slab & 4240 \\
\hline
\end{tabular}

Source: Authors' data.

So far we have obtained 196 accelerator mass spectrometry (AMS) radiocarbon dates on single pieces of charcoal from these 18 excavated squares. The spatial pattern of basal dates indicates the following:

1. Rich assemblages of flaked stone artefacts are found down to bedrock and in all stratigraphic units of every excavated square, except for contiguous Squares $\mathrm{F}+\mathrm{I}+\mathrm{L}+\mathrm{M}$. Here, the deepest artefacts overlie a thick layer of sands and rockfall that pre-date the period of human occupation (David et al. completed manuscript).

2. The onset of human occupation around 50,000 years ago (see David et al. completed manuscript for a more refined set of radiocarbon and OSL dates) is accompanied by the onset of deposition of aeolian sands within the site.

3. There is no evidence of in situ charcoal until after the arrival of people at the site.

4. The earliest evidence for human occupation is in the northwestern sector of the site, where cultural horizons overlie earlier pre-cultural sediments.

5. Evidence of pigment use in the form of in situ used ochre crayons, dried drops of paint, tiny fragments of imported pigments deposited during processing for the making of paint pastes, and tiny painted pieces of (exfoliated?) rock are present in large numbers underground, and variably go back into Pleistocene layers. The oldest excavated painted rock, dating to 26,739-27,657 cal BP, came from Square E (David et al. 2013, 2014; see also Chapter 11).

6. The ceiling is richly decorated with rock art, with 1391 paintings including some stencils identified. Hundreds more paintings, and cupules, occur on 36 pillars, but these have not yet been systematically recorded.

7. While some of the excavated squares have revealed isolated rock slabs buried horizontally underground (e.g. Squares E, F+I+L+M, P), there is a paucity of accumulated roof-fall and debris from pillar collapse. Exceptions are contiguous Squares $\mathrm{C}+\mathrm{G}+\mathrm{K}+\mathrm{N}$ and the area immediately abutting Pillar 20 in Square F; it remains to be determined whether the buried rocks in those two pits can account for the bulk of the missing adjacent pillar rock. What is clear is that they cannot account for the missing rock strata overhead. 
To make sense of the above findings, we turn to an integrated geomorphological-archaeological approach that we have come to term 'archaeomorphology' (Delannoy et al. 2013, 2017). Additional information aiding these investigations are five AMS radiocarbon dates obtained directly from the rock art (mainly beeswax figures), as well as two AMS radiocarbon dates on mud wasp nests (reported in Gunn 2016). Each of these samples comes from a ceiling surface, and is therefore useful for determining the minimum age of that extant ceiling surface.

\section{Nawarla Gabarnmang: Archaeomorphology}

As noted above, Nawarla Gabarnmang's internal structure contains wide, open spaces with few pillars and high ceilings near the central and central-east sections of the site along with its northern and southern margins, versus a dense pillarscape with lower ceiling to the west and to the east. The archaeological excavations and rock art have also revealed a similar spatial division, with the western sector having the oldest archaeological remains (Squares A, D+H, $\mathrm{E}+\mathrm{J}+\mathrm{O}+\mathrm{Q}+\mathrm{R}, \mathrm{F}+\mathrm{I}+\mathrm{L}+\mathrm{M}$ ) in the ground and the oldest art on the ceiling, in contrast to a central and central-eastern sector where both the excavated deposits (Squares B and P; see Chapters 11 and 12) and ceiling art tend to be relatively recent.

We now ask why there is such a west versus central and central-east differentiation in the physical structure of the site, buried archaeology and ceiling art. This question ventures into the site's spatial history, requiring detailed information of its spatial characteristics through time. Our approach has been to obtain evidence from specialist geological, geomorphological, sedimentological, archaeological and rock art studies, and to inter-relate these various lines of evidence. This interdisciplinarity is fundamental to our ability to understand how spatial patterns in the site's rock structure, accumulation of soft sediments at ground level, buried evidence of human activity and rock art may or may not be inter-related, including the role of taphonomy in those patterns. That is, to adequately understand how site formation processes have influenced the physical matrix of the site, human occupation, rock art and the preservation of rock surfaces and sediments, we need to involve disciplines capable of addressing each of these.

Two fundamental analytical tools have been used across all of these studies, and indeed it is these tools that have facilitated cross-communication and understanding: 1) archaeomorphological mapping (see below); and 2) 3-D mapping and modelling of the site.

Much of our analytical reasoning revolves around the geomorphological maps (Joly 1977; Delannoy et al. 2001, 2004). On such maps are plotted all material items deemed relevant. 'Everything' needs to be represented on a geomorphological map, not for the sake of being exhaustive, but to enable questions to be asked about each object, on their relationships with other adjacent or more distant static and movable objects and on the processes that caused them to be deposited where they are now. The act of representing each one of these objects on a map gives them an existence that requires explanation, and that requires a history. It is this line of enquiry that enables us to build a historic account of how Nawarla Gabarnmang's present state came to be.

In the first instance, archaeomorphological mapping has been of utmost importance, because it has enabled us to identify where specific objects, structures and surface characteristics are found across the site. It has also enabled all members of the research team, irrespective of their field of study, to work with a common map that includes the details from each of the specialist studies; in this way, all these aspects became usable and potentially meaningful to all participants. From an early stage, the maps focused on the rock surfaces, distribution of soft sediments, detached rocks found at ground level, archaeological objects and rock art. Two key maps came to be 
repeatedly consulted: one relating to ground level, the other to the ceiling (Figures 10.13 and 10.22). The juxtaposition of these two maps has enabled us to see how the archaeology and rock art map onto the spatial patterning of pillars and inter-pillar spaces (David et al. 2011; Delannoy et al. 2013); for an example of how this was applied in the area of Square P, see Chapter 11.

It soon became apparent, however, that the site's complex three-dimensional space (voids, pillars, staggered ceiling levels and so forth) required a more powerful tool than flat maps, one that was fully three-dimensional, so the site was mapped in 3-D by laser, enabling a high-resolution, virtual 3-D model to be built. This 3-D model has enabled us to visualise the site in new ways, to approach it from different perspectives to those from which we can see things in the field. The 3-D model allows visualisation of the site and its landscape at spatial scales that enable us more easily to connect cause and effect. This is in part due to the masking effects of features in the real world, where, for example, the aesthetic pull of the ceiling art may hinder us from seeing underlying rock surfaces, or where pillars in the foreground may stop us from seeing or relating to rock structures that lie beyond. The 3-D model enables us to move quickly between spatial scales, even to look through physical barriers such as paint layers or rock pillars or thick ceilings, and to bring forward background details, making them more easily compared with foreground details. The 3-D model also enables us to measure and quantify distances and volumes in ways that cannot be easily done in the field, be it for reasons of accessibility or conservation. The 3-D model also enables us to 'pick up' movable items such as blocks of rock lying on the ground, for example, to match their edges with original remnant joins on the site's pillar walls or ceilings (see Chapter 15 for a good example of where this has been done at JSARN-124 site 3 a few kilometres away). And at Nawarla Gabarnmang, the 3-D model proved its value when it brought together the evidence from each of the different analytical fields (see below).

\section{From geomorphological to archaeomorphological mapping}

Understanding what happened at the site through time is closely connected with understanding the changing physical shape of the site along with the processes that have caused those transformations. Objects on the ground today could have lain there since their original deposition, or they could have been displaced by geomorphological processes, by animals, by people or by a combination of these. Geomorphological investigations allow us to discriminate between these different causes, to measure their relative impacts and to determine what happened when. In effect, geomorphological analysis aims to explain the origins of particular forms and deposits by identifying phases when specific processes took place on those items of interest. Rock surfaces and deposits at Nawarla Gabarnmang could be put into historical order by associating specific processes with each form and with the present positioning of objects.

In this way, we distinguish between processes of erosion (removal of material), transport and sedimentation. Each process involves chemical, mechanical, gravitational and/or anthropic forces. Employing the high-resolution 3-D model, the specialist lines of evidence enabled us to (Figures 10.13 and 10.22):

1. Distinguish a range of natural morphogenic processes responsible for the general evolution of the site, through traces of chemical alteration of the rock, gravitational collapse of rock strata, water flow, aeolian deposition of sands and the like.

2. Bring to evidence anthropic actions that caused the configuration of the site to be modified, for reasons that remain to be determined (see below).

3. Determine where and when across the site those natural and cultural modifications took place. 


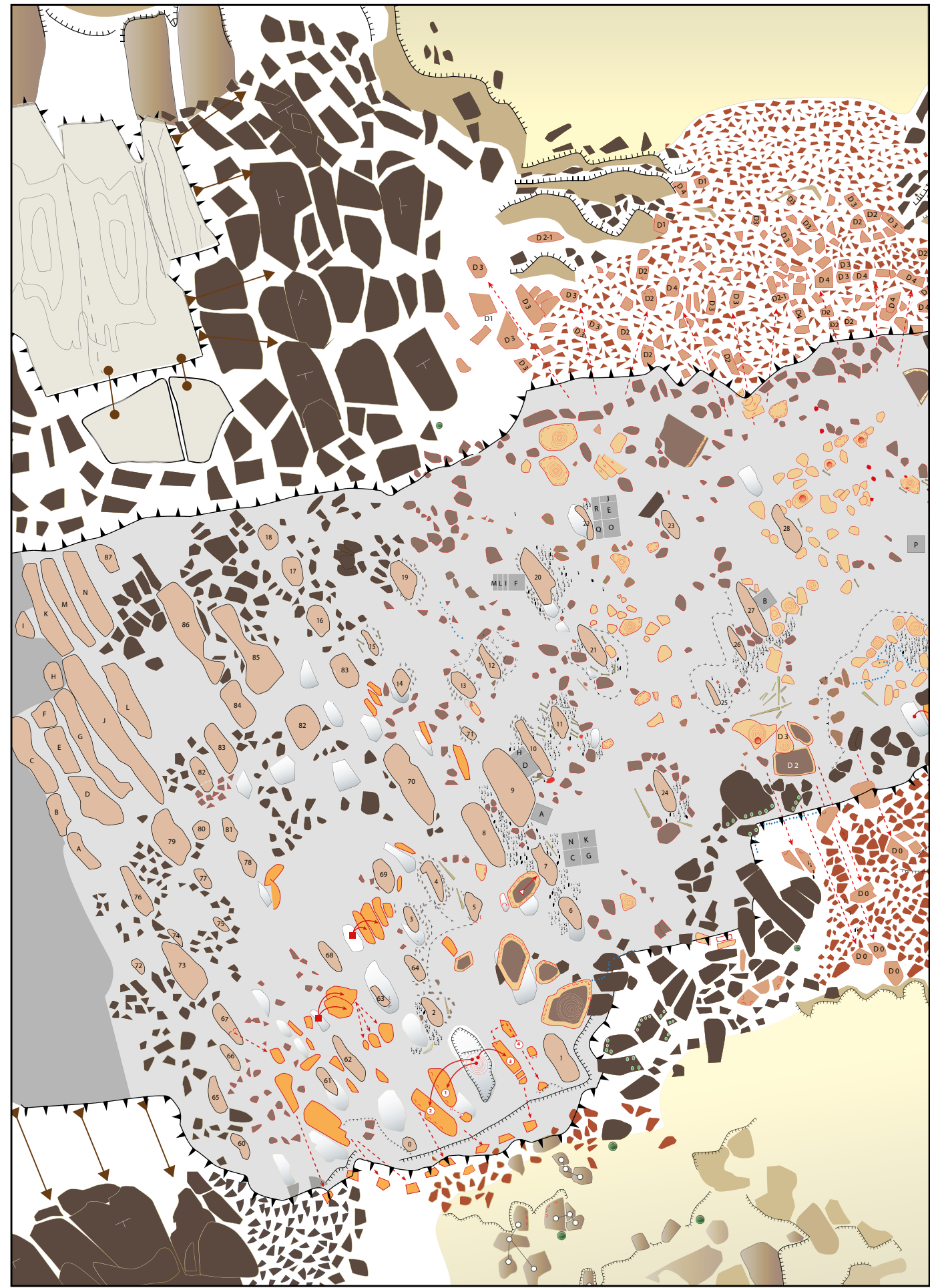

Figure 10.22 Plan of site floor, based on details recorded during on-site archaeomorphological mapping and the 3-D laser model.

Source: Illustration by Jean-Jacques Delannoy. 


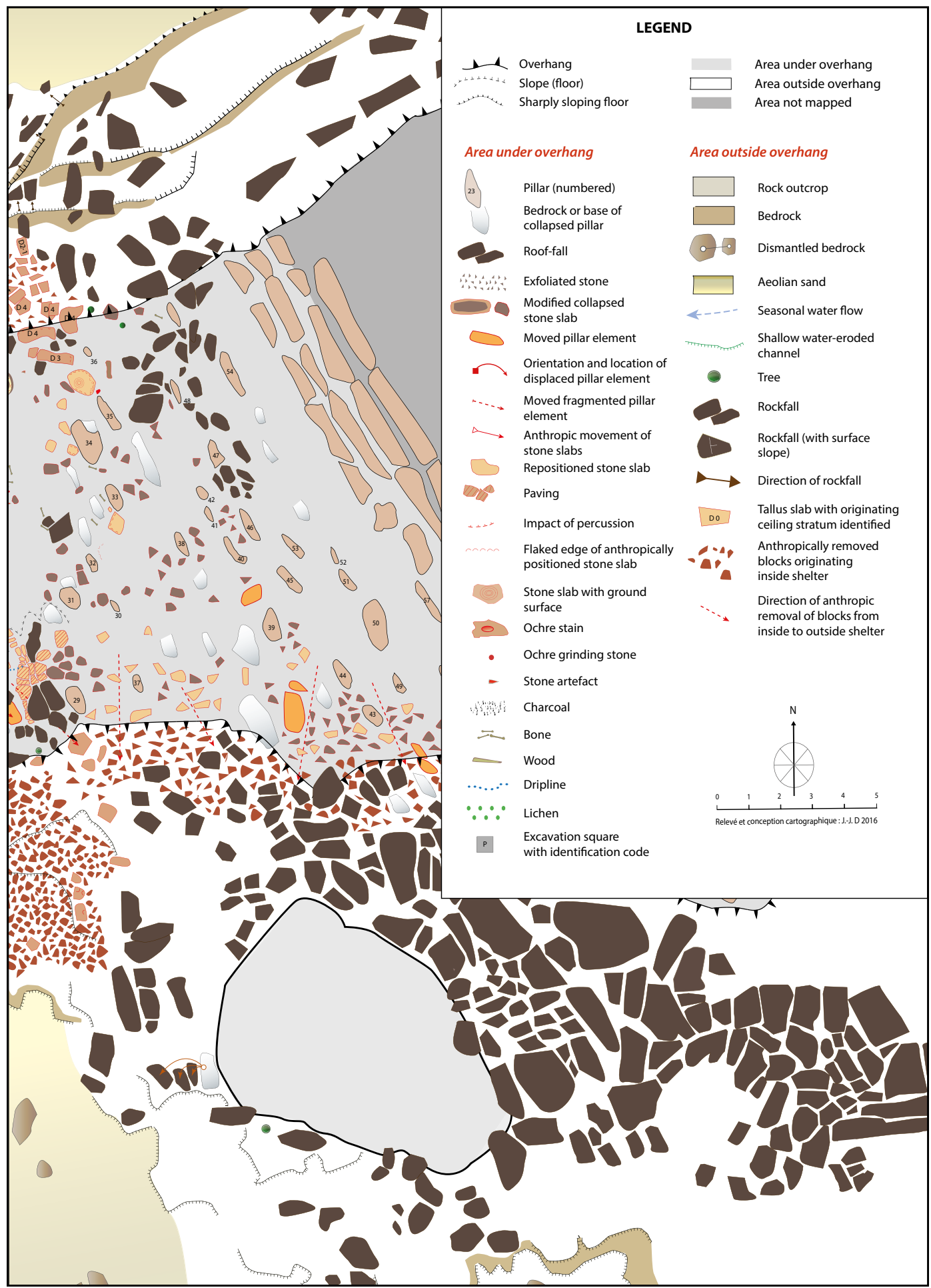

Figure 10.22 Continued. 


\section{Results of archaeomorphological mapping}

At Nawarla Gabarnmang, the rock structure, rock art and buried archaeological deposits each differ between the western and the contiguous central and central-eastern sectors of the site. Conventional geomorphological mapping does not explain what caused this spatial patterning. Nawarla Gabarnmang is a complex site that witnessed multiple and, through time, varying kinds of effects caused by a range of agencies. We now aim to identify those effects and their causes.

In studies of complex systems, it is often essential to define a vector by which the evolution and structuring of the system can be determined at given points in time. In the case of Nawarla Gabarnmang, the vector of morphogenesis we have focused on is the density of pillars across space. The wide, open nature of ceiling spaces across the central and central-eastern sector of the site appears to be associated with the collapse of ceiling rock strata following the weakening of mechanical support when the number of pillars was reduced. Understanding this differential density of pillars is essential to understanding the site as a whole.

\section{A problematic pillarscape}

We ask of the site's architecture: Does the current layout of pillars across the site have a geological origin explained by lateral variations in the properties of rock features indicating their formation ('facies')? Did pillars originally exist in the central and central-eastern, northern and southern sectors where today they are either absent or very widely spaced?

Lateral variations of facies are common in bedrock of littoral origins, across the site and continuing onto the rock pillars that form the northern edge of the low rock outcrop bordering the courtyard immediately to the south of Nawarla Gabarnmang. However, rock strata D4 to D-12 show similar petrographies and levels of compaction across space, indicating an absence of the kinds of variability that would have weakened mechanical support and thus a lesser density of pillars in parts of Nawarla Gabarnmang.

The rhythm and spacing of voids between pillars in sectors neighbouring those parts of the site with widely spaced pillars show that they map perfectly onto the network of fractures in the rock. In plan view, the pillars and their interstitial spaces have the same fractal pattern as the triplecheckerboard structure of the Arnhem Land plateau; this structure represents lacerations of the rock caused by geological forces. As noted above, those fractures are oriented in three intersecting directions: north-northwest to south-southeast, north-northeast to south-southwest and east to west. The first two of these feature prominently in the orientation of inter-pillar voids (as in the processes of phantomisation), and in the original spatial configuration of the pillars (see below).

Keeping in mind an absence of spatial variation in the facies, and the presence of a network of fractures in the rock, we compared the expected original distribution of pillars for the site (as determined by the intersection of the axes of alignment of the extant pillars) against those extant today (Figure 10.23). This pairing clearly shows that in some parts of the site expected pillars are absent; and those pillars are missing where there are vast flat ceiling surfaces. Using the 3-D model as well as field observations, geomorphological traces of now-missing pillars could clearly be seen on the ceiling. But unlike the extant pillars, these remnant pillar ceiling surfaces have not been heavily altered (they do not feature strong patination), indicating that they cannot have been chemically weathered away in deep geological time as would be required of phantomisation. While the discovery of these remnant pillar surfaces at ceiling level confirms the original full 
structure of the pillarscape within the site as proposed by the geological evidence (network of fractures and phantomised voids), they also point to other causes for how they disappeared. This is even more so given an absence of rocks at ground level that would normally be required to explain their collapse, for example. This lack of fit between the collapse of pillars (as well as ceiling strata) and the flatness of the ground level (indicating a paucity or absence of accumulated blocks below ground) has already been discussed above (Figure 10.24).
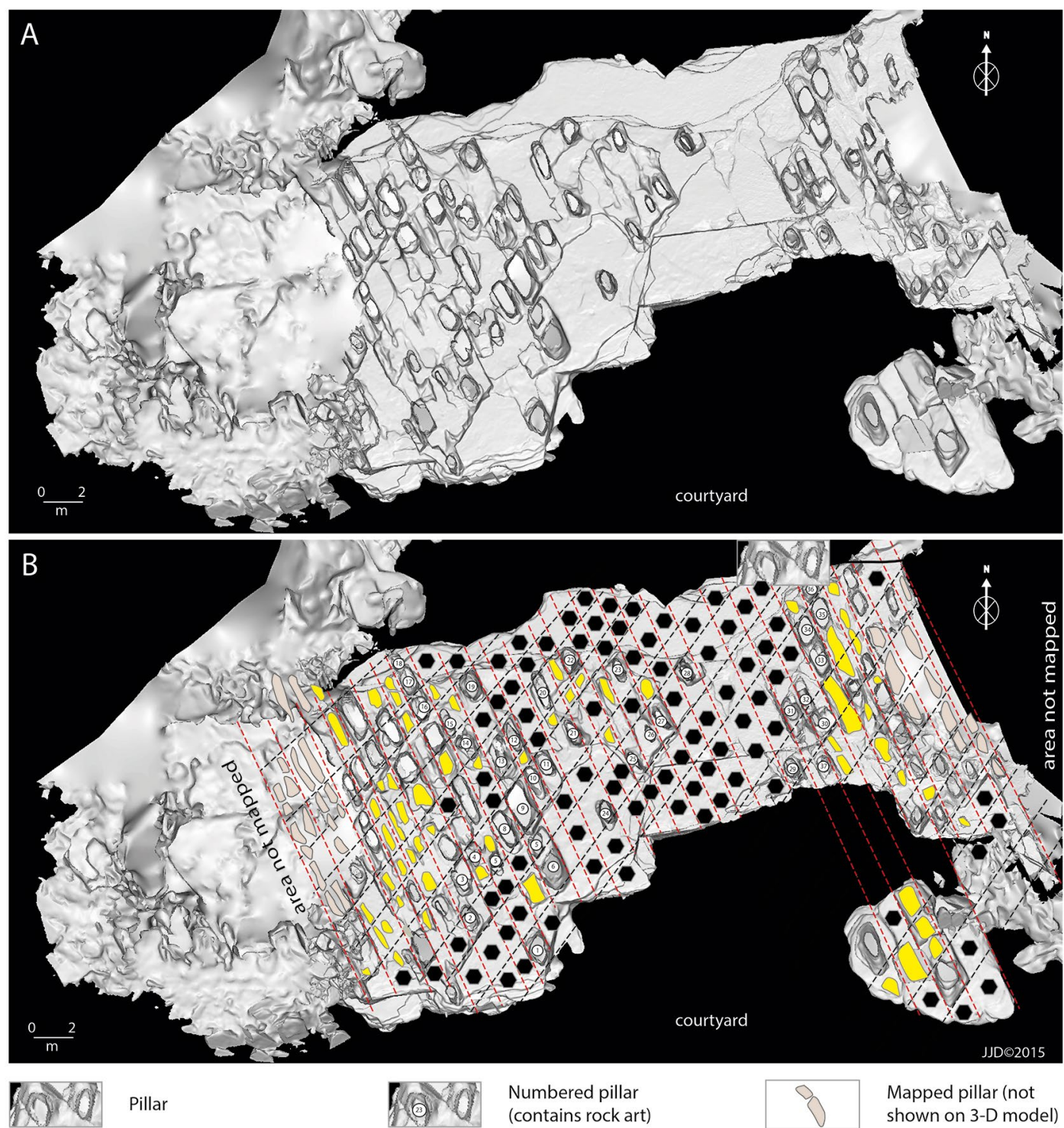

Mapped pillar (not
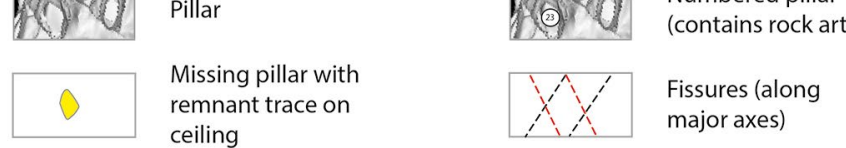

shown on 3-D model)

Figure 10.23 Nawarla Gabarnmang present ceiling, showing also remnant traces of missing pillars. A: View of ceiling from 3-D model. B: Reconstitution of the original distribution of pillars and inter-pillar voids, as evident from geological and geomorphological traces.

Source: Illustration by Jean-Jacques Delannoy. 


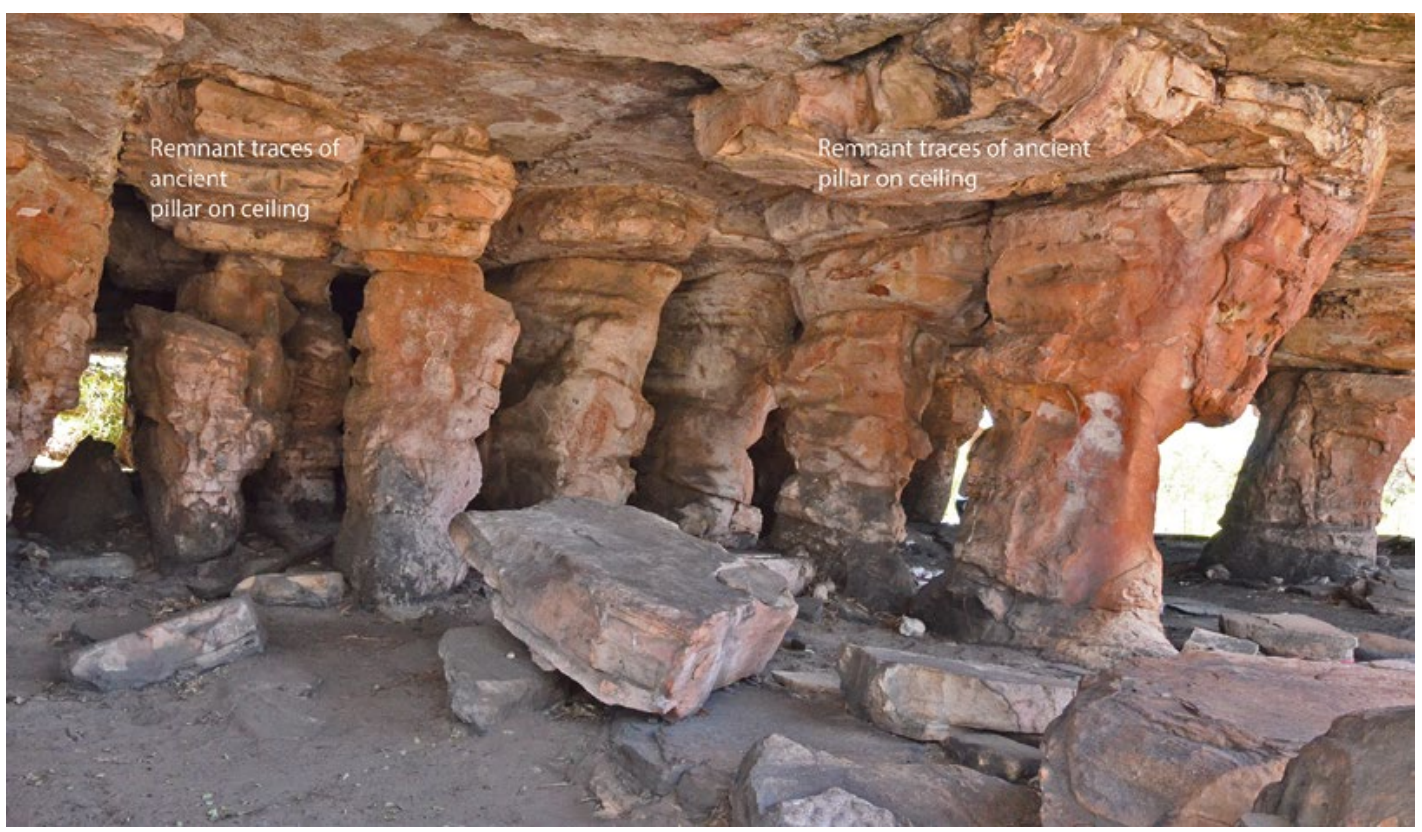

Figure 10.24 Southwestern sector, showing two remnant traces of missing pillars on the ceiling.

Source: Photograph by Jean-Jacques Delannoy.

Areas with missing pillars were examined more closely to understand their disappearance. Other than Square P (see Chapter 11), archaeological excavations have not been undertaken in or near areas where pillars are expected to have fallen. Rather, research has focused on the relatively open southwestern sector of the site where pillars have disappeared (Figure 10.24). Here, blocks of rock are commonly encountered on the ground, and traces of ancient pillars can be seen both at ground level and on the ceiling. Moreover, this sector is located close to excavated squares (Squares A and D) that have revealed long sequences of human occupation dating to more than 45,000 years ago and recurring to 'recent' times. Finally, this is also a richly decorated area, with paintings occurring both on the remaining pillars and on the flat ceilings.

\section{The aménagement of Nawarla Gabarnmang}

Nawarla Gabarnmang's southwestern sector contains two contiguous alcoves that open directly onto the courtyard to the south of the site (Figure 10.25). Both of these alcoves have flat ceilings caused by the collapse of overhead rock strata (Figures 10.24 and 10.26). They also both have blocks of rock resting directly on bedrock or on skeletal soils at ground level. The area to the north behind these two alcoves is dark, and the pillar and ceiling surfaces exhibit little art. Here, the space is largely enclosed where pillars are very closely spaced; the only easy access to this sector is by the site's southern edge and through the two alcoves. It contrasts starkly with the wide, open spaces of the northern, southern and contiguous central and central-eastern sectors. 

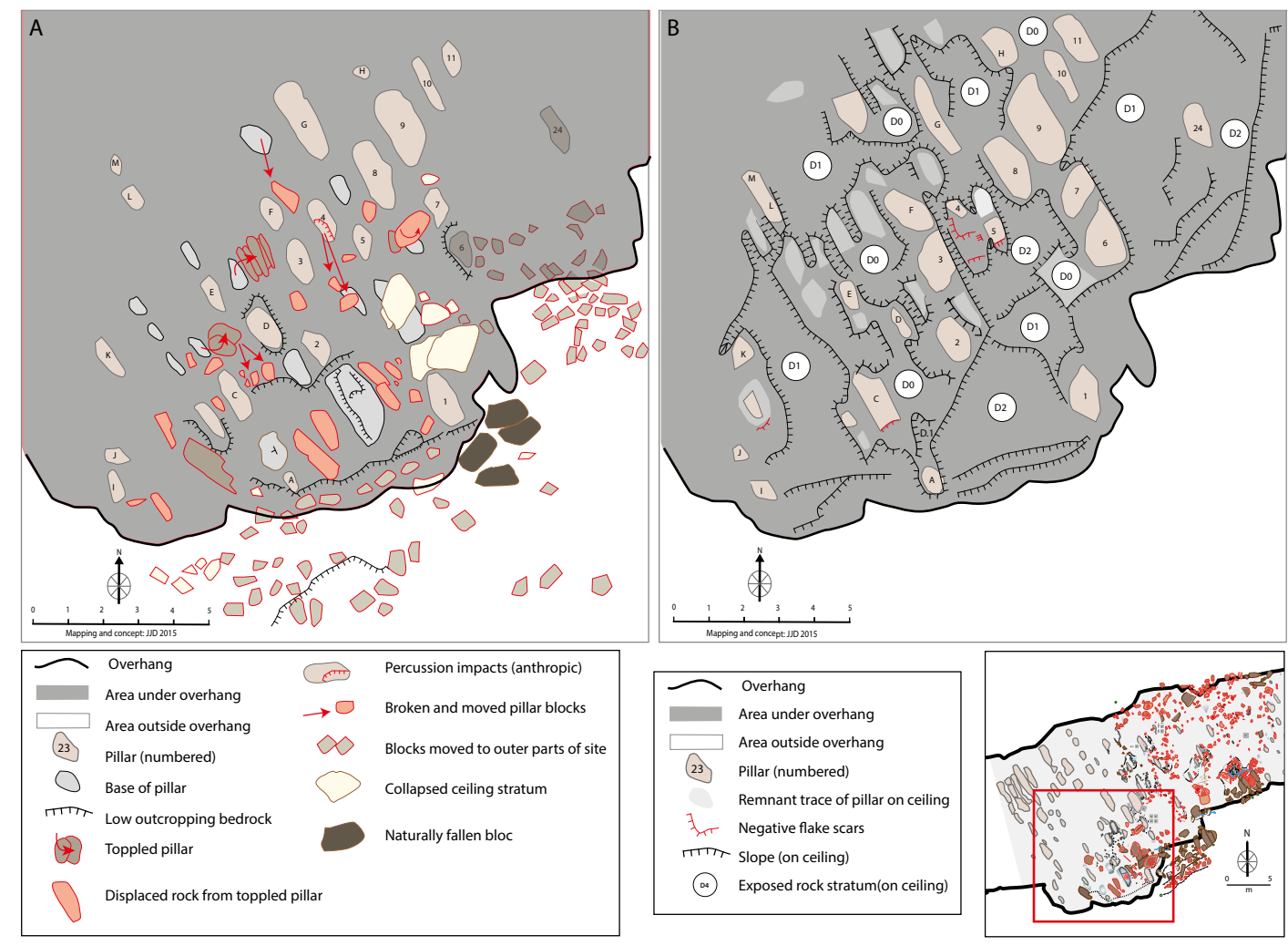

Figure 10.25 Archaeomorphologial mapping of southwestern sector of Nawarla Gabarnmang.

A: Floor plan. B: Map of ceiling. Seen together, these two maps highlight the anthropic aménagement of this part of the site, as the floor plan shows an absence of pillars whereas the ceiling map shows remnants of missing pillars.

Source: Illustration by Jean-Jacques Delannoy.

\section{Analysis of collapsed blocks: The first signs of anthropic actions}

The southwestern sector of the site is key to understanding the evolution of the site as a whole. We began by investigating the nature and origins of the large blocks strewn on the ground in the alcoves. Petrographic and morphogenic analyses revealed that some came from ceiling strata, while others came from pillars.

Let us begin with the fallen ceiling rocks; this is the only sector of the site where fallen ceiling rocks are today found in, or near, their fallen positions (Figure 10.25). However, even here not all of the fallen material occurs on the ground today; the missing parts of the ceiling collapse were removed by people sometime in the past. The evidence that it is people who removed the rocks is as follows:

1. The blocks that lie at ground level today are not necessarily those that fell last. On Figure 10.26, we show how material that fell from the collapse of ceiling stratum D1 is missing at ground level. All that remains today is one block, originating from a lower ceiling stratum that came from an earlier roof-fall.

2. The blocks still present at ground level carry clear negative flake scars from heavy hammer impacts - presumably aimed at breaking them up. Conjoining or matching flakes are sometimes found nearby, but mostly a moderate distance to the south immediately outside the site. Some of these removed flakes are very large, measuring tens of centimetres in length. 
3. Petrographic analysis of the blocks that have accumulated on the scree, right up to the entrance of the alcoves, indicates that they did not fall from the outer edges of the overhang, but rather from ceiling levels within the shelter.

4. Some fallen rock strata have been moved from the inner edges of the alcoves outwards.

5. Only the largest blocks - those of great weight and difficult to break up because of their large mass - remain in place; we see this as because they were too heavy to move (e.g. Blocks A, B and C on Figure 10.26).
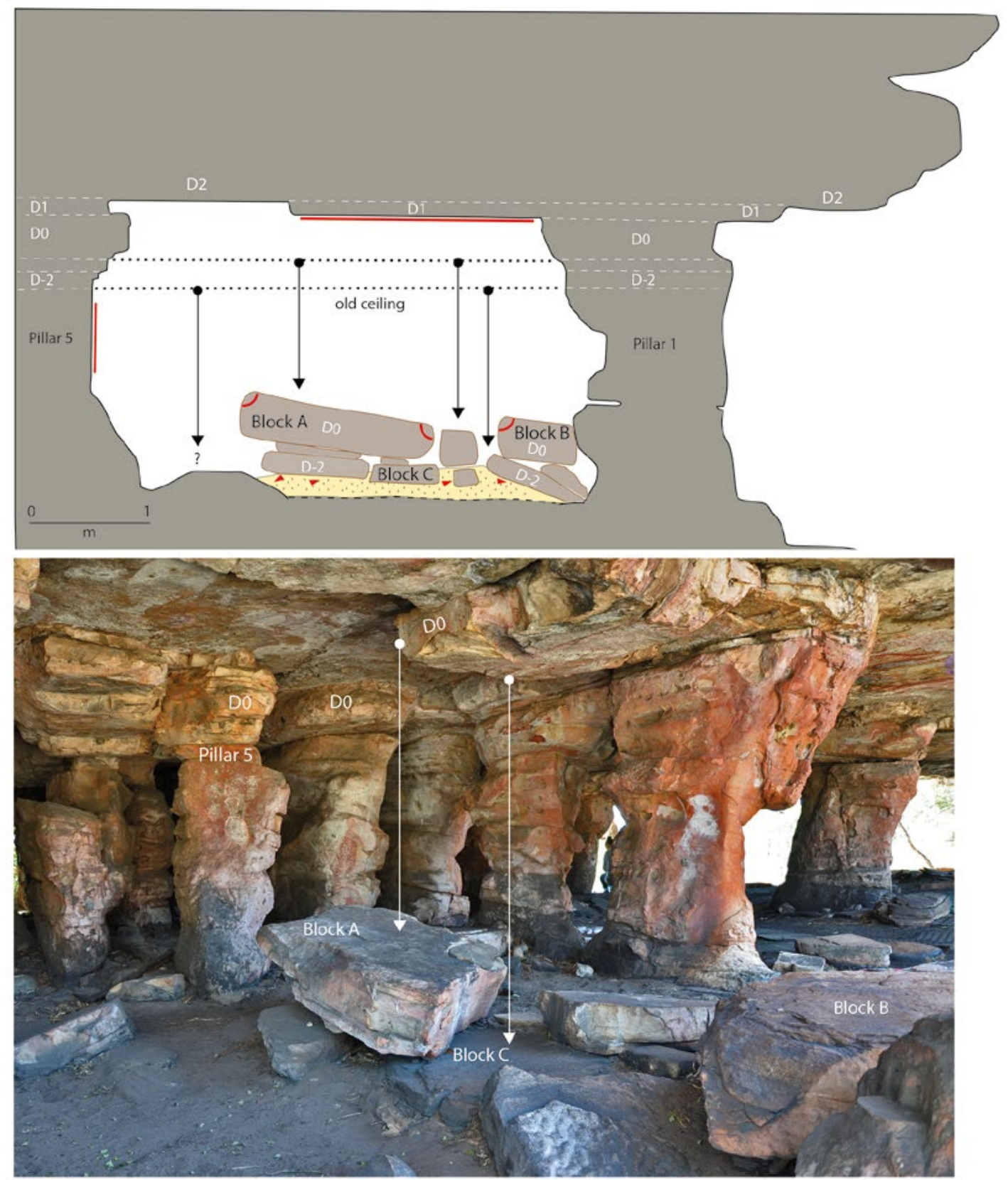

Figure 10.26 Alcove $A$ of the southwestern sector, showing the horizontal and vertical relationships of features discussed in text.

Source: Photograph and illustration by Jean-Jacques Delannoy. 
These first observations allow us to determine that clearly anthropic actions of aménagement have been undertaken; blocks fallen from the ceiling were dismantled on the ground and removed to areas outside the overhang. The reasons for these actions remain to be determined (see also Delannoy et al. 2013). We use the French word aménagement, as no English equivalent has the same nuances. Aménagement refers to the development of a place, or of one's affairs, through active human participation. It is more than 'fitting out' or 'ordering' a pre-existing location, going beyond the addition of new objects to involve its active construction through meaningful engagement.

Investigations were then made on the status of the ground surface on which the rock strata fell from the ceiling. Here, two different phases of rock collapse were distinguished, each bringing to light new evidence on the site's evolution. First, rock strata D-3, D-2 and D-1 from the upper parts of the pillar fell; a second, separate collapse of stratum D0, the first ceiling stratum, followed (Figure 10.25).

On falling, stratum D0 landed on, and in doing so damaged, those strata D-3, D-2 and D-1 blocks that were already on the ground and which themselves overlay stratified sands containing stone artefacts. The presence of this archaeological material under the collapsed blocks confirms that people were already at the site prior to or during the first collapse. This occupation precedes the collapse of both ceiling strata D-3 to D-1 (the first collapse) and stratum D0 (the second collapse) in the area between Pillars 6-7-8-5-3-2-1 (Figure 10.25). Here, it is possible to determine when strata D0 and D1 fell from the ceiling, as a radiocarbon date was obtained from a wasp nest underlying rock art on the extant (decorated) stratum D2 ceiling surface (a surface that now exhibits rock art Panels A3, A5 and A6; Figure 10.26). The radiocarbon date enables us to determine that strata D0 and D1 fell sometime before 10,154 $\pm 40 \mathrm{BP}$ (Wk-31730), calibrating at 11,624-12,024 cal BP (95.4 per cent probability) (median probability =11,833 cal BP); so the rock art superimposed above the wasp nest is more recent than this. Such radiocarbon dates are valuable, because we currently have very few absolute dates at hand by which to date the various ceiling levels and pillars across the site.

We can take the analysis further, as some of the blocks that fell from the ceiling lie directly on top of a locally outcropping section of the bedrock. For example, Block A on Figure 10.27 came from the collapse of ceiling stratum D0; it lies directly on an exposed rock base. If we locate this locally outcropping bedrock onto the map that shows the location of the original pillars across the site (Figure 10.23), it is found to be where an ancient pillar once stood: the locally outcropping patch of elevated bedrock represents the base of an ancient and now-missing pillar.

We can now determine:

- Block A (originating from ceiling stratum D0) rests directly on the base of an ancient pillar, indicating also the absence of rocks fallen from lower-level (and therefore earlier) rock strata D-3, D-2 and D-1. We would have expected these to be sandwiched between the base of the pillar and Block A.

- Petrographic examination of a partly buried block indicates that it fell from strata D-11 and D-12; it thus belongs to an ancient pillar. Its original stratigraphic position was just above the same base of the pillar that is today capped by Block A.

- Block A has been extensively flaked along its periphery; it was also slightly moved towards Pillar 7. It was slightly rotated during its displacement; the orientation of the ripple marks on the block are different from those in its matching position on the ceiling. 


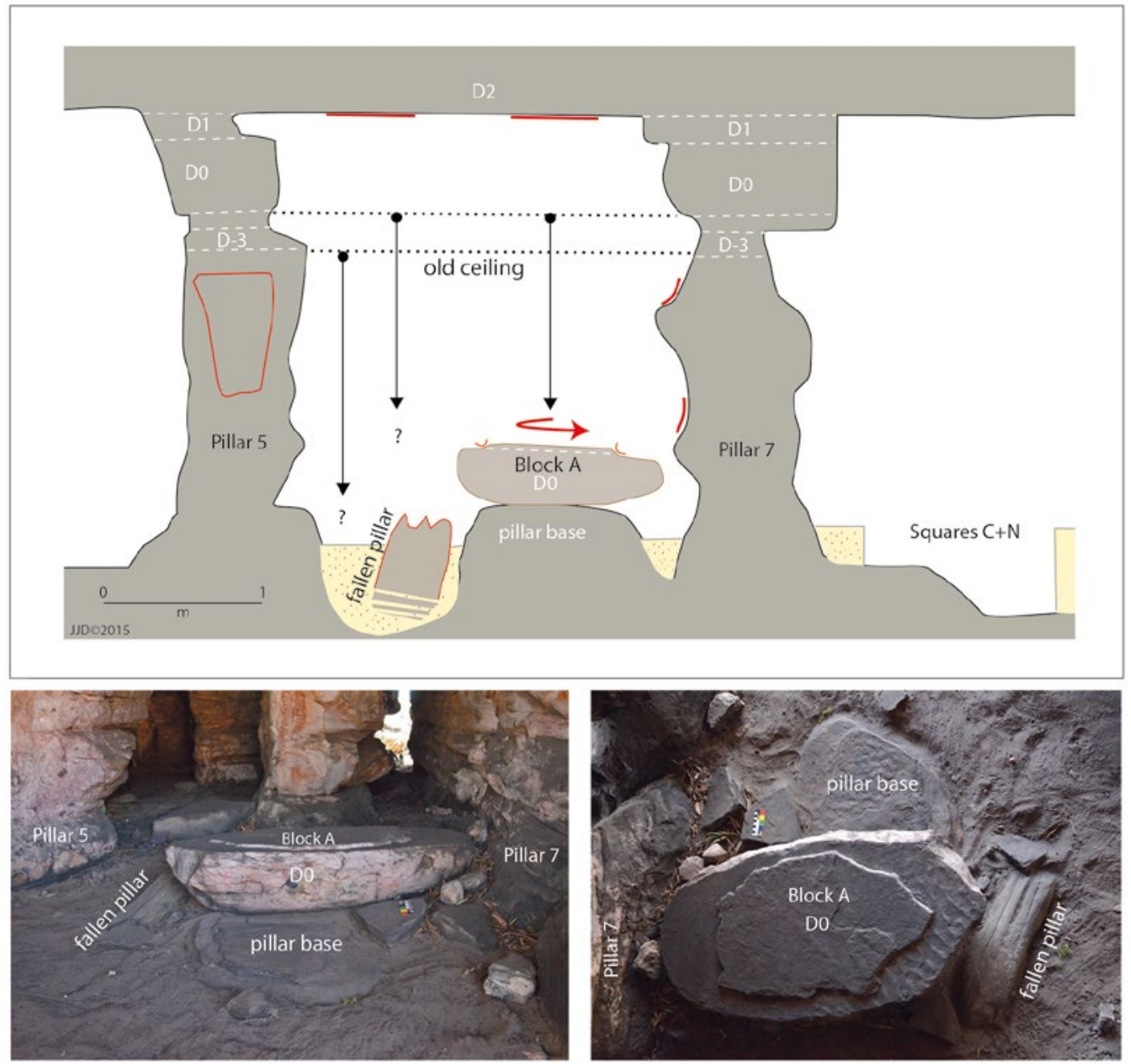

Figure 10.27 North-south transect across Alcove A in the southwestern sector.

Source: Photographs and illustration by Jean-Jacques Delannoy.

These observations, adding to others for the southwest sector of the site, highlight the important aménagement by people in the past. We can now determine that the pillars were removed before the collapse of ceiling strata, and that they were removed to outer parts of the site. In the studied southwestern sector, the fact that Block A (from stratum D0) rests directly on the footing (stratum D-13) of an ancient pillar indicates that pillar strata D-4 to D-12 had previously been removed from this part of the site, along with the blocks that fell from strata D-3 to D-1 higher up on the pillar.

Analysis of the collapsed blocks revealed: first, that people were directly implicated in removing collapsed blocks to areas immediately outside the site, in the process creating more open spaces in the cleared areas; second, the disappearance of pillars precedes the collapse of rock strata from the ceiling. The removal of blocks that had fallen from pillars was, in itself, due to the actions of people. It remains to be seen whether people just cleared fallen pillar blocks after they had collapsed naturally, or whether they intentionally removed standing pillars themselves. We now turn to this question. 


\section{The archaeomorphological study of pillars: The site's intentional aménagement}

In order to determine better human actions relating to the removal of pillars, three different states of pillar fragmentation were investigated. Do these states represent three different modes of operation, or three stages of a single strategy to expand the space within the site?

Let us first consider the base of an ancient pillar still clearly visible in the area of Alcove B. Located in the exact southern extension of extant Pillar 2 (Figures 10.28 and 10.29), this pillar base consists of a pedestal close to $2 \mathrm{~m}$ long $\times 1 \mathrm{~m}$ wide $\times 70-80 \mathrm{~cm}$ high. The pillar base corresponds with rock strata D-12 to D-10; it sits directly on top of the bedrock (whose upper level is stratum D-13). In this area, 15-20 cm thick blocks of rock are strewn flat across the floor. All exhibit percussion impact marks at their extremities (Figure 10.30). Petrographic study shows that they represent collapsed strata D-9 to D-6, which once lay on the extant pedestal. Blocks from the overlying strata are absent; they do not occur anywhere near the space of the ancient pillar. Taking into account the remnant base, extant ceiling and strewn blocks (Figures 10.25 and $10.28-10.30$ ), what is missing from the original pillar column are only strata D-5 and D-4. Here, a study of the positioning of the fallen blocks, including their morphologies and orientations at ground level, allows reconstruction of the sequence of actions that took place:

1. The dismantling of the different strata.

2. Their removal one-by-one from the area.

3. Their fragmentation into smaller pieces while on the ground.

4. Their removal to outer parts of the site.

The end-states created by this chaine opératoire are blocks of relatively homogeneous shape and size. We have previously discussed the presence of scree accumulations along the site's northern and southern entrances; here, the shape and size of blocks are regular, and they did not originate from nearby roof-fall or overhang collapse. Understanding the mode of operation relating to the removal of pillars informs equally on the origins of these accumulated blocks immediately outside the site. We will return to this association below when discussing the large volume of rock represented by four scree accumulations in relation to the creation of wide, open spaces within the archaeological site.

Other than this partially removed pillar, in the area of Alcove B, all other missing pillars have been entirely dismantled and removed from the area (Figure 10.25). This further brings to the fore the unfinished state of the partially dismantled pillar's removal. Does this signal the last throes of pillar removal and of the opening of space within the site? And, if so, when did this cessation take place? If its age precedes the last phases of human presence in the site, does it indicate a change in the conceptualisation, organisation and meaningfulness of space at Nawarla Gabarnmang? We will return to these questions below. 

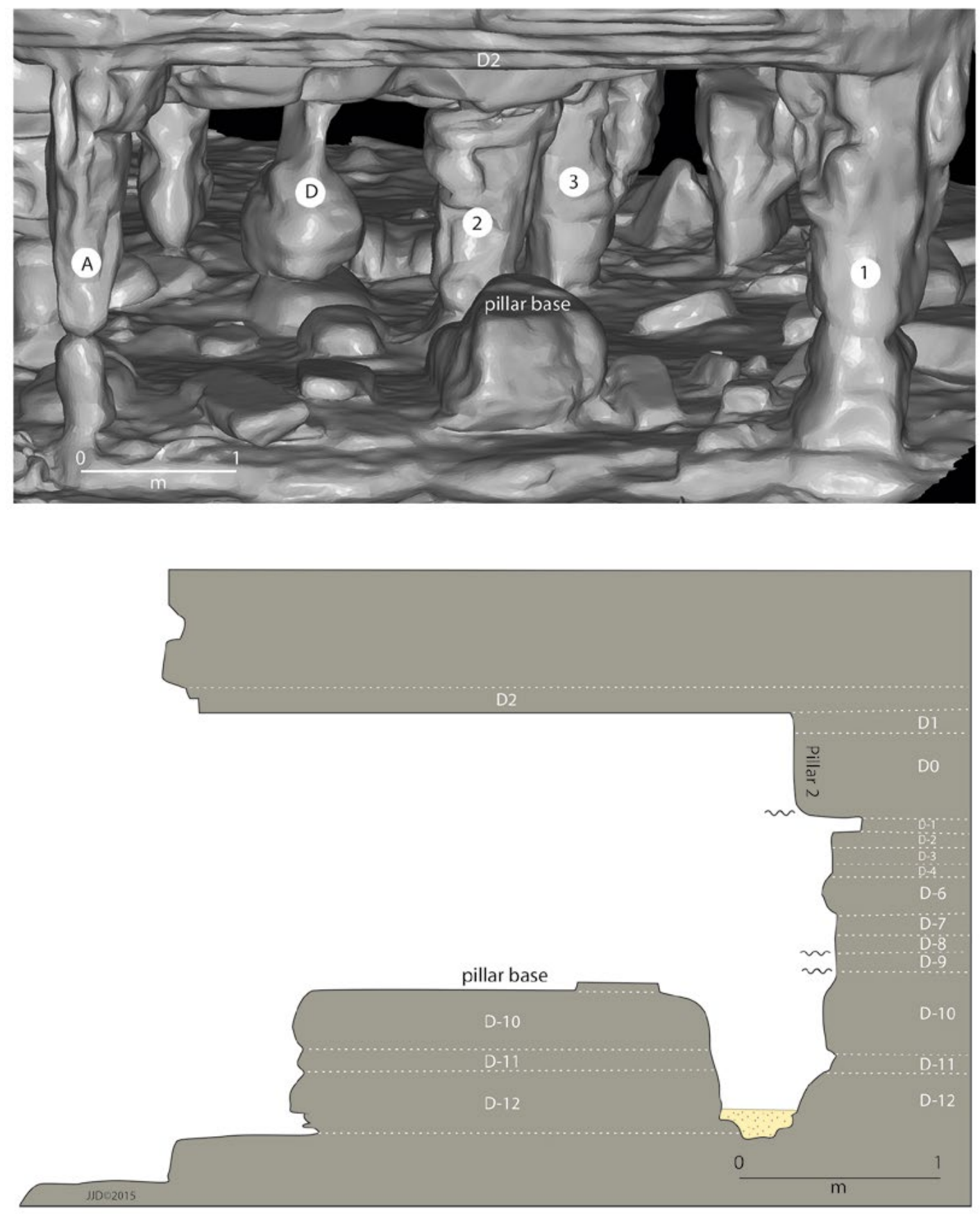

Figure 10.28 North-south transect across Alcove B, southwestern sector, as based on the laser 3-D model. This alcove retains elements of a partially dismantled pillar (including the 'pillar base'). Source: Illustration by Jean-Jacques Delannoy. 

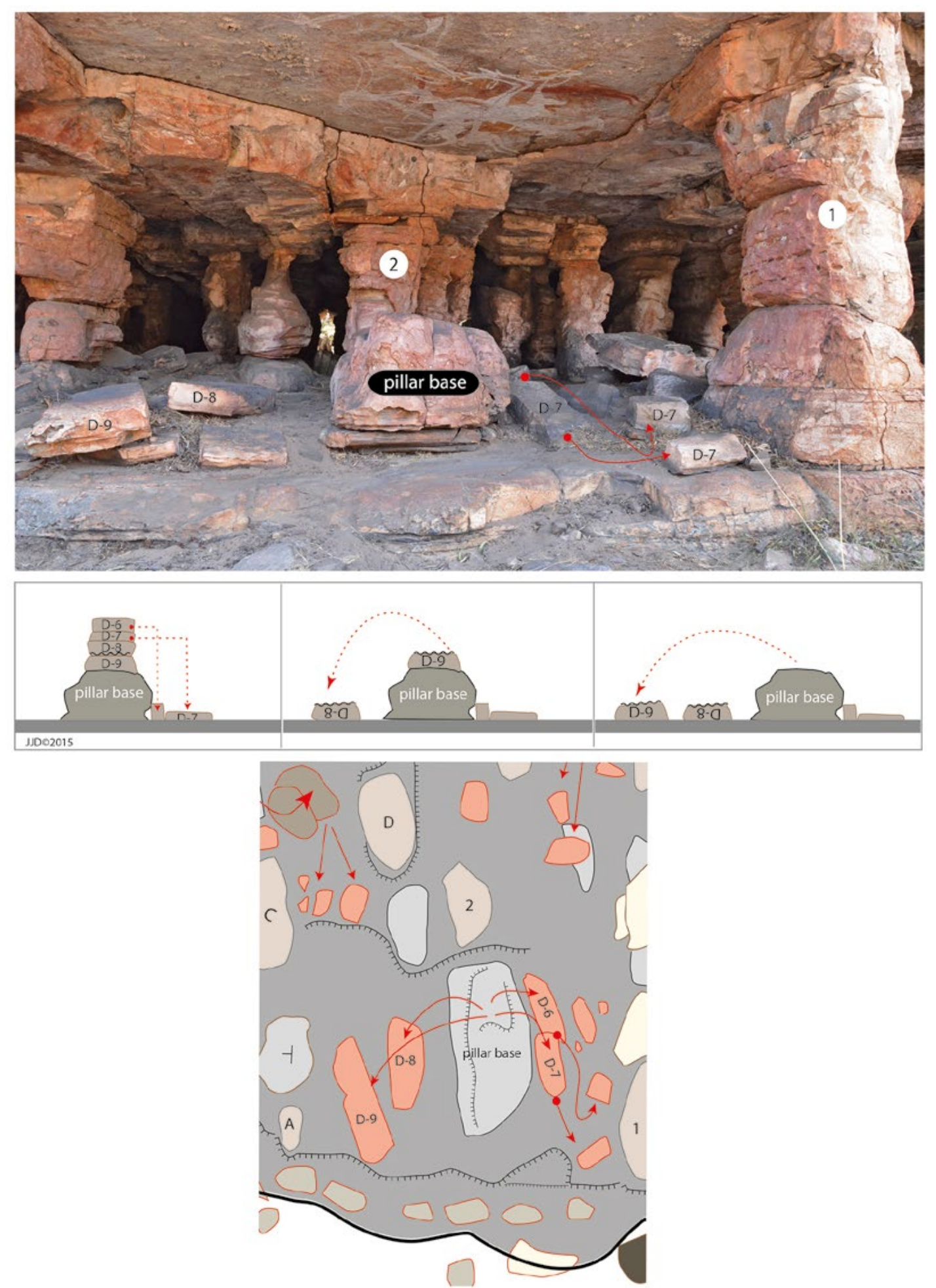

Figure 10.29 Photograph and reconstruction of sequence of events in Alcove B, southwestern sector. Source: Photograph and illustration by Jean-Jacques Delannoy. 


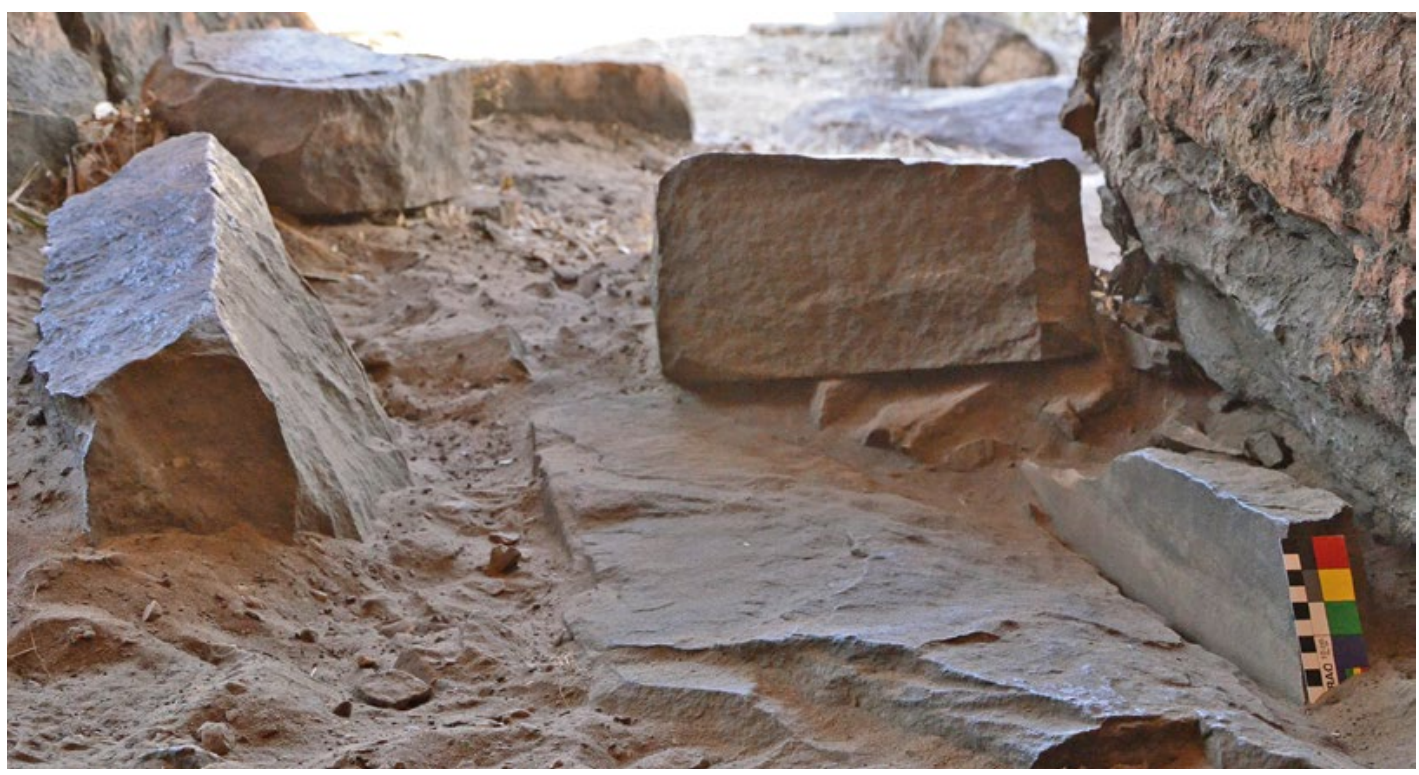

Figure 10.30 Strewn rocks on and near a remnant pillar base in Alcove B.

Source: Photograph by Jean-Jacques Delannoy.

Immediately north of the two alcoves discussed above, in the transition zone with the more enclosed space where pillars are more tightly packed (Figure 10.31), are a number of toppled pillars (see also Figure 10.25). Here the fallen blocks pertain to various states of dismantlement. In some cases, most of the strata making up the pillars are still present. In other cases, only the lower strata remain, the higher levels having been taken outside. Parts of these collapsed pillars can still be seen on the ground, lying between their original positions and the outside of the site. Again, we find indications that works in progress suddenly ceased; in this instance, toppled and dismantled blocks in the process of being removed were left behind on their way out of the site. The more we move away from these two alcoves in the southwestern sector of the site, the less the removal of toppled pillars appears to have been important. This spatial patterning of more or less dismantled and removed pillars suggests that, in the southwest of the site, spatial expansion was progressing northward. How this relates to what was happening in other parts of the site remains to be determined.

Finally, those blocks remaining on the ground indicate the systematic absence of the highest parts of pillars. This absence is a clue as to how the pillars were toppled. A pillar holding the weight of the ceiling cannot be toppled; it can only be tilted over if there exists a space between the pillar and the ceiling.

One possible sequence would start with removal of a less resistant rock stratum near ground level; we wondered if chemical alteration of the base of the pillar (e.g. through heightened humidity levels on the bedrock) caused that part of the pillar to weaken and the pillar to slump, creating a space between the top of the pillar and the ceiling. We searched for this kind of effect on all of the extant pillars across the site, but could find no trace of it.

A second approach to creating the needed void would be to remove the pillar's upper strata. Unambiguous evidence of this exists, again in the southwest sector of the site, where extant pillars show clear percussion impact marks on their uppermost, easily accessible sections. Partially removed upper sections of neighbouring pillars cannot be attributed to natural processes (Figures 10.32-10.34). This evidence confirms that it was indeed people who intentionally took these first steps, removing the upper parts of pillars, detaching them from the ceiling and toppling them, before dismantling them after they fell and taking the fragments outside the site. 


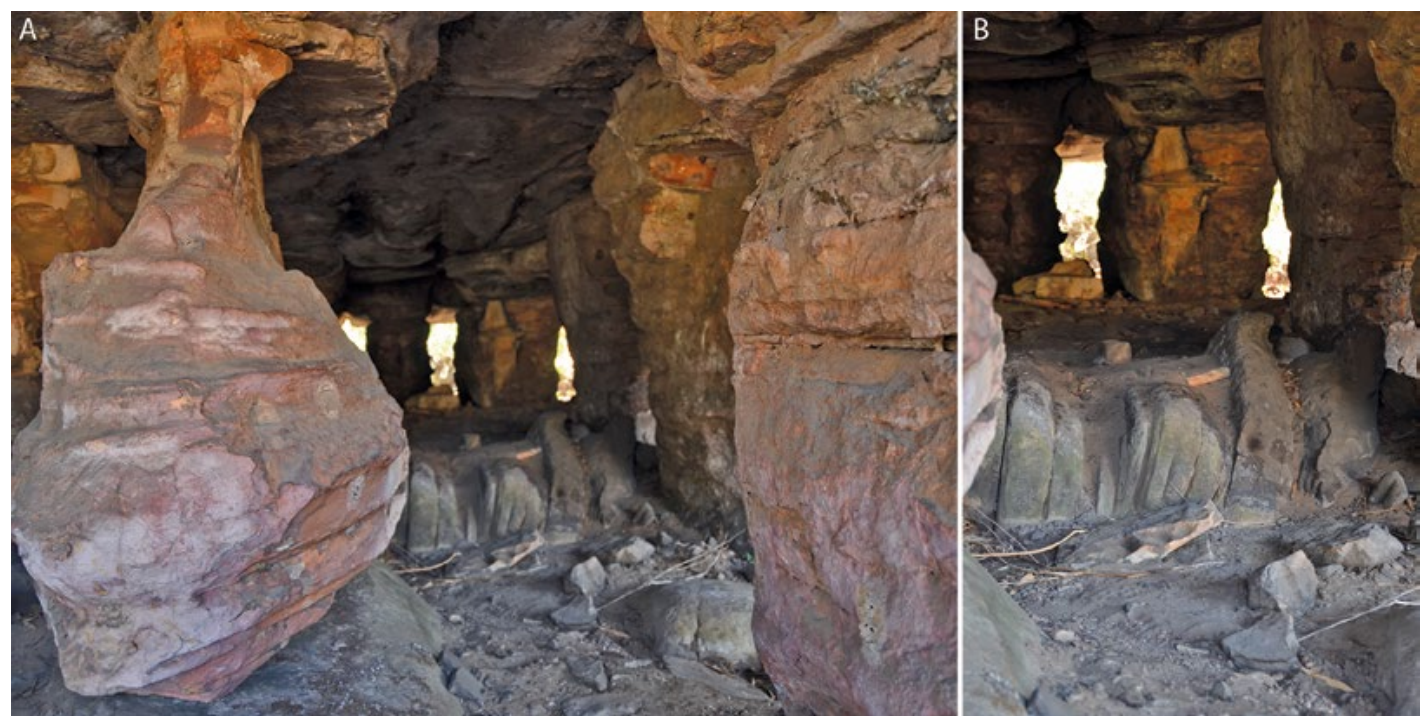

Figure 10.31 Transition zone between Alcoves A and B, and the darker, more close-knit pillar space immediately to the north, showing a toppled pillar on the floor in the mid-ground. Source: Photographs by Jean-Jacques Delannoy.
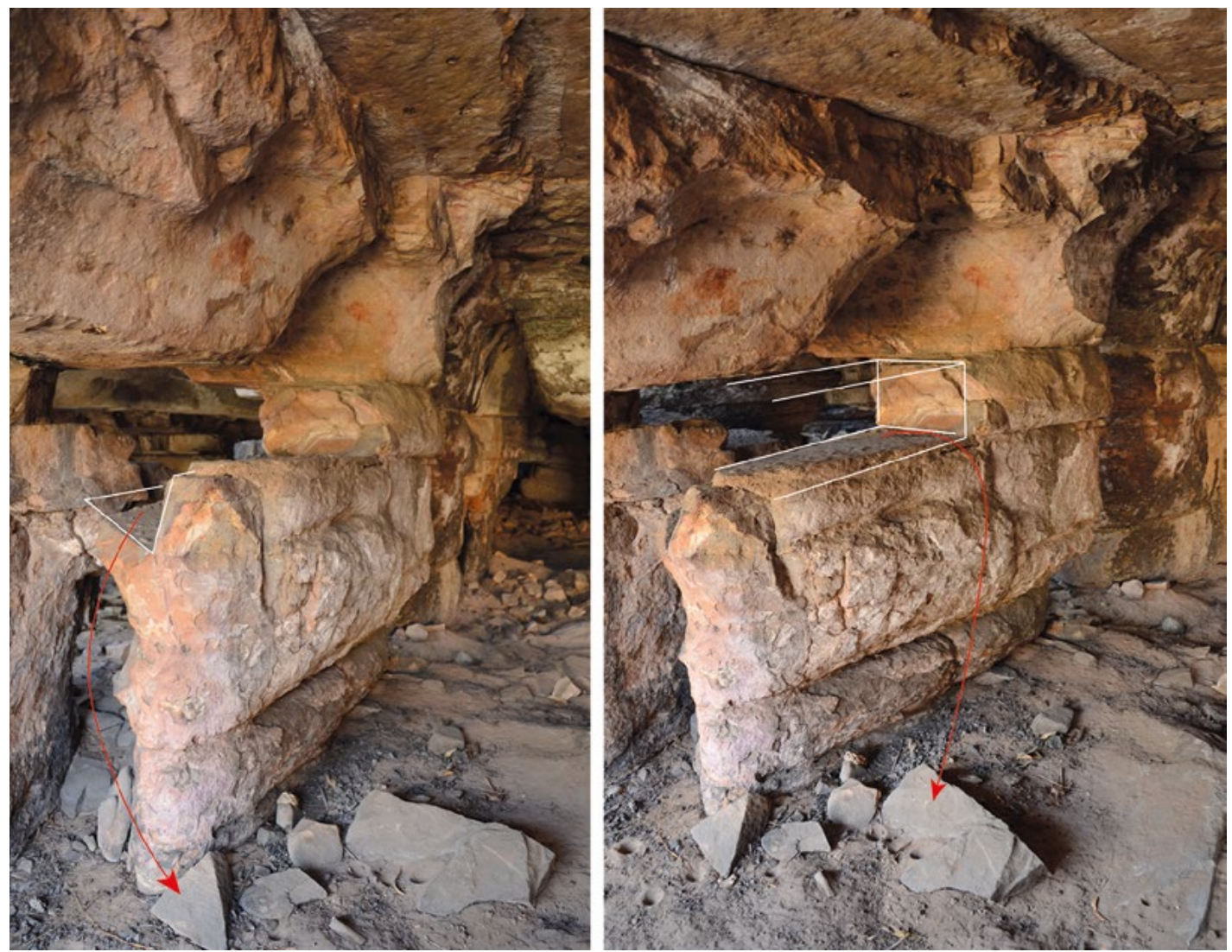

Figure 10.32 Partially removed pillar, with upper parts missing, southwestern sector. Source: Photographs by Jean-Jacques Delannoy. 

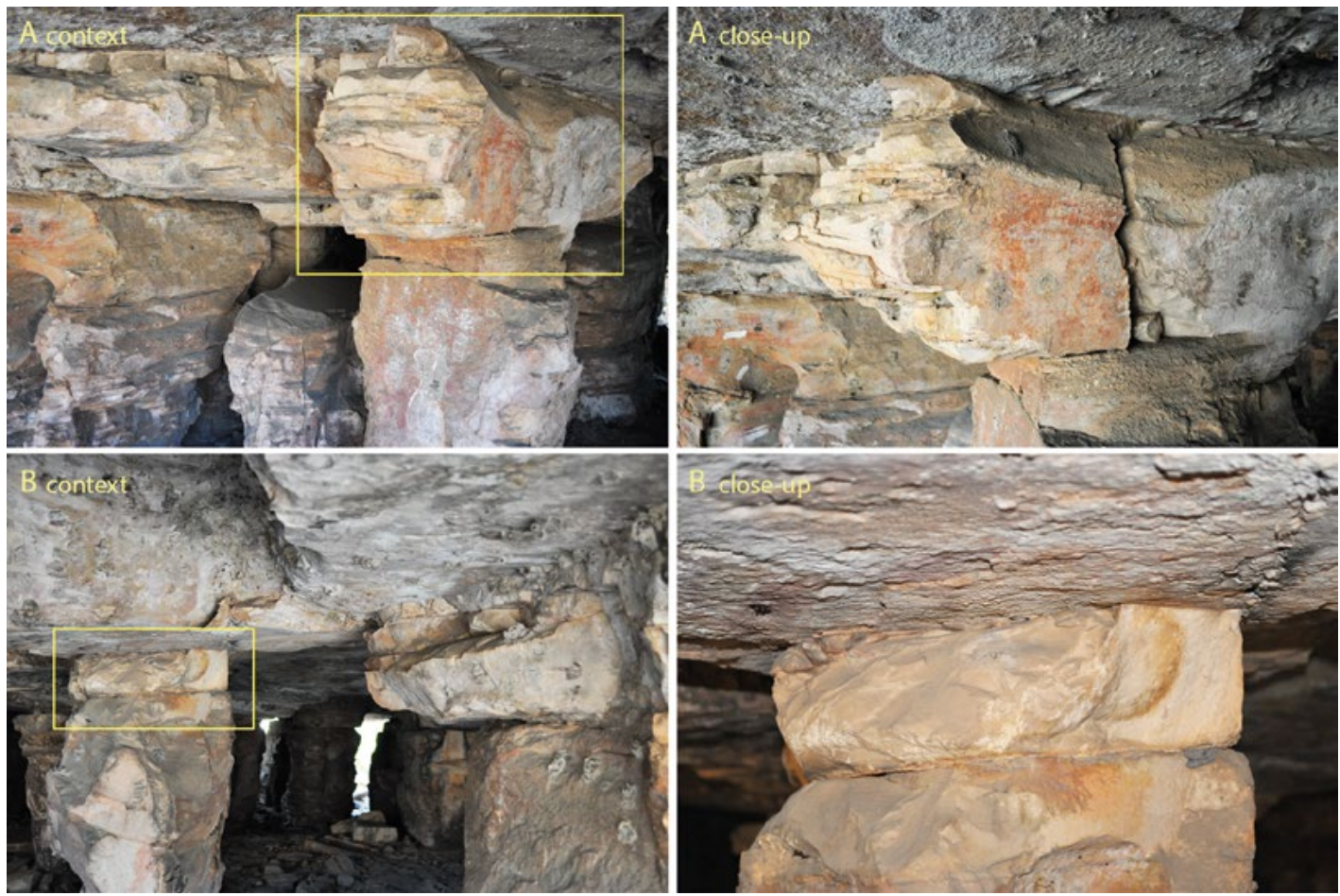

Figure 10.33 Two ways of removing the upper level of pillars prior to toppling, southwest sector of site. A: Sectioning by flaking of stratum D0 at top of a pillar. B: Gradual removal by flaking away of stratum D-1 at top of a pillar. Source: Photographs by Bruno David.

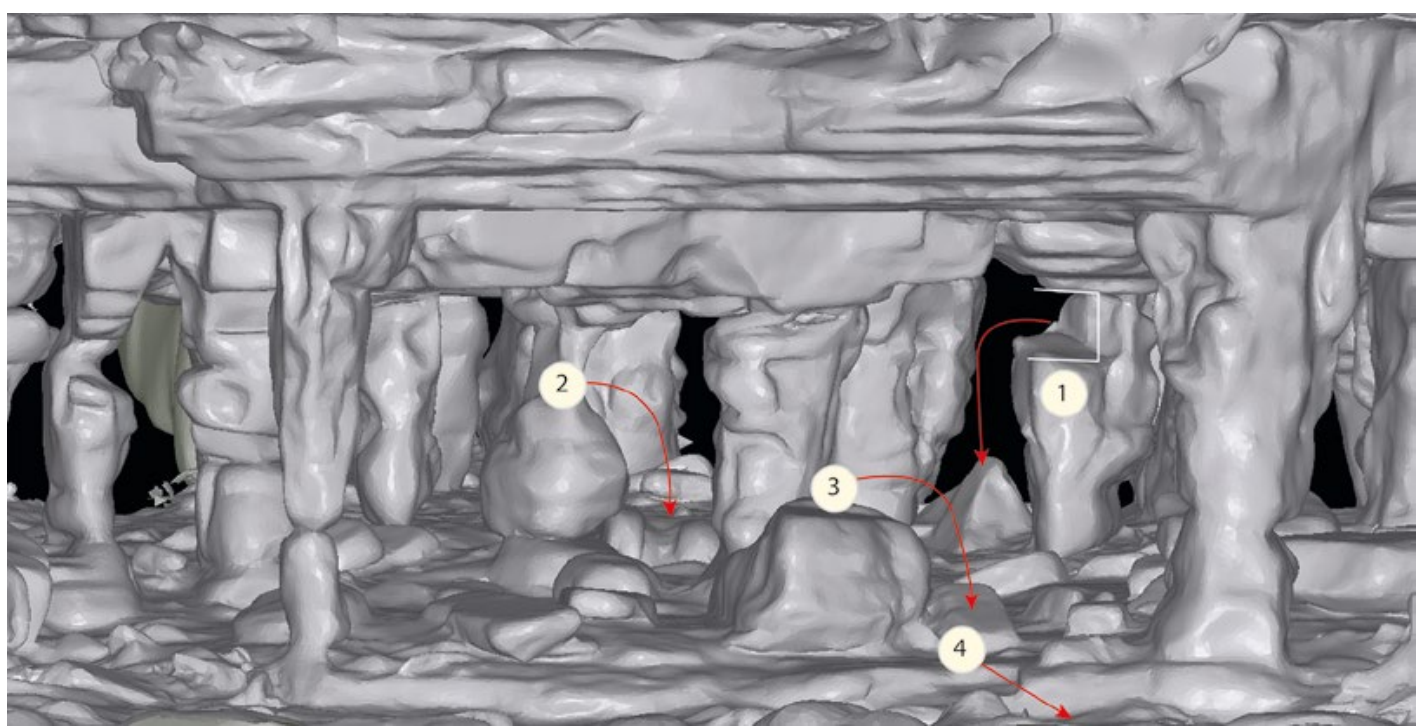

Figure 10.34 Alcove $B$ in southwest sector, showing standing lower sections of pillars with upper sections missing (from laser 3-D model).

1: Upper part of pillar removed. 2: Toppled pillar. 3: Dismantling of pillar. 4: Removal of toppled pillar parts to outside the site. Source: Illustration by Jean-Jacques Delannoy. 
This sequence of events in the southwest sector of the site identifies Nawarla Gabarnmang's remarkable architecture as a feat of human engineering. It is an anthropic space, where material evidence of a historical sequence of human actions still lies on the ground. The pillars not completely removed, and the unfinished character of the site's construction makes us think that the southwestern sector is a space that began to be opened up later than elsewhere in the site.

\section{Understanding Nawarla Gabarnmang through archaeomorphology}

Archaeomorphological investigations have revealed clear material traces of Nawarla Gabarnmang as an actively refashioned and engaged space; its present configuration results from anthropic modifications of a natural pillarscape, in sequence:

1. The intentional removal of standing pillars by people.

2. The collapse of ceiling strata resulting from lack of support after the removal of pillars causing natural gravitational collapse or intentional removal by people.

3. The removal of toppled pillars and fallen ceiling strata onto scree deposits outside the northern and southern entrances of the site.

The volume of accumulated rock on the sum of the artificial scree deposits is proportional to the volume of the opened space within the site (that is, it is proportional to the sum of missing pillars and missing ceiling strata); its quantity is determined by volumetric calculations made from the 3-D model. Petrographic analyses of the scree blocks indicate that they came from removed pillars and collapsed ceiling strata, confirming that the blocks are a product of the opening of the site. They also show that the scree accumulated in a number of different phases, the phases representing the progressive removal of ceiling strata in particular. Rather than coming from a number of different strata, as would be expected of natural collapse of nearby overhangs, sections of the scree slope have accumulated rocks from single ceiling strata only; this indicates the accumulation of one stratum at a time, irrespective of the number of strata missing on the nearby extant ceiling. The spatial layout and patterns of superimposition of rocks originating from different ceiling strata now lying on the scree slopes signal that the most recent open spaces within the site are those of the contiguous central and central-eastern sector of the site, the zones where pillars are now most widely spaced.

Until now, we have focused on those processes that have led to the creation of Nawarla Gabarnmang's wide, open spaces. We now ask what the site would have looked like before people first came, or at least before people began removing rock pillars and transformed its layout. The internal space of the site - along with the entrance ways now made up of accumulated screes - has been so transformed that it is only those sectors exhibiting the least degrees of human modification where we can address this question. These sectors are those where the least number of pillars are missing and where the collapse of ceiling strata is so minimal that it is hardly noticeable: the western and northwestern sectors between Pillars 22-21-7-8-18. Here, in the northwestern sector, excavations in Squares $\mathrm{F}+\mathrm{I}+\mathrm{L}+\mathrm{M}$ and $\mathrm{D}+\mathrm{E}+\mathrm{J}+\mathrm{Q}+\mathrm{R}$ have revealed the oldest evidence of occupation. In the western and northwestern sectors, the ceiling art also appears to be more ancient in its styles than in the central and central-eastern sectors (see David et al. 2013, completed manuscript; Gunn 2016). It is also in the northwestern sector that highly weathered cupules are found on the vertical pillars; given the hardness of the quartzite, they undoubtedly have considerable antiquity. Excavations against those pillars have not yet commenced; we might there recover the tools used to make the cupules, and the crushed rock fragments caused by their manufacture. Like Squares A, D+H and $\mathrm{C}+\mathrm{G}+\mathrm{N}+\mathrm{K}$ in southwestern parts of the site, here we were curious to determine how the archaeological deposits sit relative to the bedrock, and whether they are preceded by earlier, pre-cultural deposits that could shed further light on the site's evolution. 

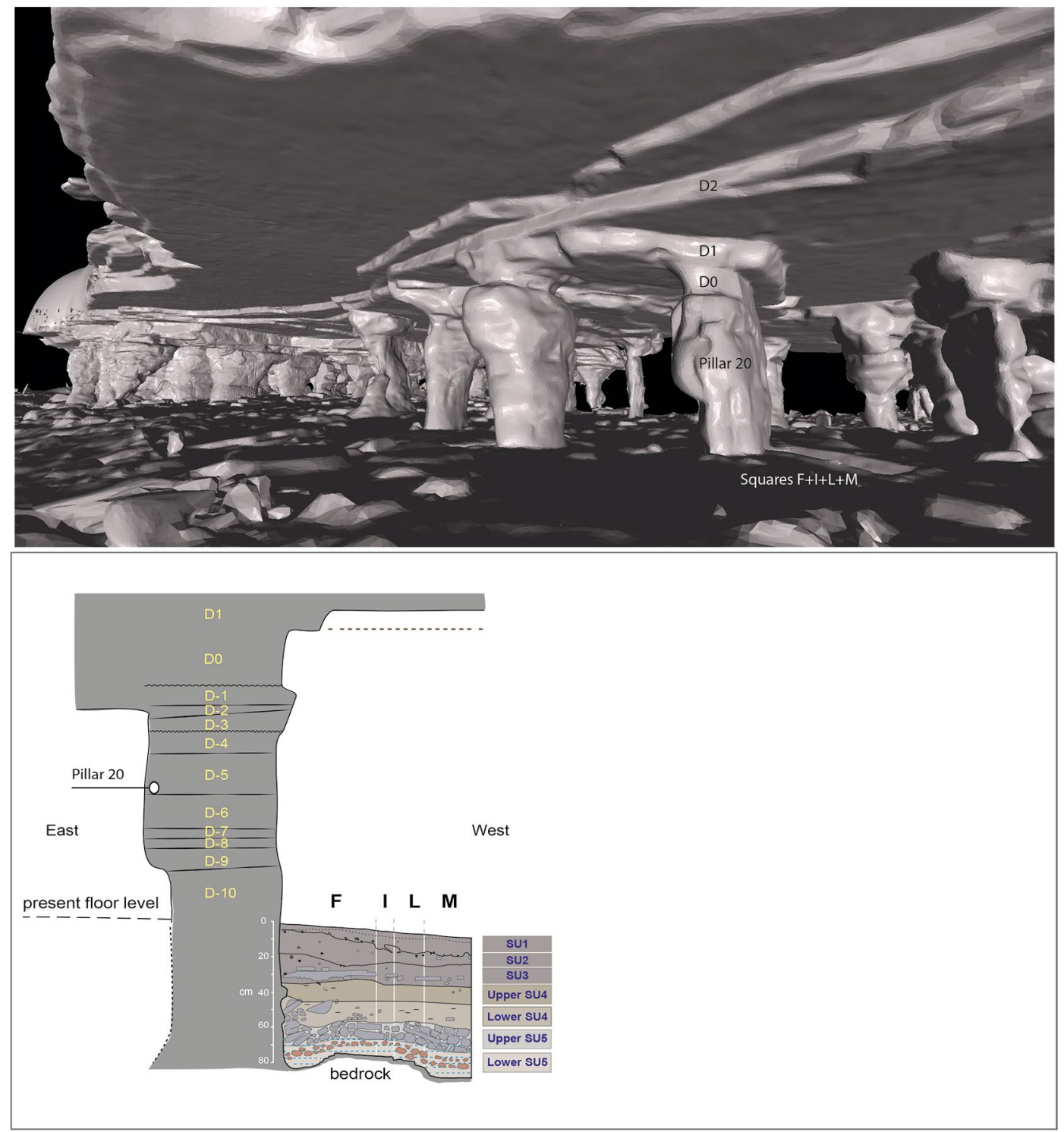

Figure 10.35 Area of contiguous Squares $F+l+L+M$, northwest sector, showing the stratigraphy along the south wall of the excavation against Pillar 20.

Source: Illustration by Jean-Jacques Delannoy.

Five major stratigraphic units (SU) are apparent in Squares $\mathrm{F}+\mathrm{I}+\mathrm{L}+\mathrm{M}$, each corresponding with one or more chronological phase. From the base upwards, the following chronostratigraphic sequence can be distinguished (for details, see David et al. completed manuscript) (Figure 10.35):

1. Lower SU5: At the base of the excavation, weathered quartzite lies immediately above the hard bedrock. This weathered quartzite represents the remains of ancient geological processes of phantomisation.

2. Upper SU5: Above the lower SU5 are found a layer of large rocks. Petrographic analysis indicates that they came from the collapse of ceiling stratum D1.

3. SU4: A layer of sand lies immediately above upper SU5. Granulometric and morphoscopic analyses of 5200 quartz grains from the contiguous Squares $\mathrm{I}+\mathrm{L}+\mathrm{M}$ sequence indicate that, unlike the sediment particles from underlying SU5, they overwhelmingly consist of aeolian sands. It is at the well-defined stratigraphic contact between upper SU5 and the base of SU4 
that the deepest and oldest stone artefacts are found at the site. Here, they have been dated to $47,200-51,700 \mathrm{cal}$ BP by AMS radiocarbon dating, and to slightly more than 50,000 years ago by single-grain OSL.

4. SU3: A mass of tabular blocks relates to a new phase of ceiling collapse; the age of this collapse was determined by radiocarbon dating of wood charcoal immediately below and immediately above the blocks. It dates to sometime between 17,936 $\pm 68 \mathrm{BP}$ (Wk-31713) and 19,601 $\pm 84 \mathrm{BP}$ (Wk-31714), equating to between 21,495 and 23,909 cal BP, taking the extreme ends of the 95.4 per cent probability calibration curves (with median probability ages of 21,734 cal BP and 23,619 cal BP, respectively).

5. SU2: This is overlain by a late Holocene layer of aeolian sand devoid of collapsed rocks but rich in stone artefacts and charcoal, with other artefactual materials such as ochre.

6. SU1: An upper level of culturally rich sandy sediments disturbed by treadage, dating to the past few hundred years.

These findings allow us to further refine our understanding of the site's evolution, including the role of people in its transformations. First, it allows us to imagine the site before the first arrival of people when the site exhibited a pillarscape similar to that seen today along the edge of the rock outcrop south of the site. At that time, the inter-pillar voids had already attained a height of 1.50$1.75 \mathrm{~m}$. The base of the void then corresponded with the weathered bedrock, and the top with the then-exposed surface of ceiling stratum D0. This natural pillarscape stood amidst labyrinthine passageways between the pillars. Some localised ceiling collapses had already taken place, but these were not spatially extensive. These collapses must have been greater along the edges than inside the site, by virtue of mechanical detent in the face of more open, less supported spaces.

This is what people saw when they first arrived at Nawarla Gabarnmang. Immediately upon this first arrival of people - as indicated by the deepest stone artefacts in Squares $\mathrm{F}+\mathrm{I}+\mathrm{L}+\mathrm{M}-$ the sediments began to take on a markedly different character, as considerable quantities of windblown sands were deposited, for which there was no previous evidence. During the period of human presence, the earliest ceiling collapse dates to between 21,495 and 23,909 cal BP. As this is in a sector of the site somewhat distant from the open spaces of the centre and eastern-centre where the main pillar removals and ceiling collapses took place, we do not know when those wide, open ceilings collapsed (Figure 10.36).

The chronological schema in the northwestern sector of the site compares well with that of the southwest. In both cases, the earliest layers of rock lying on or in the ground originated from the collapse of ceiling stratum D0, and on rare occasions stratum D1, representing the lowermost ceiling levels that join(ed) immediately onto the pillars. When people first arrived, this indicates, the exposed ceiling at or near both the northern and southern entrances consisted of strata D1 or D2 surfaces. The earliest evidence of ceiling collapse during the period of human presence occurred sometime between c. 33,998-35,129 cal BP (oldest evidence of roof-fall in cultural layers of Square D) and 11,624-12,024 cal BP (age of the dated wasp nest in southwestern sector); the phase of roof-fall dated to between 21,495 and 23,909 cal BP in Squares F+I+L+M also falls nicely within this time frame, as does all of the other evidence of roof-fall in Squares $\mathrm{A}, \mathrm{C}+\mathrm{G}+\mathrm{K}+\mathrm{N}, \mathrm{D}+\mathrm{H}, \mathrm{E}+\mathrm{J}+\mathrm{O}+\mathrm{Q}+\mathrm{R}$ and possibly $\mathrm{P}$. This broad window of time is important evidence for how people engaged with the site. If we can determine when during this time frame various ceiling levels collapsed across different parts of the site, we can construct a finer-grained spatial history for the site as a whole - a research in progress. In the meantime, we can now specify that across the site, the evidence indicates roof collapse only before c. 11,000 cal BP, the uncertainty of the age of the slab at the base of Square P notwithstanding (see Chapter 11). The age of the dated wasp nest on rock art Panel A3 in Alcove B in the southwestern sector of the site is consistent with these findings. 

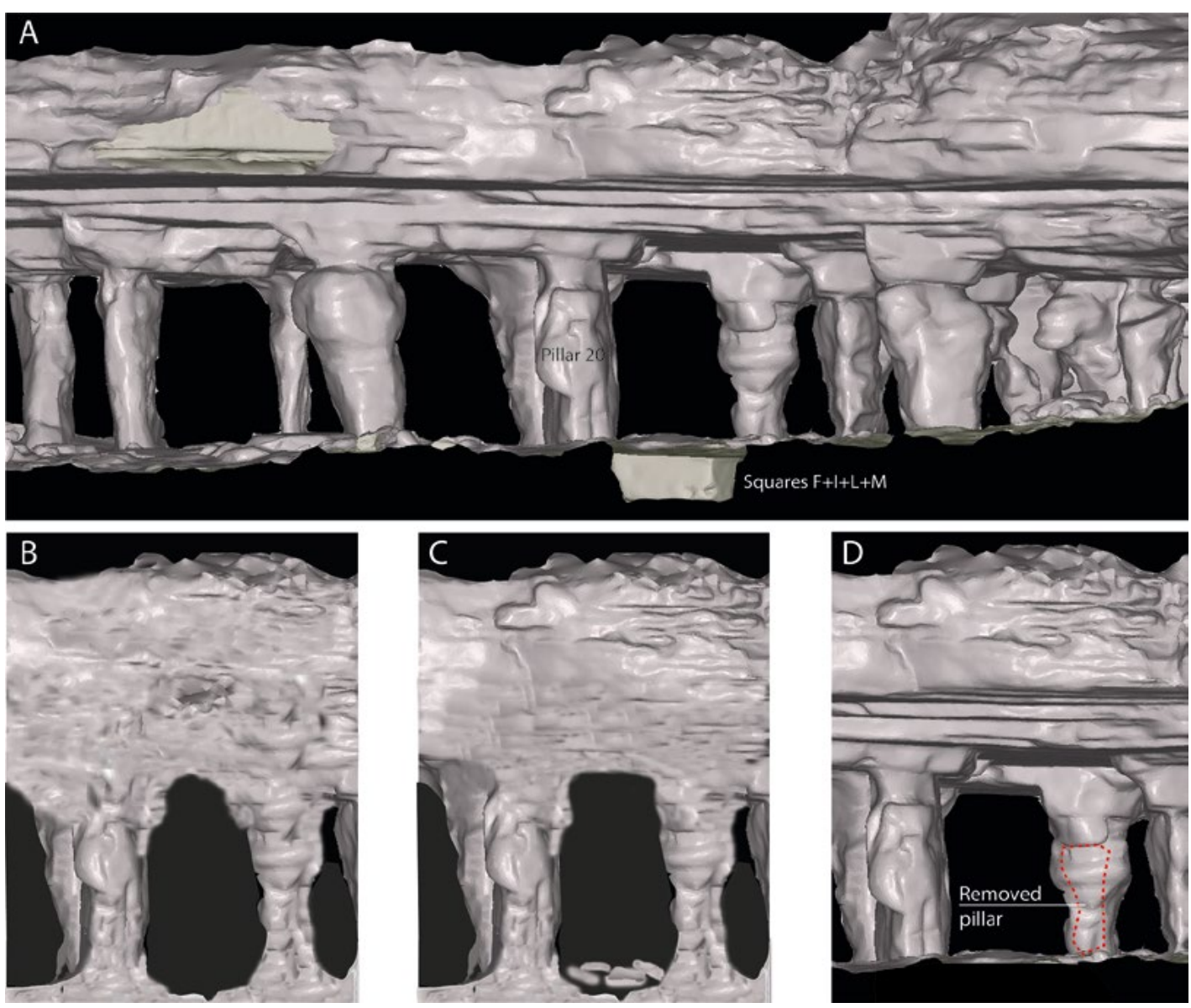

Figure 10.36 Area of contiguous Squares $\mathrm{F}+\mathrm{I}+\mathrm{L}+\mathrm{M}$ in the 3-D model, northwest sector, showing the natural accumulation of fallen rocks on the ground prior to human arrival $(B, C)$ followed by a more elevated floor caused by the accumulation of aeolian sands and removal of pillar during the period following the first arrival of people (D).

Source: Illustration by Jean-Jacques Delannoy.

These integrated geological (identification of rock strata, etc.) and geomorphological (study of the excavated sediments, etc.) and archaeological results enabled us to determine:

- What the site looked like at the time of first human arrival; a dense pillarscape with voids already $1.50-1.75 \mathrm{~m}$ in height.

- That when the first people arrived, the bedrock was not flat, but rather consisted of an undulating surface with numerous fissures largely infilled with weathered, gravelly sediments. In localised places, the ground was covered with blocks that had naturally collapsed from low ceiling.

- A general phase of ceiling collapse across more or less the entire area where archaeological excavations have been undertaken. This phase pre-dates c. 11,000 cal BP, but post-dates $35,000 \mathrm{cal} \mathrm{BP}$ at most (and probably began more recently than this, likely no earlier than c. 23,000 cal BP). The art on the most recently exposed ceiling surfaces, such as Panel A3 where the most recent signs of anthropic modification have been found for the site, is probably younger than 11,000 cal BP (see Gunn 2016).

- An entire Holocene phase of human occupation (evident in stratified artefacts dated by radiocarbon dates on wood charcoal) during which there is no evidence at all of further major transformations to the site, the uncertain age for the rock slab at the base of Square P notwithstanding (i.e. the ceiling ceases to collapse). 
This sequence of events from the northwestern sector of the site contrasts with the evidence from the southwestern sector for what appears to be the sudden cessation of the toppling of pillars, fragmentation of large rocks on the ground and removal of manageable blocks to outer parts of the site. This difference in human engagements across space and through time leads us to ask if they signal different modes of inhabitation for the site as a whole through time, or, rather, if they relate to different levels of preservation of archaeological materials. Two options are possible at this stage of analysis:

1. People first began to use the western sector of the site, as indicated by the distribution of earliest archaeological deposits across the site (cf. David et al. 2013, completed manuscript) and possibly by the location of the very heavily patinated cupules. The pillarscape in this western space has not been altered very much, with only rare pillars and only the lowermost ceiling strata (D0 and sometimes D1) having been removed. Human engagement then shifted further to the east in an intensive phase of modification with vast spaces created by the removal of pillars and collapsed ceiling strata.

2. All of the site has been occupied since the earliest phases of occupation. The removal of pillars and ceiling strata largely in the contiguous central and central-eastern sector of the site has removed any archaeological traces, including rock art, on those rock surfaces, and possibly on the floors as well. The oldest evidence of human presence has survived only in those sectors that did not witness the clearance of pillars and heightening of the ceiling level, that is, on the western side. Under this scenario, older cultural sediments were eroded out of those parts of the site with wide, open spaces by a combination of wind activity through the site and human (and animal) traffic, which through treadage and other activities repeatedly destabilised ancient surface sediments. Alternatively, ancient information remains preserved under collapsed ceiling strata that had not been removed, or that were only partly removed, from the ground, such as those at the base of the Square P excavations (see Chapter 11).

We cannot determine with the available evidence which of these best explains the spatio-temporal patterning of human presence across the site. New research involving excavation is required.

\section{Conclusion}

Detailed geological and archaeomorphological investigations at Nawarla Gabarnmang have revealed aspects of the site's history never previously encountered - or at least, never reported - at an Australian archaeological site: the intentional manipulation and transformation of the material fabric of the site - its rock walls and ceiling - dramatically to open up its interior space.

The question remains, why? - a more difficult question than the 'what', 'when', 'how' and 'where' that we have tried to address in this chapter. At this stage of analysis, it is clear that limited parts of the site were quarried for rock for the manufacture of stone tools, as is evident at many occupied rockshelters on the Arnhem Land plateau. But this sourcing of stone cannot explain the broad-scale toppling and removal of pillars and collapsed ceiling strata, which in the main do not exhibit traces of targeted quarrying, or why the fallen blocks were dumped outside the site rather than worked for stone tools (unless they were some kind of stockpile). In a similar vein, while the extant ceiling strata are today extensively painted, this does not appear to have been the case deeper in antiquity; the older surfaces do carry art, but nowhere as expansively or as densely as during the latter half of the past millennium (see Chapter 12; see also Gunn 2016). The buried archaeological evidence across the site also indicates a massive proliferation of small fragments of imported pigment late in the Holocene, further suggesting that making art with pigment was less common during earlier times. And last but not least, at Nawarla Gabarnmang much of the earliest art occurs on pillars rather than on horizontal ceilings - as indicated, for instance, by the cupules on Pillars 23 and 28 (Figure 10.37), 
and the only Dynamic Figure seen at the site (Figure 10.38) on the pillar of a slightly isolated alcove (other Dynamic Figures occur in other rockshelters within one to two minutes' walking distance). If upright pillar surfaces were preferred during early art phases, it would not make sense to topple those pillars and so create additional horizontal ceiling surfaces, remembering that the site contains numerous undecorated or poorly decorated pillars, and that pillar clearance appears only to have taken place during Pleistocene times (see above).

This leaves the expansion of the site's internal space as being for that reason, the opening-up of the sheltered space itself. We can conjecture specific motivations for this: To follow cosmological imperatives? To shelter from monsoonal rains? To create greater social space for community dwelling?
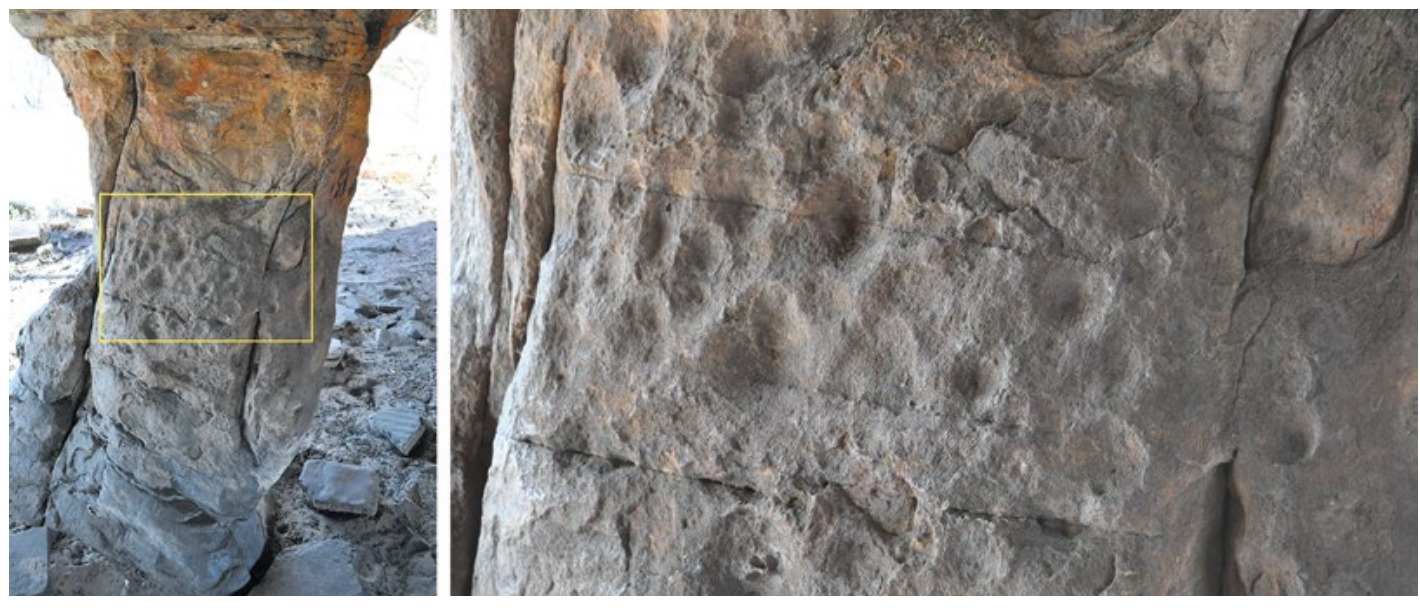

Figure 10.37 Heavily weathered cupules on the western side of Pillar 28.

Source: Photographs by Bruno David.
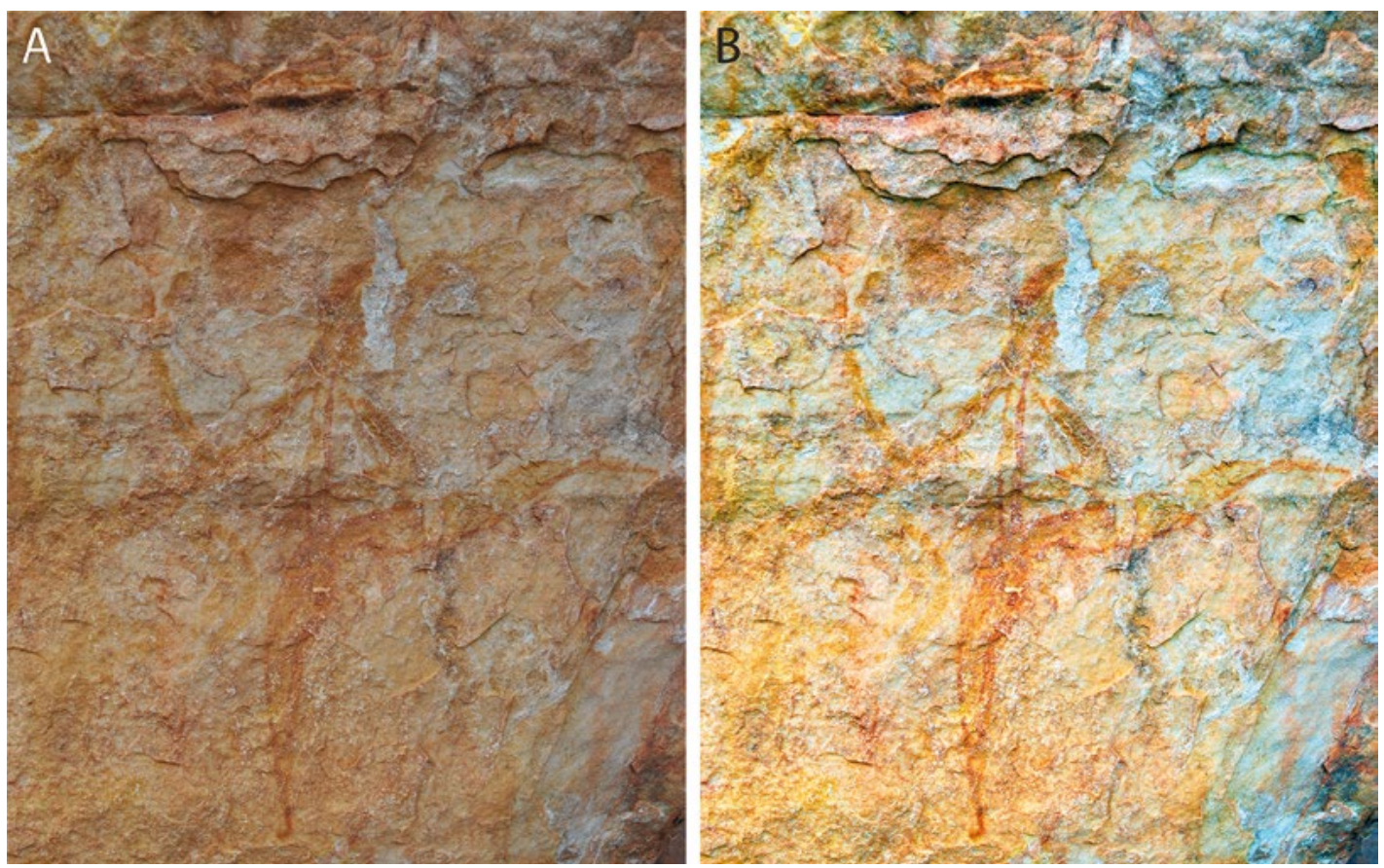

Figure 10.38 Dynamic Figure carrying boomerangs, Nawarla Gabarnmang.

A: Original photograph. B: Digitally enhanced photograph.

Source: Photographs and enhancement by Bruno David. 
That we can recount this spatial history of Nawarla Gabarnmang is made possible by our novel, closely integrated archaeomorphological approach to the site's material fabric, geological history and archaeological evidence. We doubt the key details of human inhabitation would have been noticed without that approach. This integrated vision has revealed, in the context of a geologically ancient, phantomised pillarscape, some 50,000 years of human presence beginning with initial landscape encounters and low-level occupation, followed much later during the terminal Pleistocene with evidence for complex engineering feats that turned a natural site into a constructed, architectural space. During this phase of history, the site's material fabric was dramatically modified as its internal space was gradually opened up by people, until suddenly - it appears - pillars were toppled and cleared for the last time shortly before 11,000 years ago.

Why people seem to have suddenly abandoned this clearance in the southwestern sector of the site remains a mystery. Nawarla Gabarnmang as we know it today is not the only rockshelter that witnessed clearances in the past: nearby, abutting the western side of the site's southwestern sector, a second rockshelter once stood, a now-collapsed sheltered entrance into the site via the courtyard to the south (Figure 10.39). We know that pillars had also been removed in that longgone shelter; while the large mass of tumbled rocks show evidence of past pillars, its configuration is not staggered as a collapsed pillarscape would be. We are tempted to see the shock of that collapse as the stimulus for the final abandonment of pillar clearances at Nawarla Gabarnmang. A detailed archaeomorphological research of that western, former shelter might tell us if its collapse was contemporaneous with the cessation of pillar clearance in the southwestern sector of Nawarla Gabarnmang.

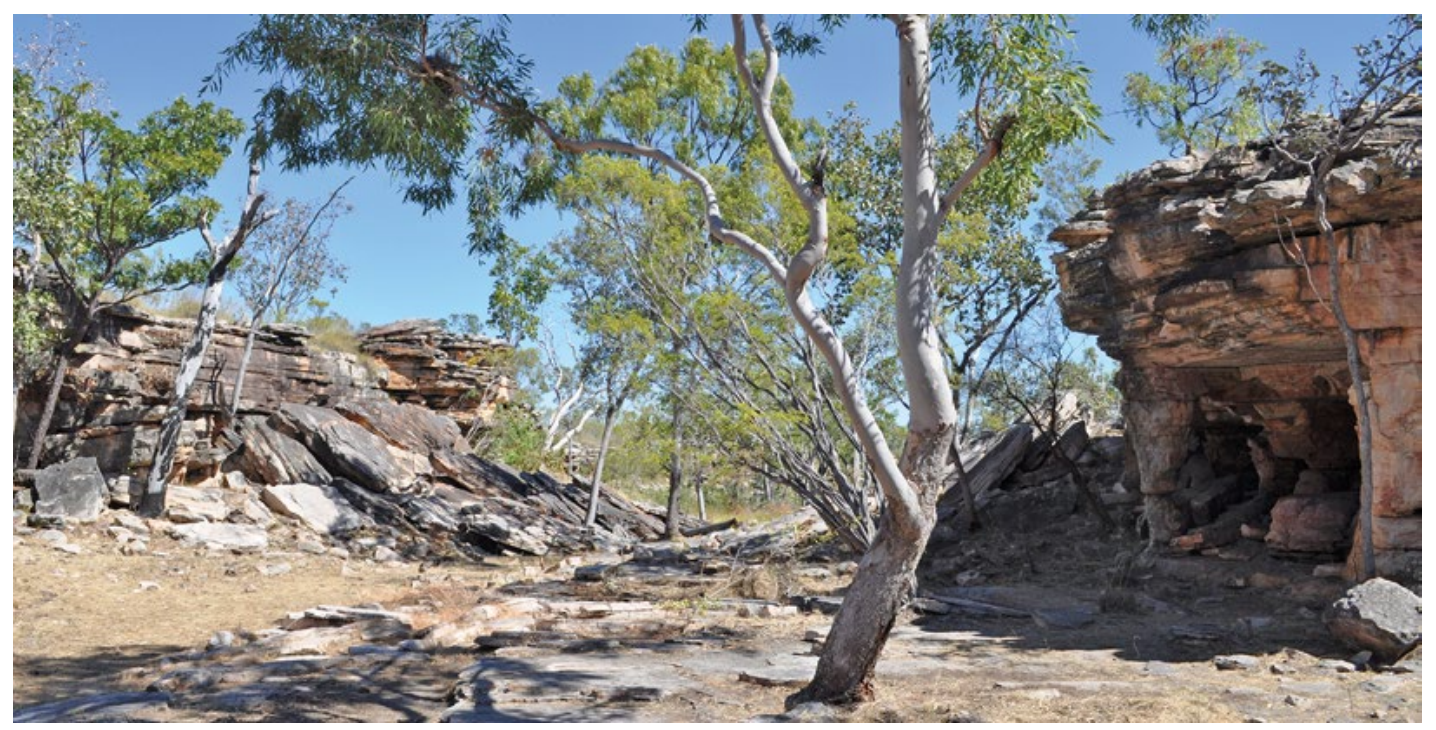

Figure 10.39 The collapsed rockshelter that once formed the entry way into the courtyard from the southwest of the extant Nawarla Gabarnmang.

The southwestern sector of the current site, as discussed in this chapter, can be seen on the right-hand side of the photograph. Source: Photograph by Bruno David.

Our archaeomorphological study of Nawarla Gabarnmang challenges us to think in new ways about how Aboriginal people interacted with their surroundings; here, a site of everyday engagement was a place of construction that retains material traces of those past engagements. While the scope and scale of activities during the era of pillar clearances at Nawarla Gabarnmang ended many thousands of years ago, other practices flourished, of which Arnhem Land's complex sequence of rock art conventions is an apt example. These artistic transformations, much like the era of pillar clearances long gone, are a clear answer to the kinds of critique that are sometimes 
made of archaeological stories - that they create an Aboriginal history that simply transfers ethnography progressively deeper into the past; that a present is 'historicised' by making that past a timeless image projected back from the first ethnographic encounters.

\section{Acknowledgements}

We thank Margaret Katherine and family, Wes Miller, Ray Whear and the Jawoyn Association Aboriginal Corporation for asking us to undertake archaeological research at Nawarla Gabarnmang. Thanks to Bryce Barker (University of Southern Queensland), Elisa Boche, Lara Lamb (University of Southern Queensland), Magen O'Farrell, Stéphane Hoerlé, Daniel James (Monash University), Jacqueline Matthews (University of Western Australia) and Chris Urwin (Monash University) for helping with the excavations; Kara Rasmanis (Monash University) for drafting Figure 10.1 and parts of Figure 10.3; and A.L. Develle (EDYTEM, Université de Savoie, France) for the XRF core scanner analysis (Figure 10.15). We thank the Australian Research Council for Linkage grant LP110200927 and Discovery grants, QEII and Discovery Outstanding Research Award (DORA) Fellowships DP0877782 and DP130102514.

\section{References}

Armstrong, R., L. Osborne, W.S. Weliange, P. Jayasingha, A.S. Dandeniya, A.K.P.P. Algiriya and R.E. Pogson 2013. Caves and karst-like features in Proterozoic gneiss and Cambrian granite, southern and central Sri Lanka: An introduction. Acta Carsologica 42(1):25-48.

Carson, L.J., P.W. Haines, A. Brakel, B.A. Pietsch and P.A. Ferenczi 1999. Milingimbi SD53-2, 1:250 000 Geological Map Series Explanatory Notes. Northern Territory Geological Survey, Government Printer of the Northern Territory, Darwin.

David, B., J.-J. Delannoy, R. Roberts, Z. Jacobs, B. Brook, J.-M. Geneste, F. Petchey, J. Mialanes, T. Richards, B. Barker, M.I. Bird, C. Clarkson, E. Boche, S. Hoerlé and M. Katherine completed manuscript. Human colonisation of Sahul prior to fifty-one thousand years ago.

David, B., J.-M. Geneste, R.L. Whear, J-J. Delannoy, M. Katherine, R.G. Gunn, C. Clarkson, H. Plisson, P. Lee, F. Petchey, C. Rowe, B. Barker, L. Lamb, W. Miller, S. Hoerle, D. James, E. Boche, K. Aplin, I.J. McNiven, T. Richards, A. Fairbairn and J. Matthews 2011. Nawarla Gabarnmang, a 45,185 \pm 910 cal BP site in Jawoyn Country, southwest Arnhem Land Plateau. Australian Archaeology 73:73-77.

David, B., B. Barker, F. Petchey, J.-J. Delannoy, J-M. Geneste, C. Rowe, M. Eccleston, L. Lamb and R. Whear 2013. A 28,000 year old excavated painted rock from Nawarla Gabarnmang, northern Australia. Journal of Archaeological Science 40:2493-2501. doi.org/10.1016/j.jas.2012.08.015

David, B., B. Barker, J.-J. Delannoy, J-M. Geneste, F. Petchey and L. Lamb 2014. A Pleistocene charcoal drawing or painting from northern Australia. INORA 69:18-22.

Delannoy, J.-J., B. David, R. Gunn, J.-M. Geneste and S. Jaillet 2017. Archaeomorphological mapping: Rock art and the architecture of place. In B. David and I.J. McNiven (eds), The Oxford Handbook of the Archaeology and Anthropology of Rock Art. Oxford University Press, Oxford.

Delannoy, J.-J., E. Debard, C. Ferrier, B. Kervazo and Y. Perrette 2001. Contribution de la cartographie morphologique souterraine dans l'étude spéléogénique de la grotte Chauvet: Implications paléogéographiques, préhistoriques et paléontologiques. Quaternaire 12:235-248. doi.org/10.3406/ quate.2001.1696 
Delannoy J.-J., Y. Perrette, E. Debard, C. Ferrier, B. Kervazo, A.S. Perroux, S. Jaillet and Y. Quinif 2004. Intérêt de l'approche morphogénique pour la compréhension globale d'une grotte à haute valeur patrimoniale: La grotte Chauvet (France). Karstologia 44:25-42.

Delannoy, J.-J., B. David, J.-M. Geneste, M. Katherine, B. Barker, R.L. Whear and R.G. Gunn 2013. The social construction of caves and rockshelters: Chauvet Cave (France) and Nawarla Gabarnmang (Australia). Antiquity 87:12-29. doi.org/10.1017/S0003598X00048596

Erhard, H. 1967. La Genèse des Sols en Tant que Phénomènes Géologique. Masson, Paris.

Ferenczi, P.A. and I.P. Sweet 2004. Mount Evelyn, Northern Territory 1:250 000 Geological Map Series, SE53-05 (Second Edition). Northern Territory Geological Survey, Darwin.

Geneste, J.-M., B. David, H. Plisson, C. Clarkson, J.-J. Delannoy, F. Petchey and R. Whear 2010. Earliest evidence for ground-edge axes: 35,400 410 cal BP from Jawoyn country, Arnhem Land. Australian Archaeology 71:66-69. doi.org/10.1080/03122417.2010.11689385

Geneste, J.-M., B. David, H. Plisson, J.-J. Delannoy and F. Petchey 2012. The origins of ground-edge axes: New findings from Nawarla Gabarnmang, Arnhem Land (Australia) and global implications for the evolution of fully modern humans. Cambridge Archaeological Journal 22:1-17. doi.org/10.1017/ S0959774312000017

Gunn, R.G. 2016. Art of the Ancestors: Spatial and Temporal Patterning in the Rock Art of Nawarla Gabarnmang, a Major Jawoyn Cultural Site on the Arnhem Land Plateau. Unpublished PhD thesis. Monash University, Clayton.

Joly, F. 1977. Point de vue sur la géomorphologie. Annales de Géographie 86(477):522-541. doi.org/ 10.3406/geo.1977.17626

Jones, R. (ed.) 1985. Archaeological Research in Kakadu National Park. Special Publication 13. Australian National Parks and Wildlife Service, Canberra.

Martini J.E.J. and K.G. Grimes 2012. Epikarst maze cave development: Bullita Cave system, Judbarra/ Gregory karst, tropical Australia. Helictite 41:37-66.

Quinif, Y. 2010. Fantômes de Roche et Fantômisation. Essai sur un Nouveau Paradigme de Karstogénèse. Karstologia Mémoires, Volume 18. Association Française de Karstologie, Mons. 
This text is taken from The Archaeology of Rock Art in Western Arnhem Land, Australia, edited by Bruno David, Paul Taçon, Jean-Jacques Delannoy and Jean-Michel Geneste, published 2017 by ANU Press, The Australian National University, Canberra, Australia.

dx.doi.org/10.22459/TA47.11.2017.10 